\title{
THE DEVELOPMENT OF INTENSIVE CARE NURSING AS A SPECIALTY AT WELLINGTON HOSPITAL INTENSIVE CARE \\ UNIT, WELLINGTON, NEW ZEALAND, $1964-1989$
}

\author{
by \\ Elinore Harper
}

A thesis submitted to Victoria University of Wellington in fulfilment of the requirements

for the degree

of

Masters of Nursing

Victoria University of Wellington 


\section{Abstract}

Intensive care nursing developed as a specialty with the advent of intensive care units (ICUs) following the poliomyelitis outbreaks of the 1950s. In New Zealand (NZ) the first ICU was opened in the early 1960s in Auckland. Many ICUs were quickly established in other NZ hospitals around this time with Wellington Hospitals ICU opening in 1964. This work explores the first 25 years of the development of the Wellington ICU and the specialisation of ICU nursing. Oral history interviews with past and present staff who worked and taught in the ICU during this time and Hospital archives and primary documentation sources provided much of the background information about this development. One find during the cataloguing of materials and administrative records prior to the move to the newly built Wellington Regional Hospital was the patient admission records documenting each year of the unit's operation since it opened. The information gathered from these records provided data on patient demographics, giving age, admission diagnosis, discharge destination, mortality information and admission source for each patient admitted. Education of the nurses, many of whom were embracing the knowledge and technology required to look after ICU patients for the first time was paramount to the care of the critically ill patient. With the advent of an ICU six-month nursing course in 1968 many of the educational needs of the nurses were met. Working relationships with the medical staff were very different from those that many nurses had been used to when working in the wards with the Doctor - Nurse relationship becoming less formal and more collaborative. This thesis illustrates the hard work and determination of those early nurses to provide excellent and appropriate care and translate knowledge into practice in order to look after these critically ill patients.

Key Words: Nursing, Intensive Care, History, Development, Specialisation 


\section{Acknowledgements}

This thesis has been an informative and challenging journey. Without the help, support and encouragement of many it would firstly not have begun, but also may never have been finished.

Firstly I must extend thanks and gratitude to Dr Pamela Wood whose enthusiasm and passion for historical inquiry inspired me to begin this journey. Her encouragement and support as a supervisor, sounding board and champion mean so much to me; thank you somehow does not seem enough. A special Thanks also to Dr Kathy Nelson who provided thoughts and information on quantitative data gathering and analysis, stepped in as fill in supervisor when Pamela was away and then took on the job of primary supervisor following Pamela's departure from the University. It must never be easy to take on a student and shape their ideas and work with so little time left.

To those nurses who agreed to be interviewed I am very grateful. I feel privileged to have had you share your stories and memories with me and that you did so so freely with me was a great honour. To those of you who recommended others again thank you.

Jan Wigmore, Wellington Hospital's Records Management Administrator who discovered the patient admission records and passed them on to me was pivotal in the development of this thesis. Her love of historical documents and willingness to share these with me is appreciated as were her emails informing me of yet another find, aptly referred to by Pamela as "gems". Also Marion Elliot, ICU secretary, who kindly ordered and returned boxes of records from the Hospital archives whenever I asked, without her help and support the flow of information would have been slow and tedious.

Those of my ICU colleagues who have been enthusiastic and supportive upon hearing about this work I hope that you find it informative. Thanks to the ICU consultants and others who fielded my emails and questions and gave suggestions of who and where to go to get information. 
Particular mention must go to my friend and colleague Diane Mackle, who provided valuable insight into the research process, ethics and data gathering and more importantly in the latter half of this journey has shared the highs and lows, been my conscience and provided a valuable sounding board. As a fellow thesis student she understands the journey that this is.

I must also thank the Victoria University Graduate School of Nursing, Midwifery and Health for the opportunity to undertake this journey of discovery and learning. To my fellow thesis students the stories you shared during the research schools were inspirational and sent me home with a renewed enthusiasm for my work. It was always a pleasure to hear your presentations and see your work develop; I hope that my journey was equally inspiring to you.

Lastly, I must thank my family and Richard for their support and encouragement, and for being so understanding when I was busy and stressed. 


\section{Table of Contents}

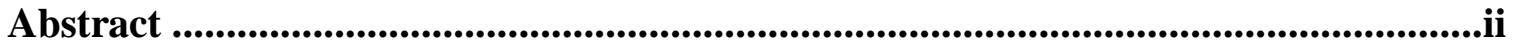

Acknowledgements ................................................................................................................... iii

Table of Contents ......................................................................................................................v

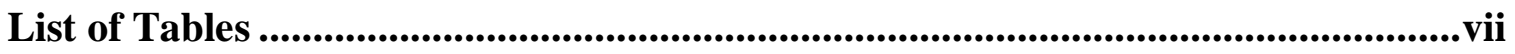

List of Figures..................................................................................................................vii

Chapter One - Background .........................................................................................1

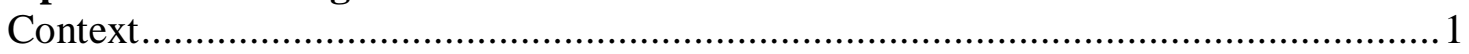

The Question ................................................................................................... 3

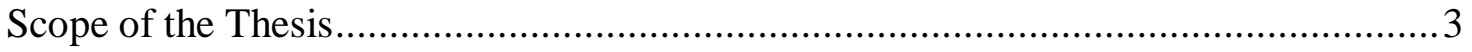

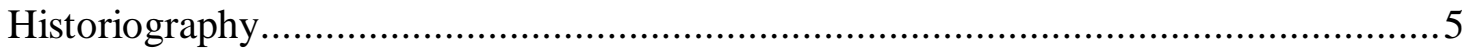

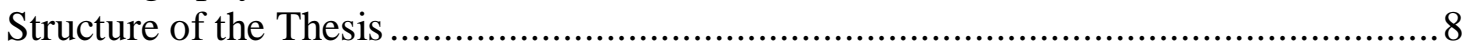

Chapter Two - Methodology and Method ............................................................10

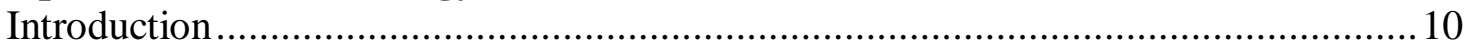

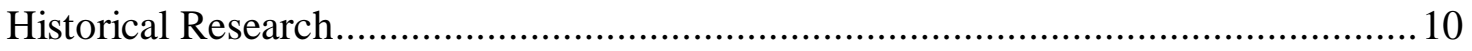

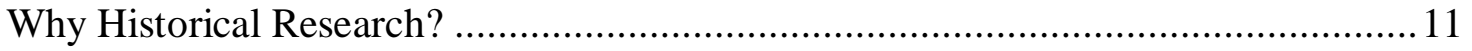

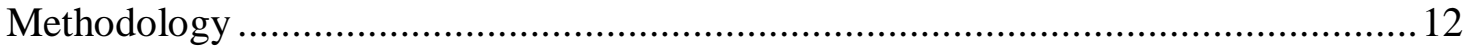

Documentary Primary Sources ......................................................................... 12

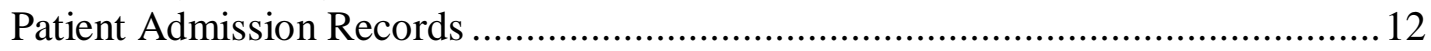

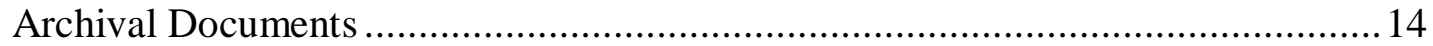

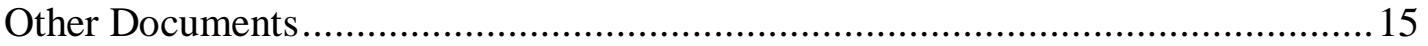

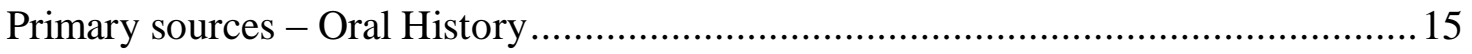

Rigour and Reliability ................................................................................. 17

Ethical Considerations .................................................................................... 19

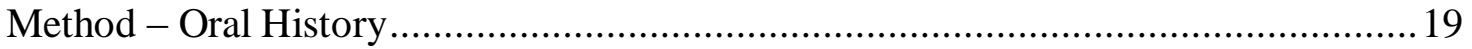

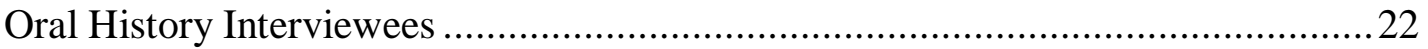

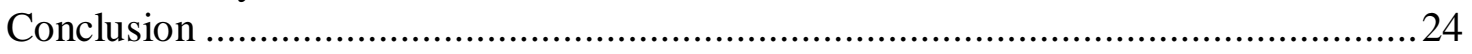

Chapter Three - Intensive Care: The Beginning ..........................................................25

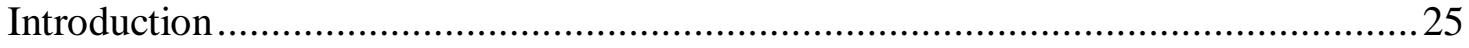

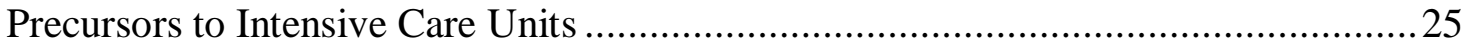

Impetus for ICU Development ...................................................................... 27

The First Intensive Care Units .......................................................................... 28

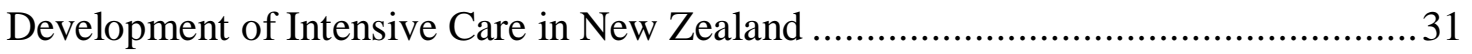

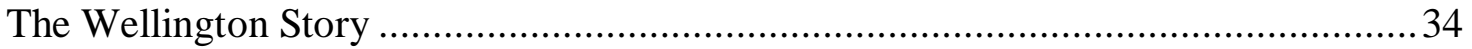

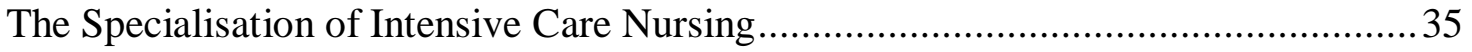

Nursing Staff - Why Work in ICU? ................................................................ 40

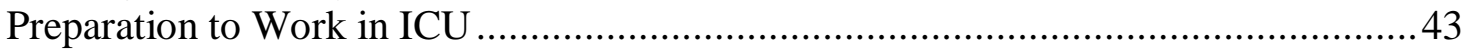

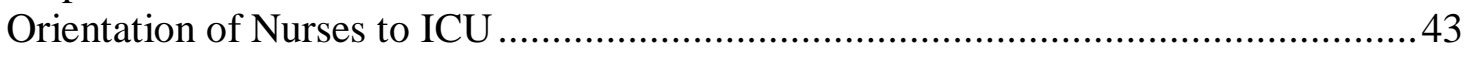

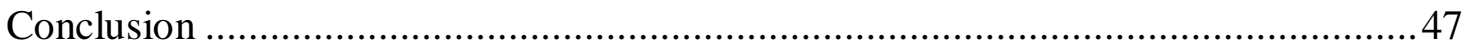

Chapter Four - Intensive Care Patients ........................................................48

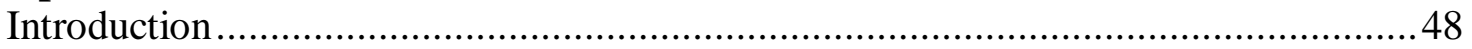

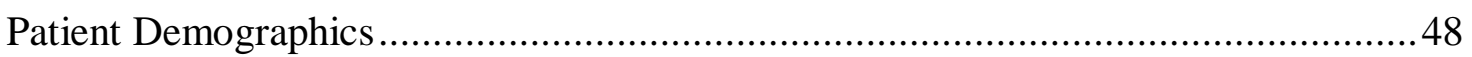

Numbers of Patients Admitted to ICU ....................................................... 51

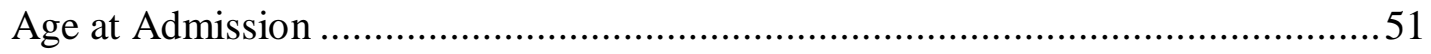

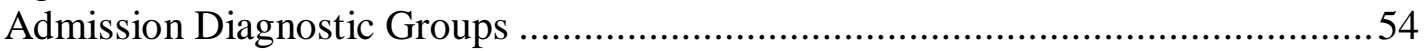




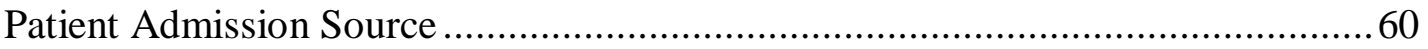

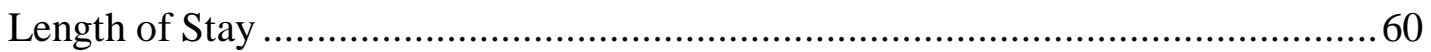

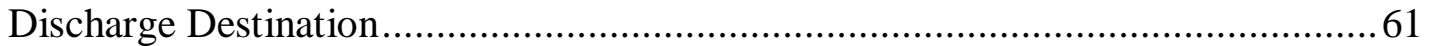

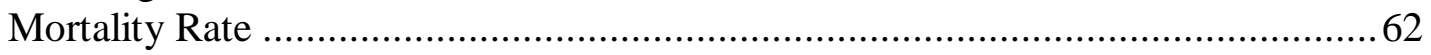

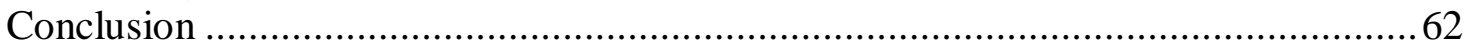

Chapter Five - Doctor-Nurse Working Relationships .....................................................64

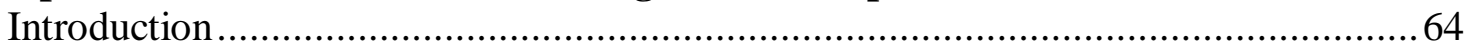

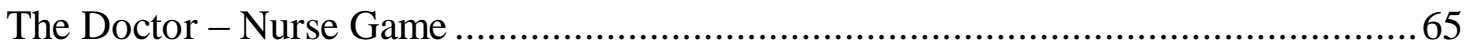

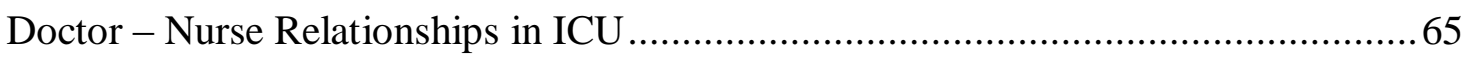

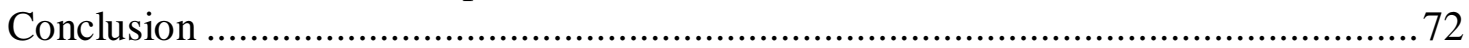

Chapter Six - ICU Design, Technology and the Rituals of Caring in ICU .................74

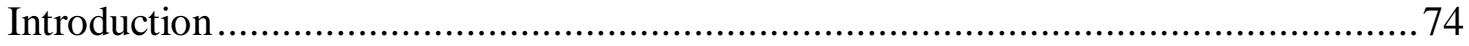

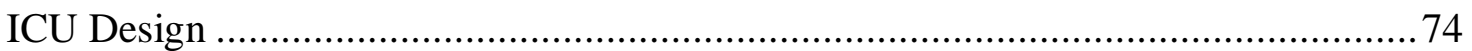

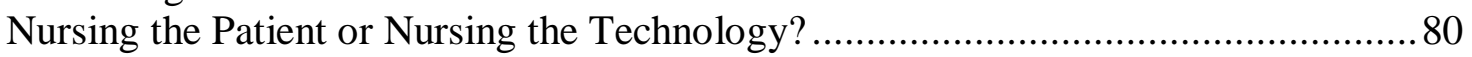

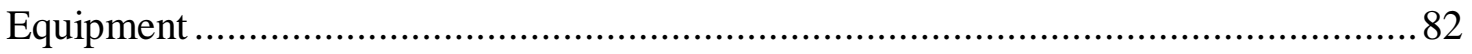

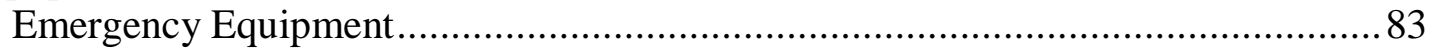

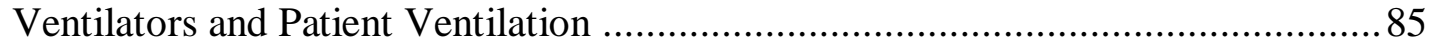

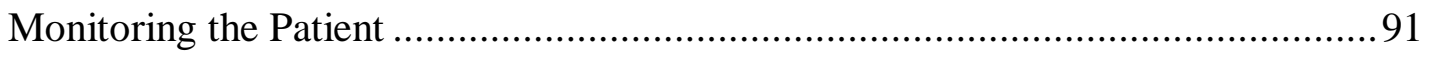

Daily Routines and Delivery of Patient Care ...........................................................99

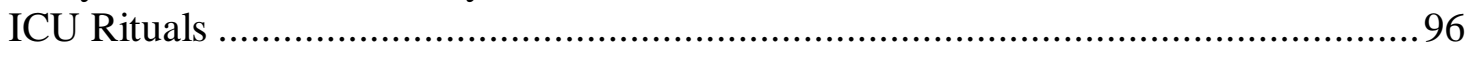

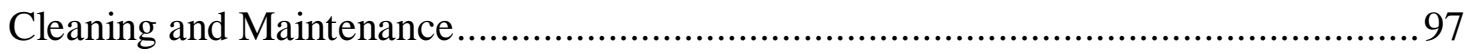

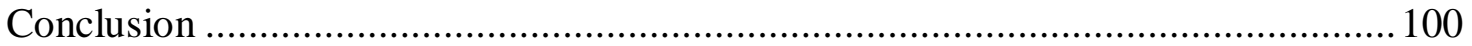

Chapter Seven - Formal and Informal Education............................................................102

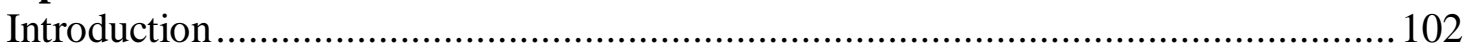

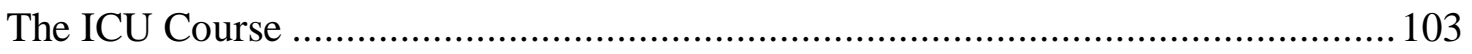

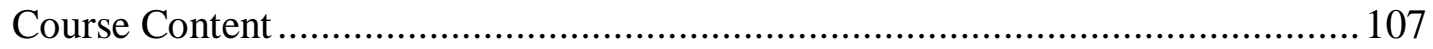

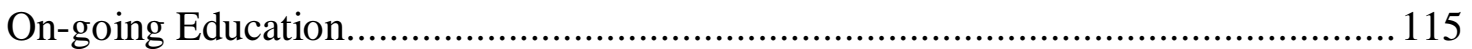

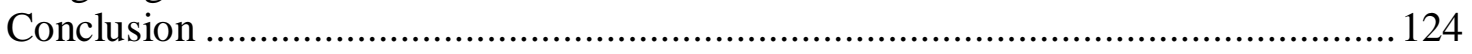

Chapter Eight - Final Thoughts............................................................................................126

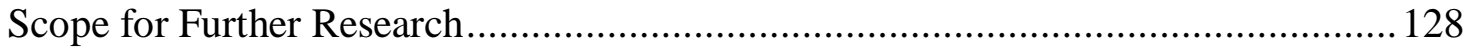

Appendices.................................................................................................................130

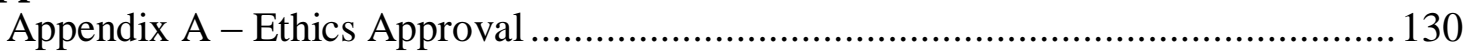

Appendix B - Oral history Interviewee Letter..................................................... 132

Appendix C - Oral History Interviewee Information Form ...................................... 133

Appendix D - Oral History Interview Schedule ………........................................ 135

Appendix E - Oral History Interview Consent Form............................................... 136

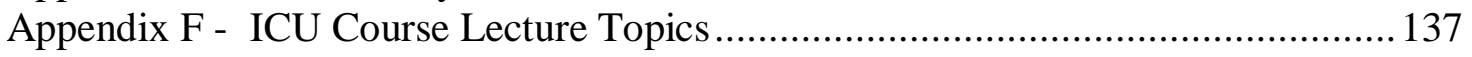

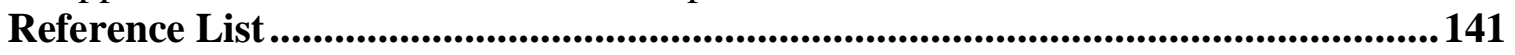

Primary Sources ......................................................................................................................... 141

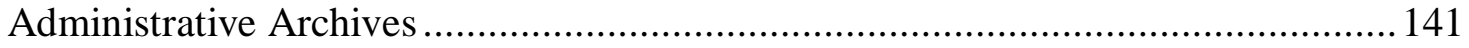

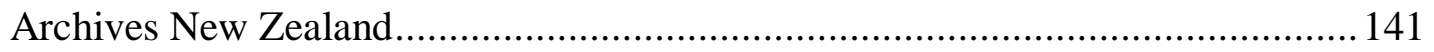

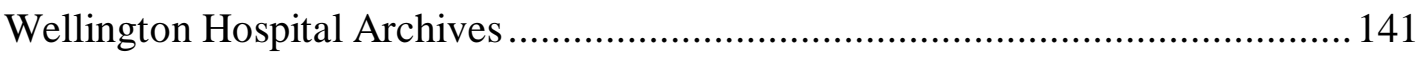

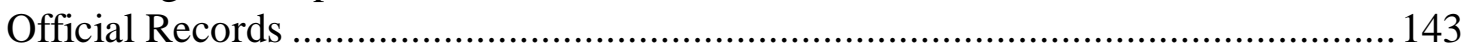

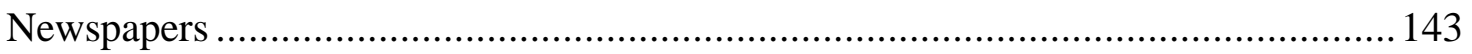

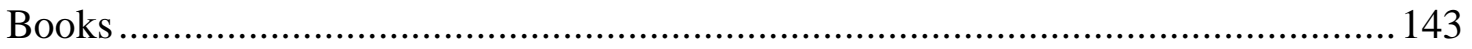

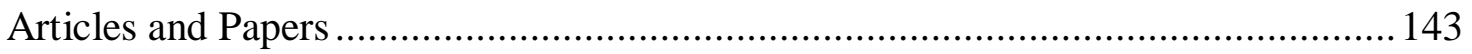




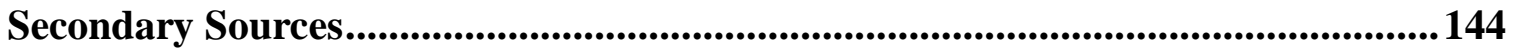

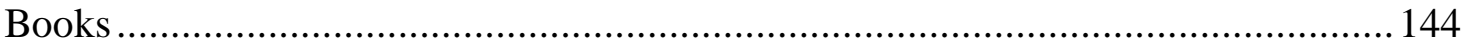

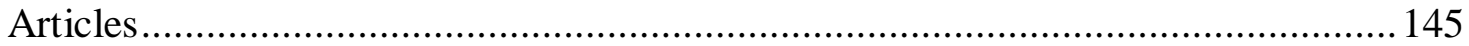

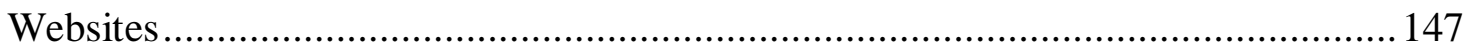

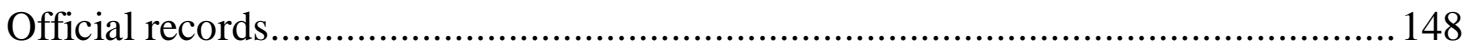

\section{List of Tables}

Table 1: Peplau's Eight Categories of Nursing Specialisation .........................37

Table 2: Patient Demographic and Clinical Profile .................................49

Table 3: Medical Diagnoses Sub-Groups .......................................55

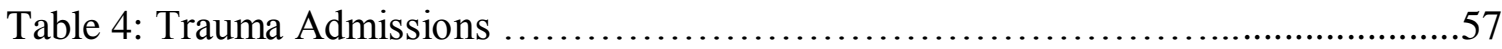

Table 5: Admission Source ..................................................60

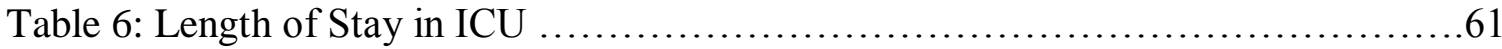

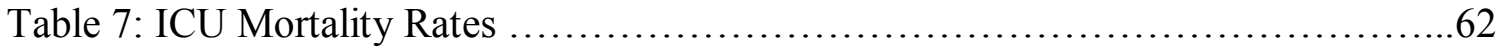

Table 8: Examples of Final Exam Questions: ICU Course 1976 ......................112

\section{List of Figures}

Figure 1: Wellington ICU Layout c.late 1960s ..................................... 77

Figure 2: The New ICU Central Monitoring Console c.1980 ........................80

Figure 3: Bedside Equipment Wellington ICU c.1970s ...........................83

Figure 4: Emergency Equipment Kept at the Head of a Bed Space - Wellington ICU

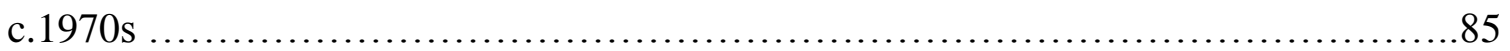




\section{Chapter One - Background}

\section{Context}

Historians of nursing have little doubt about the importance of research to nursing's sense of itself now and in the future. The past informs the present. Understanding the historical experiences of health and illnesses, people and institutions, problems and possibilities, enriches our encounters with patients, peers, colleagues and students. Exploring the past shapes our professional culture. ${ }^{1}$

Through learning about the origins of intensive care units (ICUs) and hence the development of intensive care nursing as a specialty, intensive care nurses today can understand why it is that they care for their patients as they do. In understanding how this field of nursing emerged they can be inspired to continue to strive to mature and grow further as a discipline. In order to do this the following questions need to be asked: What is intensive care, why does it exist within the greater hospital context and what is it that ICU nurses do?

There are different views about the timing and origin of the introduction of ICUs. Zalumas attributes the emergence of modern ICUs in the Unites States of America (USA) to three major factors. ${ }^{2}$ Firstly, the experience gained from the post anaesthetic recovery rooms of the $1940 \mathrm{~s}$ and $1950 \mathrm{~s}$ demonstrated to both medicine and nursing the effectiveness of continuous nursing surveillance of very ill patients. From this it was also found that concentrating those patients who were waking up from anaesthesia in one large room enabled patients to be observed for immediate complications such as respiratory distress, blood pressure anomalies or bleeding. The second factor was economy and efficiency; hospital planners were proposing a progressive patient care

\footnotetext{
${ }^{1}$ P. D’Antonio, 'Nursing and History', Nursing Inquiry, 12, 4 (2005) p.241.

2 J. Zalumas, Caring in Crisis: An Oral History of Critical Care Nursing, University of Pennsylvania Press, Philadelphia, 1995, p.1.
} 
model in which patients would be grouped according to the amount and intensity of nursing care that they required. The third factor was the introduction of complex technology that had come about as the result of new surgical procedures and more sophisticated post-operative nursing care and monitoring. In contrast, Crocker attributes the outbreak of the 1952 poliomyletis epidemic in Copenhagen which resulted in an increased number of patients requiring ventilation as being commonly recognised as the precursor to ICUs. ${ }^{3}$ Treating paralysed patients in the "iron lung" respirators required intensive supervision and care. ${ }^{4}$ As a result of this it was found that better use could be made of available staff and equipment when patients were nursed within a combined area. $^{5}$

ICUs by definition treat patients who during a period of critical illness require strict supervision, extraordinary care, special qualified staff and very often mechanical aids to support vital functions. "The patient may require artificial ventilation, treatment for shock, cardiac monitoring, cardiac stimulation via pacemaker, dialysis, biochemical correction of severe metabolic disorders and protection against and/or treatment of infection". 6 Zalumas describes intensive care nursing as the consideration of the complex relationship between both the physiologic and psychological components of illness on the patient. $^{7}$ The ICU nurse can be considered an extension of the patient who is unable to care for themselves; managing individual responses to illness, rehabilitation or dying. ${ }^{8}$

\footnotetext{
${ }^{3}$ C. Crocker, 'The development of critical care in England', Intensive and Critical Care Nursing, 23 (2007), p.325, citing Hercus (1962) on the development of intensive care.

${ }^{4}$ J. Fairman and J.E. Lynaugh, Critical Care Nursing: A History, University of Pennsylvania Press, Philadelphia, 1998, p.11.

${ }^{5}$ Sister B. Mercer, 'Intensive Care Units at Wellington', New Zealand Nursing Journal, (August 1971) p.21.

${ }^{6}$ Per Erik Wiklund, 'Intensive Care Units: Design, location, staffing ancillary areas, equipment', Anesthesiology, 31, 2 (1969), p.123.

${ }^{7}$ Zalumas, Caring in Crisis, pp.6-7.

${ }^{8}$ Zalumas, Caring in Crisis, pp.6-7.
} 


\section{The Question}

In formulating my research question the primary objective was to explore the development of intensive care nursing at Wellington Hospital's ICU with a timeframe spanning its first 25 years of operation. In order to do this I needed to become familiar with the role of the nurse in ICU during this period: what their daily work routine consisted of, what types of patients they were looking after, what technology and equipment were utilised in order to care for these patients, what training and education they received and what the working relationships were like between the medical and nursing staff. Secondly, how did all of these factors change over the 25 years as knowledge and understanding of care of the critically ill patient evolved? Considering all of these factors the following question was formulated: How did intensive care nursing develop as a specialty at Wellington Hospital from 1964 to 1989 ?

\section{Scope of the Thesis}

This thesis describes the development of intensive care nursing at Wellington Hospital's ICU from its opening in 1964 through to 1989. Wellington Hospital is located in the capital city of NZ and is a tertiary level hospital. It opened in 1847 and has been situated on its current site in Newtown, Wellington since 1878. ${ }^{9}$ In 2004 construction began on a new Wellington Regional Hospital which was opened in 2009 on the existing site. The thesis provides a detailed descriptive history of the Wellington Hospital ICU documenting its evolution over the first 25 years in response to developments and trends in nursing and patient care. In order to represent this local context, the development of ICUs and intensive care nursing internationally will be discussed alongside the NZ and Wellington perspectives. The 25 year time period was chosen as it was appropriate for the size and scope of this Masters thesis and would identify the changes in intensive care practice in its first phase of development.

My rationale for undertaking a historical piece of research is that despite having worked in ICU since 1999 I have a very limited understanding of the genesis of my chosen field

\footnotetext{
${ }^{9}$ http://www.ccdhb.org.nz/History/timeline.htm.
} 
of practice. Also whilst completing a historical research methods paper as part of my post-graduate diploma studies I conducted a small scale research project into this subject. What I discovered roused my interest in both historical research as a methodology and the origins of intensive care nursing as a specialty. Coupled with this was an imminent move to a newly built regional hospital being constructed on the same site as the then existing hospital. This upcoming move provided the perfect catalyst from which to begin my research. In the process of planning for this move all of the old patient admission records for the ICU were discovered stored in a cupboard in the administration offices of the ICU. This find provided a wealth of information about the types and numbers of patients cared for over the years. Once people became aware of my interest in the history of the unit I was also made aware of many other useful archival documents pertaining to the history of Wellington ICU.

In writing this thesis I position myself as an intensive care nurse interested in the history of intensive care nursing. Insider bias as a result of my knowledge and 10-plus years of experience in intensive care nursing may have at times influenced my understanding and interpretation of events. However, this same knowledge and experience also gave me the ability to approach information and facts with the benefit of an insider's understanding and vision. This research will contribute to the international body of literature and knowledge of how the specialty of intensive care nursing developed. The research involved the use of primary documentary sources including national and local archival records and documents and interviews with six nurses who worked in the ICU anytime between 1965 and 1989.

A limitation of this research is that I have been unable to ascertain the evolution of the nursing hierarchy within Wellington Hospital during the research timeframe. It has therefore not been possible to represent when the terminology changed from ward nurses and charge nurses over the 25 year period or to describe the way nurses and patients were overseen, e.g. Matron's rounds and the after-hours supervision of nurses. Finally, in choosing to take a broad overview of the development of ICU nursing as a specialty, I have focused on describing the salient points of this development. 


\section{Historiography}

In order to establish the existing body of knowledge on the history of ICU and intensive care nursing I undertook a literature review of research and narratives already written on these subjects. In conducting the literature review, I found that the body of literature available was predominantly written by doctors describing the establishment of ICUs internationally, with limited literature written with consideration to nursing in this field. The literature and research that is available on the subject of the history of intensive care nursing is primarily published in the United States of America (USA) and Great Britain, with one significant piece of literature available detailing the history of ICU nursing in Australia. Although these narratives provide a picture of ICU development overseas the lack of material published in NZ means comparisons between NZ and international practices are difficult.

In undertaking the literature search I initially conducted a CINAHL search using the key words intensive care, critical care, nursing, history, and development. I used the search terms intensive care and critical care as I was aware that these terms are used interchangeably both in nursing and medicine. Once I had sourced all available literature relating to this search I was able to compare my keyword search terms against those used in the articles found. This revealed that my search terms were consistent with those used by other authors. The second strategy used was to review references cited in these articles to gauge their suitability and relevance to this topic. This strategy netted several useful articles not revealed in my original search. The search was limited to articles and research published in English. In doing this I acknowledge that I may have excluded histories and developments of ICUs and intensive care nursing in other countries.

The New Zealand Nurses Journal (Kai Tiaki) was a further valuable source of information pertinent to NZ. It contains several firsthand accounts written by NZ nurses working in and undertaking opportunities to understand the specialty of ICU nursing both nationally and internationally. Kai Tiaki - the Journal of the Nurses of New Zealand, as it was originally titled, was founded by the nursing visionary Hester Maclean and was first 
published in January 1908. Hester Maclean was New Zealand's chief nurse from 19061923 and was the founding editor of Kai Tiaki from 1908 - 1932. The journal has undergone a number of name changes but despite its various official titles has always been referred to by the profession at large simply as Kai Tiaki. ${ }^{10}$ A full collection of Kai Tiaki journals is held at the library of the New Zealand Nurses Organisation (NZNO) in Wellington. My search strategy in relation to these journals consisted of visiting the NZNO library and reading the index pages of each of the journals from the 1960s through to the 1980s looking for any reference to ICU or ICU nurses or nursing. This search netted several useful articles written by ICU nurses.

Although three unpublished doctoral dissertations were identified during the literature search I was unable to obtain copies of any of these for reference. ${ }^{11,12,13}$ Two originated in the USA and one was written from a Canadian perspective. However, in 2011, shortly before completion of this research project, I became aware of a thesis published in Canada in 2010 detailing the historical development of intensive care nursing at Vancouver General Hospital which I was able to access online ${ }^{14}$. Of significance this Canadian thesis reports on developments over a similar timeframe $(1960-1985)$ to this current study. Also Fairman's thesis, from which she has published, covers a similar period.

It would appear that in the past decade awareness in documenting the history of intensive care and ICU nursing has become more prevalent, with the publication of three key texts

\footnotetext{
${ }^{10}$ http://www.paperspast.natlib.govt.nz

11 Jacqueline Christine Zalumas, Critically ill and intensively monitored: patient, nurse and machine: The evolution of critical care nursing'. Ph.D. Thesis, Emory University, 1989.

12 Julie A. Fairman, New hospitals, new nurses, new spaces: The development of intensive care units, 1950 1965 University of Pennsylvania, 1992.

${ }^{13}$ Christine Cutungo, The historical development of intensive care nursing in the United States, Ph.D. Dissertation, New York University, Division of Nursing Science, 1992.

14 Deborah Hamilton, The Historical Development of Intensive Care Nursing at Vancouver General Hospital, 1960-1985, Masters Thesis, The University of British Columbia, Faculty of Graduate Studies, Vancouver, 2010.
} 
on the subject. Firstly, Jacqueline Zalumas's book entitled Caring in Crisis: An Oral History of Critical Care Nursing, which she describes as occurring as a result of the "gradual realisation of the invisibility of nurses and nursing practice in the history of health care". ${ }^{15}$ Secondly, Fairman and Lynaugh's book Critical Care Nursing: A History was published as a result of a study sponsored by the American Association of Critical Care Nurses $(\mathrm{AACN}){ }^{16}$ The final was written by Wiles and Daffurn, who in 1997 responded to the call from the Australian College of Critical Care Nurses (ACCCN) to write a history of critical care nursing from an Australian perspective. ${ }^{17}$ The resulting book is currently the only nursing research I have been able to find on this subject in Australasia. These books were considered significant in that they all focused specifically on the development of ICUs and intensive care nursing and provided a useful international perspective. One further noteworthy publication was Trubuhovich and Judson's history of the NZ region of ANZICS. ${ }^{18}$ Whilst this book was useful in determining the history of each of the ICUs in NZ and the timeframe in which they were established, it was written from a medical perspective with little reference to nursing.

Early nursing textbooks and reference books pertaining specifically to intensive care nursing often dealt with what was often referred to as intensive nursing care, meaning all of the specialties providing care for critically ill patients, for example coronary care, haemodialysis units and intensive care units. These text books were published primarily in the USA with no nursing textbooks originating in NZ found on this subject. Two American intensive nursing care textbooks, Principles of Intensive Care Nursing and

\footnotetext{
${ }^{15}$ Zalumas, Caring in Crisis, p.xi.

${ }^{16}$ Fairman and Lynaugh, Critical Care Nursing.

17 V. Wiles and K. Daffurn, There's a Bird in my Hand and a Bear by the Bed - I Must be in ICU, Southwood Press Pty Ltd, Marrickville, NSW, 2002, p.XV.

${ }^{18}$ R.V. Trubuhovich and J.A. Judson, Intensive Care in New Zealand: A History of the New Zealand Region of ANZICS, Department of Critical Care Medicine, Auckland Hospital, Auckland 2001. ANZICS (Australia and New Zealand Intensive Care Society) is a professional body established for Doctors involved in intensive care medicine in this region.
} 
Intensive Nursing Care were able to be obtained from an online historical book store and provided useful insight into nursing practices of the time. ${ }^{19,20}$ These secondary sources enabled corroboration of information gathered from both the oral history interviews and the primary documentary sources.

\section{Structure of the Thesis}

This thesis differs from the available literature in that it documents the development and experience of only one ICU and is written from a NZ perspective. In focusing on one ICU it will contribute a more detailed account of nurses' experience of the development of ICU nursing as a specialty. Specific to this is the inclusion of the patient demographic data; something which none of the other books or journal articles sourced, discussed.

Chapter Two overviews the process of historical research and the methodology utilised in the data collection for this thesis. Chapter Three summarises the precursors to ICUs and the reasons for ICUs being established. In addition the historical development of ICUs from both an international and a local context is presented. With the evolution of ICUs came the specialisation of intensive care nursing; why those nurses interviewed came to work in ICU and the orientation that they received when first starting their employment in the unit will also be examined. Chapter Four describes the patient demographic data of three separate time subsets within the research period and the changes that occurred. This provides a snapshot of the clinical profile of patients, how long patients stayed, where they were admitted from and mortality and survival rates of the patients admitted. The key to providing good patient care is the functional relationship between the nursing and medical staff. The perceptions of these relationships by those nurses interviewed and how they changed over the years is outlined in Chapter Five. Chapter Six focuses on the design and layout of the ICU. As the location of the ICU moved within the hospital

\footnotetext{
${ }^{19}$ F. Storlie, E. Rambousek and E. Shannon, Principles of Intensive Care Nursing, Meredith Corporation, The United States of America, 1969.

${ }^{20}$ Z.L. Burrell Jr and L.O. Burrell, Intensive Nursing Care, The C.V. Mosby Company, The United States of America, 1969.
} 
during the research timeframe, the differences in design and how these impacted on nursing practice is described. Although the technology associated with those early ICUs would in 2011 be considered basic, the relationship between technology and ICU nursing work will be discussed and how some of this equipment changed over the years will be considered. Alongside this sit the daily routines and delivery of care, specifically the rituals of patient care delivery and working in the ICU. Education of nurses working within ICU is paramount to the delivery of safe and appropriate care. The development and ongoing provision of Wellington Hospital's intensive care course instructing ICU nurses from around NZ, along with the ongoing education of nursing staff forms the basis of Chapter Seven. The final chapter summarises the findings and the limitations of this study and offers suggestions for future historical research. 


\section{Chapter Two - Methodology and Method}

\section{Introduction}

This chapter will examine the process of historical research and the methodology used in the data collection for this thesis. Both the primary and secondary documentary sources utilised are discussed as is the method of data collection employed for each source. Establishing the authenticity of documentary sources used helps determine the rigour of historical research and this process will be outlined, as are the ethical considerations. Following a discussion on the method of oral history interviews each of the oral history interviewees is introduced.

\section{Historical Research}

In reviewing the literature on undertaking historical research it became evident that there is no one clear method to use. However, there are similarities in the approaches and stages in the process of "doing" historical research. No specific tools or frameworks are required; rather it is a process that involves a number of formal yet overlapping stages, similar to and in keeping with other research traditions. ${ }^{21}$ It has been argued by Sweeney that the objective of historical research encompasses more than the simple unearthing of facts but includes understanding what they mean and how they interrelate. ${ }^{22}$ It is this understanding of the past that shapes and informs our nursing practice today.

The primary methodology of historical research is historiography; Lusk describes this as being the study, writing and interpretation of history and is broadly referred to within the methodology literature as the techniques, principles and theories that pertain to historical

\footnotetext{
${ }^{21}$ J.F. Sweeney, 'Historical research: Examining documentary sources', Nurse Researcher, 12, 3 (2005), p.65, citing the work of Fox.

${ }^{22}$ Sweeney, 'Historical research', p.65 commenting on the work of Newton, 1965.
} 
matters. ${ }^{23}$ Similarly, Sarnecky refers to it as the process of examining data from the past and integrating it into a coherent unity in order to put it to some practical use for the present and the future. ${ }^{24}$

\section{Why Historical Research?}

In the past, the process of historical inquiry has been considered by many nurses ${ }^{25}$ as less

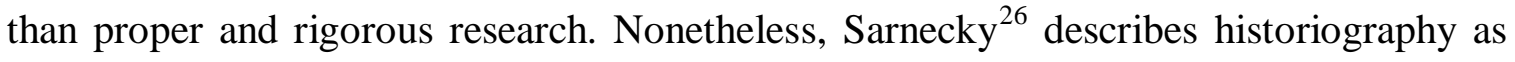
steadily gaining momentum as a professionally acceptable method of nursing research with much of the academic world now acknowledging the validity of this approach to the survival and progression of nursing and to the enrichment of clinical practice.

Barnard $^{27}$ describes the purpose of historical research as investigating the past with the hope of gaining insight into our present behaviour. Historical methodology and design is considered to have particular relevance to those nurses who seek to study the social, political, economic and historical context of decisions made in any given period in time that affected healthcare or the practice of nursing. ${ }^{28}$ Furthermore Newton ${ }^{29}$ proposed that the search for a profession's identity is bound up with the social and historical roots that lead to its creation. In developing a robust professional identity, nursing must have a clear understanding of its history. ${ }^{30}$

\footnotetext{
${ }^{23}$ B. Lusk, 'Historical methodology for nursing research', Image: Journal of Nursing Scholarship, 29, 4, (1997), p.334.

${ }^{24}$ M.T. Sarnecky, 'Historiography: A legitimate research method for nursing', Advances in Nursing Science, 12, 4 (1990), p.2.

${ }^{25}$ Sarnecky, ‘Historiography', p.3.

${ }^{26}$ Sarnecky, 'Historiography', p.3.

${ }^{27}$ K. Barnard, 'Research designs: The historical method', American Journal of Maternal and Child Nursing, 6 (1981), p.391.

${ }^{28}$ Sweeney, 'Historical research', p.62 discussing the work of Christy, 1975.

${ }^{29}$ Sweeney, 'Historical research', p.62 citing Newton 1965.

${ }^{30}$ Sweeney, 'Historical research', p.62 referring to the work of Church, 1987.
} 


\section{Methodology}

In the process of undertaking historical research there are primary and secondary sources of information. These sources of information may include both written material and information obtained from individuals in the form of oral histories or interviews. ${ }^{31}$ Primary sources are essential to historical research as they provide firsthand accounts of events, practices or experiences and offer important insight into a particular period in time. $^{32}$ Documentary sources are generally found in archives and are described as documents by people who participated in or witnessed an event. ${ }^{33}$ This is further clarified as information emerging from those who have personally witnessed events, is considered original, and is thought to have existed at the time of the event. ${ }^{34}$ In this research, I utilised three forms of primary sources: two documentary sources, and oral history interviews. Secondary documentary sources are considered to provide depth and meaning to the research, enhancing the researchers understanding of what has previously been written on the subject. ${ }^{35}$ The key secondary documentary sources utilised in this research project were discussed in the literature review in Chapter One.

\section{Documentary Primary Sources}

\section{Patient Admission Records}

The patient admission records consist of large books, one page for each day of the calendar year, and one volume per year. Each volume contains the details of patients admitted to Wellington Hospital ICU for that given year. Details recorded consist of the:

\footnotetext{
${ }^{31}$ Sarnecky, 'Historiography', p.4.

${ }^{32}$ S.B. Lewenson and E.K. Herman., Capturing Nursing History: A Guide to Historical Methods in Research, Springer Publishing Company, New York (2008), p.34.

${ }^{33}$ Lusk, 'Historical methodology', p.337.

${ }^{34}$ Sarnecky, 'Historiography', p.4.

${ }^{35}$ Lewenson and Herman, Capturing Nursing History, p.32.
} 
patient's name, age, hospital identification number, admission diagnosis, date of admission and discharge, admission source and discharge destination or death.

Collecting the information from each entry in the hospital admission records for the 25 years of this study would have yielded approximately 10,000 patient records, significantly more than required and manageable for a research project of this size. After seeking advice on the statistical management of the data from staff at the university, it was decided that a sample size of 300-400 records spread across the 25 year time span would be sufficient to illustrate changes through time. In order to achieve this dataset three separate years were sampled: 1965 being the first full calendar year of operation of the ICU, 1977 being the midpoint of the research timeline and 1989 being the final year. In each of these three years, data were extracted from all patients admitted to the ICU from four separate months: January, April, July and October. Using the information from these months allowed any seasonal variations in patient admissions to be captured. In utilising this method of data collection, information about 484 patient admissions were collected and analysed using descriptive statistics to describe how patient demographics had changed over the timeframe of the study.

In order to collect the extracted information, an electronic database was set up using an Excel spreadsheet with one page for each of the three years to be sampled. Each page had columns for patient name, age, hospital identification number, admission date, admission source, admission diagnosis, discharge date, and discharge destination. Each patient record for the relevant sample months was entered into the relevant year's spreadsheet. Patient names and hospital identification numbers were entered into the initial database in order to facilitate cross referencing and checking of data should any errors be identified in the data entry process. On completion of the data collection all entries were checked for anomalies before patient names and hospital identification numbers were deleted from the final database. Once completed each of the demographic variables was then analysed statistically using the software Statistical Package for Social Science (SPSS) version 18. 


\section{Archival Documents}

The "Roy Towers" collection at Archives New Zealand contains information pertinent to Wellington ICU and although not substantial in volume it was a valuable initial primary resource. Roy Towers is described as having worked at Wellington Hospital in various administrative roles from 1941 to $1983 .^{36}$ He carefully collected and preserved a wealth of historical information relating to the public hospital in Wellington and also coauthored a book on the history of Wellington Hospital titled 'Wellington Hospital 1847 $1976^{\prime}$ with Laurie Barber. ${ }^{37}$ There is no mention of the development of the ICU in this book.

Wellington Hospital archival records and documents are managed by a records management administrator. Since 2008 when preparations for the move to the new regional hospital began, the process of sorting and recording items has been on-going with documents being catalogued and archived on the hospital campus to then be sent to Archives New Zealand. However, with only one individual responsible for this it is a slow and painstaking process and it is likely that some valuable material related to the Wellington ICU was not located amongst this collection in the time frame allowed for data collection.

A collection of papers including copies of minutes of meetings and correspondence pertaining to the ICU kept by Dr. Cam Barrett during his time as a clinician there are held by Dr. Peter Hicks and these were made available to me for reference. ${ }^{38}$ It was found that original copies of these papers were also contained in the archival documents sourced from the Wellington Hospital archives. The final source of information on Wellington Hospitals history was an internet database created by Dr. Ron Easthope, Wellington Hospitals honorary archivist, a retired cardiologist who worked for many years at

\footnotetext{
${ }^{36}$ http://www.ccdhb.org.nz/hhist/staff/roytowers.htm

${ }^{37}$ http://www.ccdhb.org.nz/hhist/staff/roytowers.htm.

${ }^{38}$ Dr. Cam Barrett was the first clinical leader of the ICU at Wellington Hospital and Dr. Peter Hicks was the Medical Director of Wellington ICU at the time of starting this research.
} 
Wellington Hospital. ${ }^{39}$ The information on this database provided a chronological history of Wellington Hospital and has also been transformed into a pictorial timeline spanning a main corridor within the new regional hospital.

\section{Other Documents}

As discussed in the literature review in Chapter One, Kai Tiaki the New Zealand Nurses Journal contained several valuable primary documentary sources pertaining to intensive care nursing in NZ.

A final unexpected primary source was a small notebook brought along by one of the interviewees, Marie, to her oral history interview. This notebook was used by Marie when she worked in ICU. She spoke of writing down any information she thought was important that she was told during her time working in ICU. Two examples of information that she had written in her notebook were the list of contents of the emergency resuscitation trolley kept in the ICU, and how to prepare and administer certain drugs used in the ICU. Marie could not recall how she determined what she considered important enough at the time to write in her notebook but thought that it was most likely things that she had not encountered previously in her nursing practice.

Data were extracted from these primary documents in a process that involved reading each document and considering its content for its relevance to the research. If any part of its content was deemed relevant I then considered where it best fit within the research and whether there was any other evidence to support or corroborate it. A lack of other evidence was not considered reason to discard evidence, but merely to use it more cautiously.

\section{Primary sources - Oral History}

Oral sources predominantly fall into two distinct categories each with differing connotations as historical evidence. ${ }^{40}$ Tosh describes oral reminiscence as oral

${ }^{39}$ www.ccdhb.org.nz/hhist.

${ }^{40}$ As discussed by J. Tosh, The Pursuit of History: Aims, Methods and New Directions in the Study of Modern History, $2^{\text {nd }}$ ed., Longman, London and New York, 1991, p.206. 
recollections of persons interviewed by a historical researcher. ${ }^{41}$ Frequently this is referred to as oral history and has been increasingly used in western countries since the 1960s for its importance in documenting recent social history pertaining to everyday life, particularly those aspects of working class life in the family and workplace. Tosh describes oral tradition which pertains to narratives and descriptions of past, people and events that have been handed down by word of mouth over several generations. This is primarily used in countries with a predominantly oral culture; however it is now virtually extinct in highly industrialised countries. ${ }^{42}$ For the purposes of this research oral reminiscence is the method of oral history data collection used.

The expression oral history is used to describe the process of recording the spoken memoirs of significant individuals, ${ }^{43}$ with none being better able to describe the past with more passion and articulation than those who were there. ${ }^{44}$ Personally I believe the use of oral history has resonance with one of the key methods of communication upon which nursing is based. Nursing as a profession relies on oral communication: as nurses we talk to our patients and our colleagues, we "handover", we obtain histories from our patients and it is our primary method of sharing information. Therefore it is the logical means of capturing the essence of what it is that we have traditionally done as nurses and more relevantly for this research, how intensive care nursing developed.

Capturing oral history is not without its problems. Wall, Edwards and Porter suggest that oral histories are recollections given by the interviewees typically a long time after they have occurred. ${ }^{45}$ These authors describe a key downfall of oral history as being the

\footnotetext{
${ }^{41}$ Tosh. The pursuit, p.206.

${ }^{42}$ Tosh, The pursuit, p.206.

${ }^{43}$ Oral history is an expression coined by Professor Allan Nevins as described in N. Biedermann, 'Voices of days gone by', Nursing Inquiry, 8 (2001), p.62.

${ }^{44}$ Biedermann, 'Voices', p.61.

${ }^{45}$ B.M. Wall, N.E. Edwards and M.L. Porter, 'Textual analysis of retired nurses' oral histories', Nursing Inquiry, 14, 4 (2007), p.280.
} 
participant's subjectivity. Sometimes people remember not only what they did, but also what they wish they had done, or what they believed they were doing at the time. Further to this they argue that over time interviewees may "rewrite" events in their own minds, therefore recalling what they now think their actions were. Another difficulty in capturing oral histories is that the researcher is delving into memories that are intensely personal, and there may be reluctance on the part of the interviewee to impart recollections that are painful, resulting in an incomplete picture. ${ }^{46}$ Finally, "biases in the form of deliberate exaggeration, distortion and omission to subconscious repression and the unintentional conflation of personalities and events may occur". ${ }^{47}$ Despite these limitations it is Biedermann's opinion that the information gained from oral history interviews is a crucial aspect of documenting the nature of nursing work, with one noteworthy benefit of using oral histories being that the stories or recollections can help provide clarification of the written evidence, explain underlying assumptions and motives, and provide missing evidence that may complete the picture of the event. ${ }^{48}$ This corroboration of evidence was used to establish the rigour and reliability of this historical research.

\section{Rigour and Reliability}

It is noted by Sarnecky that documentary sources held in reputable archives can generally be assumed to be authentic having already undergone a rigorous period of scrutiny. ${ }^{49}$ The testimony contained in oral history interviews is also a valid means of corroborating written records. ${ }^{50}$ Sarnecky describes the processes of verifying the authenticity of documentary sources utilised as commonly being referred to as internal and external criticism. She defines external criticism as establishing the trustworthiness and authenticity of a document by establishing whether the document is what it claims to be

\footnotetext{
${ }^{46}$ Biedermann, 'Voices', p.61.

${ }^{47}$ Biedermann, 'Voices', p.61.

${ }^{48}$ Biedermann, 'Voices', p.61.

${ }^{49}$ Sarnecky, 'Historiography', p.4.

${ }^{50}$ Lewenson and Herman, Capturing Nursing History, p.80.
} 
whilst internal criticism refers to the practice of establishing the reliability and credibility of the document. Further added to this documentary analysis she describes the process of positive and negative criticism applied by the researcher. Positive criticism pertains to the content of the document in question; significantly whether the content is fully understood by the researcher and that no more is being implied from the evidence than that which the original author intended. Negative criticism is the process by which the researcher evaluates the accuracy of the statements made in the evidence. ${ }^{51}$ As most of the primary documentary sources used in this research came from either the Wellington Hospital archives or Archives New Zealand it was assumed that they were valid and authentic.

To obtain robust and reliable findings as much evidence as possible must be gathered from a wide ranging number of sources. In doing this Hutching suggests that inaccuracies and distortions in any one of these sources are more likely to be exposed. Hutching argues that each source of evidence possesses strengths and weaknesses; therefore they must be evaluated together as a whole and compared against each other if a well reasoned argument is to be constructed. ${ }^{52}$ Lewenson and Herrmann acknowledge that authenticating documentary sources found outside of archival collections can be daunting. However, they recommend that researchers can rely on: attention to detail, common-sense reasoning, familiarity with human behaviour and ever-enlarging stores of information in an attempt to assure validity of resources. ${ }^{53}$

As part of exploring the concept of ICU nursing and to develop a greater understanding of its evolution as a specialty, I collected data and information from several sources and perspectives; oral history interviews, archival documents and secondary literary sources. In regards to information on subjects such as education of ICU nurses and the technology used in ICU much of the archival information gathered was similar to that in the

\footnotetext{
${ }^{51}$ Sarnecky, 'Historiography', p.4.

${ }^{52}$ M. Hutching, Talking History: A Short Guide to Oral History, Bridget Williams Books, in association with the Historical Branch, Department of Internal Affairs., Wellington,1993, p. X.

${ }^{53}$ Lewenson and Herman, 'Capturing Nursing History', p.35.
} 
international literature used as secondary sources, providing credibility. Information obtained from the oral history interviews corroborated other documentary sources of information. By utilising three separate data sources the rigour of the findings in this piece of research is strengthened.

\section{Ethical Considerations}

Expedited ethical approval for the use of the patient admission records and the oral history interviews was sought and obtained from the New Zealand Health and Disability Ethics Committee - Central Region prior to collection of the data (Appendix A). The National Oral History Association of New Zealand (NOHANZ) Code of Ethical and Technical Practice was utilised in the preparation and recording of the oral history interviews. In accessing and using information from Archives New Zealand and the Wellington Hospital archives all guidelines and local agreements were adhered to.

\section{Method - Oral History}

To capture the memories and recollections pertinent to the specialisation of nursing and the development of nursing practice in Wellington Hospital ICU I conducted oral history interviews with six nurses using a semi-structured interview format. As I had already identified several topics that were critical to the development of the history, my questions were based around these. During the interviews interviewees were free to talk about their memories and recollections with the questions only being used as a prompt. The topics I focused on were orientation to ICU, patient's demographics, Doctor - Nurse working relationships, technology, working routines within the ICU and education of ICU nurses. The findings related to these are presented in Chapters Four to Eight.

Oral history participants were sought primarily on the basis of experience and positions held within the ICU, but also to ensure that all years within the research time period were covered. My criteria in participant selection was that the nurse had had a significant role within the ICU such as setting up or tutoring the ICU nursing course; or had been involved in the early days of intensive care nursing; or had worked in both Wellington ICU and other ICUs overseas, therefore were able to provide a comparison of practice. In addition, nurses who had worked in ICU for a number of years were sought to provide 
insight into how nursing work had developed and changed over time. No information was available on the number of nurses who had worked in the ICU during the research period.

The nurses were identified by two methods. Firstly, there are a number of nurses currently working in the ICU who had worked there throughout various portions of the timeframe of this research who met the above criteria. I was able to approach these nurses personally and invite them to participate in an oral history interview. The second method for identifying relevant persons was that of word of mouth, or snowballing. Once I began the oral history interviews the nurses I interviewed suggested other possible sources. I was then able to contact these people to invite them to participate. On hearing about my research, several current ICU nurses also suggested nurses they knew who could be possible interview candidates. Of the six nurses approached all agreed to be interviewed. Four of these I knew personally and the other two were identified via word of mouth, one by another interviewee participant, and the other by a member of the ICU nursing staff.

In undertaking the oral history interviews, potential interview subjects were contacted initially with a letter outlining the details of the research project and inviting them to participate in an oral history interview (Appendix B). Once recruited each interviewee was provided with a written information sheet (Appendix C) outlining the purpose of the research and an interview schedule (Appendix D) that provided information on the areas to be covered during the interview. Once a participant agreed to be interviewed an appointment was made to conduct the interview and at this time formal written consent (Appendix E) was obtained. Each participant was asked if they wished to be identified by their name or use a pseudonym and their preference was indicated on the consent form. If they chose to use a pseudonym they were asked to provide one for me to use.

Of the six interviewees, five consented to be referred to by their name and one participant requested to be referred to by her given name. This was not the name that she was generally known by, in effect using a pseudonym. As one of the interviewees chose to 
use a pseudonym only first names of each of the interviewees are used to identify them in the thesis. This decison also reflects the period as surnames of nurses were not generally utilised in the ICU environment during the research period.

In the written information sheet given to them, participants were informed that a copy of their interview tape would be provided if they wanted one. As no interviewees requested a transcription of their tape I elected to destroy each of the interview tapes on completion of the interview process. Provision had been made in the ethics application and also at the time of gaining consent from each interviewee to approach them on completion of all of the interviews with a view to obtaining further consent to lodge the interview tapes with an oral history archive. On completion of the oral history interviews it was my belief that although each interview was of a standard sufficient to provide me with valuable insight and information to complete this research project, due to my novice interviewing skills I did not consider the final tapes to be of the expected standard to be passed on for future use.

There is debate among oral historians when transcribing interview tapes as to whether to transcribe the entire interview or to make an abstract of the whole interview. ${ }^{54}$ Hutching ${ }^{55}$ describes the key benefit of transcribing each interview verbatum as being that it can then be read in its entirity with the interview being presented in a form that will be easiest for researchers to use at a later date. Conversely she describes an abstract as consisting of a comprehensive listing of subjects covered in the interview with a record of at which point in the interview information can be found, thereby giving the user an idea of the interview contents without telling them exactly what the interviewee says. When abstracting an interview users then have to listen to the recorded interview to obtain the information that it contains. ${ }^{56}$ When transcribing the interview tapes I elected to make a verbatum transcript of each interview and then undertake a content and thematic analysis of the information contained within to identify common themes within each one.

\footnotetext{
${ }^{54}$ As discussed in Hutching, Talking history, p.45.

${ }^{55}$ Hutching, Talking History, p.40.

${ }^{56}$ Hutching, Talking History, p.40.
} 
Excerpts from these oral history transcripts are used throughout this thesis to support information from other sources. In using these excerpts I have used the language and words of the interviewees as spoken in the oral history interviews. This later discussion may mean that roles of the time such as Ward Sister, are also described using terms such as Charge Nurse.

\section{Oral History Interviewees}

The six interviewees as a group worked at various times in the ICU from 1965 until the end of the research timeframe with two of the interviewees still working in the ICU in 2011 and collectively they hold a wealth of knowledge and experience. As an opening question in the oral history interviews, interviewees were asked to describe their nursing careers prior to beginning work in ICU.

Pauline first worked in Wellington ICU as a staff nurse in 1964 after returning to Wellington Hospital from a stint working overseas. She was asked by the then Matron to go onto night duty in ICU, so after a week of working days with the ICU charge nurse she then went on to working the night shifts. She then left to work in Accident and Emergency (A\&E) for a period of time before going to Australia to complete a post graduate intensive care nursing qualification at St Vincents Hospital in Melbourne before returning in 1968 to set up and then tutor the intensive nursing care course. Pauline ran this course for several years before leaving ICU after receiving a Churchill scholarship which enabled her to visit hospitals in America, Canada, Sweden, England and Australia to observe practices in their ICUs. She returned to Wellington Hospital to a managerial position elsewhere after this trip.

Marie came to Wellington Hospital from Seddon Hospital in Gore in 1967 to work as a staff nurse in ICU. Having trained and worked in a small hospital she felt that it was advisable to get some experience in a more acute area before heading overseas to work in Canada. She applied to Wellington Hospital and was offered a position in ICU. She worked in the unit until 1968 when she left to travel and work in Canada. 
Maureen began her nurse training in Wellington Hospital in 1965 and occasionally spent time in ICU during the third year of her training. She recalls that whilst working in the ward next to ICU, student nurses often went into the ICU to help. One particular time recalled by Maureen was when the Wahine ferry sank in Wellington Harbour. ${ }^{57}$ After working for a year in orthopaedics on completion of her training, she came to work in the ICU as a staff nurse in 1969 after being encouraged to do so by a friend who worked in Coronary Care. She continued to work in ICU for approximately six months after completing the ICU course and then left to go overseas to work in Canada where she continued to work in various ICUs before returning to Wellington in the early 1980s. After a short stint working in the cardiothoracic ICU she then returned to the main ICU where she continues to work currently.

Maryanne trained at Hutt Hospital and spent her first year as a staff nurse there working in A\&E, medical and surgical wards. She then went to work in the ICU at Hutt Hospital as one of the first staff nurses without an ICU qualification. She was encouraged by the other staff working there to do the course so in 1974 she came to Wellington Hospital ICU to do the ICU nursing course. Immediately after completing that she went to England to work before returning to Wellington in 1976 where she worked initially in coronary care for a few months before transferring back to ICU. Within a short period of time she was invited to become the assistant tutor for the ICU course alongside the then course tutor Bernice Collins. Eventually, Maryanne became the sole course tutor and was also involved in the planning of the new ICU. She then applied for and was successful in obtaining the position of Charge Nurse in 1980, a role she held until she left the organisation in 1999.

Henny trained in Wellington Hospital and came to work in the ICU in 1977. She was one of the original nurses to transfer patients from other hosptials as a flight nurse on the developing flight retrieval team. She was active in the development of the flight nurse role both within Wellington Hospital and nationally as one of the founding members of

\footnotetext{
${ }^{57}$ The Wahine was a passenger ferry that travelled between the North and South Island and sank in Wellington Harbour on 10 April 1968 killing 51 people. www.thewahine.co.nz.
} 
the Flight Nurse Association developing standards and protocols for the safe aeromedical transport of patients within NZ. She continued to work as both a staff nurse in ICU and flight nurse until early 2000's when she left ICU to take on the role of Flight Coordinator at Wellington Hospital.

Cheryl came to work in the ICU in 1980 as a newly graduated nurse after spending the final six weeks of her nurse training working in ICU. After 18 months she left ICU to get some ward nursing experience but soon returned. She has continued to work in ICU ever since with the exception of a period off on maternity leave and currently works as an Associate Charge Nurse Manager.

\section{Conclusion}

This chapter has outlined the process of conducting historical research and introduced the historical research method. Data were collected from three primary sources: the patient admission records, archival sources and oral history interviews. The secondary documentary sourses provided validation and additional information to support the data collected. Each of the oral history interviewees was introduced with a brief synopsis of their nursing career prior to commencing work in ICU.

The next chapter will summarise the precursors to ICU and the impetus for the development of ICUs internationally and nationally. Each of the interviewee's reasons for working in ICU are presented along with their experiences in regards to their orientation and preparation to work in this field of nursing. The decision to introduce why the nurses chose to work in ICU in this section of the thesis is to allow the reader to delevop a sense of the interviewees nursing background prior to coming to work in ICU as well as their ICU nursing experience. 


\section{Chapter Three - Intensive Care: The Beginning}

\section{Introduction}

This chapter describes the historical development of ICUs from an international, New Zealand and Wellington perspective. With the evolution of ICUs came the specialisation of intensive care nursing; why those nurses interviewed came to work in ICU and what methods were employed in training them to work safely in this environment over the time period will be examined. The resources for the majority of this chapter are secondary sources. Excerpts from the oral history interviews are utilised to capture the nurses' experiences of their orientation to the unit.

\section{Precursors to Intensive Care Units}

Although ICUs and intensive care nursing have only been formally recognised since the 1950s, their history and foundations are embedded in the traditions of nursing. ${ }^{58}$ Prior to the establishment of ICUs Wiles and Daffurn describe how patients who needed critical care were nursed in general ward areas screened off from the rest of the ward by large, cumbersome screens on wheels. These screens were regarded by some patients as an ominous sign. ${ }^{59}$ According to Wiles and Daffurn if the patient was located in the first corner on the left or right of the ward entrance, it was thought by many patients that the outcome was a foregone conclusion. As far as many patients were concerned, this was being done so that when the patient died, the mortuary trolley could take the body away discretely. Located behind the screen was "the patient and nurse, a portable electric sucker and oxygen cylinder, wooden IV [intravenous] stands with non-disposable IV administration sets and glass bottles as well as a range of non-disposable trays and equipment." commonly, student nurses in their second or third year of training. Given that there were

\footnotetext{
${ }^{58}$ A. Footner, 'Nursing specialism or nursing specialization', Journal of Orthopaedic Nursing, 2 (1998), p.219.

${ }^{59}$ Wiles and Daffurn, Bird and Bear, pp. 83-84.

${ }^{60}$ Wiles and Daffurn, Bird and Bear, pp. 83-84.
} 
generally only a few registered nurses per ward, registered nurses were usually not available to provide this one-on-one care. ${ }^{61}$

The notion of specialling critically ill patients is one that has been in use for over 100 years. ${ }^{62}$ Fairman and Lynaugh describe how traditionally very ill patients were kept safe or watched over by caregivers using two very dependable means. First, caregivers usually using private duty nurses, "kept watch" by intense surveillance with one nurse watching one patient. The second means was patient triage. Long used in war and disaster to prioritise patients' injuries and need for care, triage favoured patients with some promise of recovery. ${ }^{63}$

Wiles and Daffurn describe how the origins of this placement of patients in close proximity to the nurse can be traced back to Florence Nightingale's time where the practice was to place the sickest patients at the head of the ward nearest the nurse's desk, while the convalescent or least ill patients were placed in beds farther away from the nurse's watchful eye. ${ }^{64}$ The poignant recollections of Louisa May Alcott of her nursing work after the battle at Fredericksburg, Virginia, beautifully demonstrates this traditional practice of sorting the sick according to both intensity of needs and expectation of outcomes:

My ward is now divided into three rooms... I had managed to sort out the patients in such a way that I had what I called "my duty room, my pleasure room and my pathetic room," and worked for each in a different way. One I visited armed with a dressing tray full of rollers, plasters, and pins; another with books, flowers, games, and gossip; the third with teapots, lullabies, consolation, and sometimes, a

\footnotetext{
${ }^{61}$ Wiles and Daffurn, Bird and Bear, p.85.

${ }^{62}$ Both Fairman and Lynaugh, Critical Care, pp.3-4 and Wiles and Daffurn, Bird and Bear, pp.91-107 make several references to the precursors to intensive care nursing.

${ }^{63}$ Fairman and Lynaugh, Critical Care, p.3.

${ }^{64}$ Wiles and Daffurn, Bird and Bear, p.173, citing the U.S. Department of Health, Education and Welfare, Elements of Progressive Patient Care.
} 
shroud... wherever the sickest or most helpless man chanced to be, there I held my watch. ${ }^{65}$

As early as 1930 the general premise by which ICUs developed was being considered in Germany at the University of Tuebingen's Surgical Hospital. ${ }^{66}$ Hilberman writes that a combined recovery room-intensive care ward was established by the Director of the hospital, Dr. Kirschner, for the management and treatment of patients recovering from surgery as well as the critically ill. It was his belief that such an area was essential to clinically apply the rapidly developing knowledge and surgical techniques that were being developed within the field of surgery. In addition it was his belief that patient care would be improved by placing the most skilled nurses in one area along with an experienced physician who would be responsible for the organisation of each patient's care. $^{67}$

Fairman and Lynaugh discuss how the premise of gathering sick people together in one place to provide safe, competent, and compassionate care is the pivotal concept of hospitals and one that gave rise to the creation of nursing as paid work. In addition they argue that the idea of gathering together the sickest patients - an approach emphasising group care and putting expertise and efficiency above all else - was the key concept behind the establishment of ICUs then and one by which we still practise today. ${ }^{68}$

\section{Impetus for ICU Development}

The development of ICUs evolved for many reasons. Firstly, Rosengart describes how the advancements in caring for the critically ill that occurred as a result of the wars of the 20th century provided a large impetus into the development of intensive care. ${ }^{69}$ By the

\footnotetext{
${ }^{65}$ Fairman and Lynaugh, Critical Care, p. 3.

${ }^{66}$ M. Hilberman, 'The evolution of intensive care units', Critical Care Medicine, 3, 4 (1975), p.159.

${ }^{67}$ Hilberman, 'The evolution of ICU', p.159.

${ }^{68}$ Fairman and Lynaugh, Critical Care, p.5.

${ }^{69}$ M.R. Rosengart, 'Critical care medicine: Landmarks and legends', Surgical Clinics of North America, 86 (2006), p.1305.
} 
end of World War I the ability to identify shock and institute appropriate fluid resuscitation was well established. During World War II surgical improvisation led to technical advances and the immediate survival of patients with previously lethal injuries. However, this then necessitated prolonged supportive therapy to ensure recovery. He describes this need for special care as leading to the establishment of "Shock Wards" in which soldiers injured in battle or undergoing surgery were resuscitated and cared for. ${ }^{70}$ Secondly Zalumas discusses how the establishment of post operative recovery rooms in the 1940s and 1950s demonstrated to medical and nursing staff the effectiveness of continuous nursing surveillance of very ill patients. ${ }^{71}$

Finally, the establishment of emergency or temporary ICUs in order to deal with civilian mass casualties in times of crisis is discussed by Hilberman. ${ }^{72} \mathrm{He}$ gives as an example the evening of the Coconut Grove fire in Massachusetts in 1942, where within a three hour period an entire floor of the Massachusetts General Hospital had been cleared of patients, converted to a burns unit, re-staffed and filled with 39 survivors of the fire. This temporary unit remained open for 15 days. ${ }^{73}$

\section{The First Intensive Care Units}

A combination of the two practices of intensive observation and patient triage provided the model for the care of the critically ill in ICUs. ${ }^{74}$ At the same time as the above developments were occurring a greater understanding of ventilation strategies was emerging. Judson and Fisher discuss how the superiority of intermittent positive pressure

\footnotetext{
${ }^{70}$ Rosengart, 'Critical care', p.1305.

${ }^{71}$ Zalumas, Caring in Crisis, p.99.

${ }^{72}$ M. Hilberman, 'The evolution of ICU', p.159. The coconut grove fire started at $10.30 \mathrm{pm}$ in a basement cocktail lounge and rapidly spread to the stairs cutting off the only means of exit; 491 people lost their lives.

${ }^{73}$ Hilberman, 'The evolution of ICU', p.159.

${ }^{74}$ J. Fairman, 'Watchful vigilance: Nursing care, technology, and the development of Intensive Care Units', Nursing Research, 41, 1 (1992), p.56.
} 
ventilation over negative pressure, or iron lung, ventilation for supporting respiratory function was first proved in the 1952 Copenhagen poliomyelitis epidemic. ${ }^{75}$ Rosengart suggests that this finding led to the development of what is widely acknowledged as the world's first ICU. He describes this as being "a ward where physicians and nurses observe and treat 'desperately ill' patients 24 hours a day" and was developed by Dr. Bjorn Ibsen at the Kommune Hospital in Copenhagen in December 1953. ${ }^{76}$ In $1966 \mathrm{Dr}$ Bjorn commented that

ICUs are of great value not only to the patients who are admitted for treatment but even more so to the many patients who due to the experience gained, are saved from complications later. When the patient is saved by intensive therapy it has very often been said: why was he allowed to be so ill? It would have been easier to prevent this than to cure it. ${ }^{77}$

In the USA, ICUs appeared in diverse geographical locations within months of each other in late 1953 and early 1954. It would appear that these developments were not immediately published by hospitals and physicians as papers detailing how these ICUs worked were slow to appear in the literature. ${ }^{78}$ Despite their widespread locations and the apparent lack of communication these units had four similarities: they each grouped critically ill patients together in a designated space, the units were small open rooms of four to six beds with a common observation area, each implemented more concentrated nurse staffing patterns and all provided a 24 -hour, seven day service. ${ }^{79}$

\footnotetext{
75 J.A. Judson and M. Fisher, 'Intensive care in Australia and New Zealand', Critical Care Clinics, 22 (2006), p.411.

${ }^{76}$ Rosengart, 'Critical care', p. 1306.

${ }^{77}$ Judson and Fisher, 'Intensive care', p.411 citing Gordon and Jones, 1998.

${ }^{78}$ Fairman and Lynaugh, Critical Care, p.12 cite the first published account of an ICU in America as occurring in September 1954.

${ }^{79}$ Fairman and Lynaugh, Critical Care, p.12.
} 
Closer to home in Australia, Judson and Fisher state that by 1957 the Artificial Respiration Unit at Melbourne's Fairfield Hospital ${ }^{80}$ was treating patients admitted with tetanus, acute polyneuritis, and poliomyelitis, with tracheostomy, negative pressure ventilation, and a mechanical cough arrangement. ${ }^{81}$ However, there is controversy amid the literature as to the location of the first Australian ICU. Wiles and Daffurn argue that the first formally recognised intensive therapy ward was established at St. Vincent's Hospital in Melbourne in November $1961 .^{82}$ However, Wiles and Daffurn the hospital's resuscitation officer, Dr. Galbally, implies in an earlier article written about the unit that it was in existence as early as $1955 .^{83}$ It was described as initially being built close to the operating theatres in temporary accommodation before a new unit was built in 1969. It was soon considered to be state-of-the-art with doctors and nurses visiting from all parts of Australasia. ${ }^{84}$ Judson and Fisher however, state Sydney's Prince Henry Hospital as the site of the first respiration unit in Australia, opening in 1961 and using mechanical ventilators to supply IPPV,$^{85}$ and the first general ICU being established the same year at St. Vincent's Hospital in Melbourne. ${ }^{86}$

The first documented British ICU opened in Kettering, England in 1962. Crocker explains how grouping those patients recovering from anaesthesia and surgery together who required advanced airway management and close surveillance was successful in reducing mortality rates. ${ }^{87}$ However, there was opposition from some surgeons at first,

\footnotetext{
${ }^{80}$ The Fairfield Hospital was Melbourne's infectious diseases hospital. Its artificial respiration unit first opened in 1937.

${ }^{81}$ Judson and Fisher, Intensive care, p.411.

${ }^{82}$ Wiles and Daffurn, Bird and Bear, p.110.

${ }^{83}$ Wiles and Daffurn, Bird and Bear, p.110 refer to this as an article published in the Medical Journal of Australia in 1966.

${ }^{84}$ Wiles and Daffurn, Bird and Bear, p.110.

${ }^{85}$ Intermittent positive pressure ventilation.

86 Judson and Fisher, 'Intensive care', p.411.

${ }^{87}$ Crocker, 'The development', p.325.
} 
interpreting it as necessary because 'something had gone wrong' and therefore a reflection on their surgical competence. As in other countries the concept proved viable with many more British hospitals developing ICUs over the following years. ${ }^{88}$

\section{Development of Intensive Care in New Zealand}

The sole available resource chronicling the development of ICUs in NZ was published in celebration of the first 25 years of the NZ region of the Australian and New Zealand Intensive Care Society (ANZICS). ${ }^{89}$ Contained within this book were notes on the development of intensive care in New Zealand and a record of the history of individual ICUs, many of which were small one or two bedded areas set up in smaller regional hospitals. One thing of note in this history is that the majority of NZ ICUs were developed by medical staff returning from working overseas where they had experienced the developing concept of intensive care first hand. Prior to this many of the hospital histories record the presence of three or four bedded rooms in which patients were specialled or watched over by general nursing staff. It is noted in the afterword that the biggest disappointment of the authors was the disappearance and presumed destruction prior to this of records and material pertaining to many of the units around New Zealand. ${ }^{90}$

Trubuhovich and Judson state that the acute respiratory unit established in 1957 at Auckland Hospital is generally recognised as New Zealand's first ICU; however, they note that this is disputed by some at Waikato Hospital who believe unequivocally that at Waikato there was a three-bedded ICU, quite separate and distinct from the recovery room, in operation in 1953 prior to the foundation of the formal ICU in $1963 .{ }^{91}$ On the contrary, a book written on the history of Waikato Hospital states that it was not until

\footnotetext{
${ }^{88}$ Crocker, 'The development', p.325.

${ }^{89}$ Trubuhovich and Judson, Intensive Care.

${ }^{90}$ Trubuhovich and Judson, Intensive Care, p.149.

${ }^{91}$ Trubuhovich and Judson, Intensive Care, p.105.
} 
July 1963 that a small three-bedded ICU was established in a room off the main corridor. $^{92}$ Additionally Whangarei Hospital claims that its intensive care service started in the late 1950s when seriously ill patients or those requiring "specialling" were cared for in side-rooms. ${ }^{93}$

According to Trubuhovich and Judson, during the NZ poliomyelitis epidemics of 1952, 1955 and 1961 the infectious diseases ward at Auckland Hospital treated patients using Both cabinet respirators. ${ }^{9495}$ These respirators were also used on patients suffering respiratory failure caused by illnesses, for example polyneuropathy and tetanus. In 1957 this led to the establishment of the Central Respiratory Unit for the treatment of long term patients requiring continuous assisted respiration. Patients, including those with chest and head injuries, who were expected to require ventilation for greater than 48 hours were admitted to this unit. If the patients were expected to require fewer than 48 hours of ventilation then a ventilator was taken to the patient in the ward. In 1962 the Acute Respiratory Unit at Auckland Hospital was officially commissioned. This was a standalone ICU, staffed by progressively full time doctors and its own nurses and is credited as NZs first large scale ICU. Green Lane Hospital's flagship cardio-thoracic surgical unit with its post-surgical intensive care room was established in 1963. This was limited to cardiothoracic surgical patients only, with all of the critically ill medical and non-cardiothoracic surgical patients being transferred to Auckland Hospital as required. ${ }^{96}$

This concept of ICUs proved popular in New Zealand just as it did overseas with many hospitals establishing units during the early 1960s. In a case history of Hawke's Bay Hospital, Conley refers to "a four-bedded ward being converted to make two coronary

\footnotetext{
${ }^{92}$ Trubuhovich and Judson, Intensive Care, p.105, quoting Rex Wright-St.Clair's 'From Cottage Hospital to Regional Base Hospital: Waikato Hospital 1887 - 1987’.

${ }^{93}$ Trubuhovich and Judson, Intensive Care, p.108.

${ }^{94}$ Trubuhovich and Judson, Intensive Care, p.89.

${ }^{95}$ A lightweight version of the iron lung designed in Australia by Edward and Donald Both. www.samemory.sa.gov.au.

${ }^{96}$ Trubuhovich and Judson, Intensive Care, p.97.
} 
care beds and two intensive care beds" in $1963 .{ }^{97}$ This was then expanded in 1967 to two four-bedded units to make a combined coronary care and ICU equipped with proper monitors and fibrillators. ${ }^{98}$ According to Trubuhovich and Judson Whangarei Hospital credits the opening in late 1963 of its formal three bedded ICU/CCU as originating from the Waitangi bus crash earlier that year, where 15 people were killed and 17 required admission to Whangarei Hospital. ${ }^{99}$ As had occurred overseas, this mass casualty situation would more than likely have demonstrated to medical, nursing and administrative staff the need to formally develop an area capable of providing close monitoring to the critically injured.

Trubuhovich and Judson document the establishment of many other ICUs around NZ from 1964 onwards, many of them in what would now be considered smaller or regional hospitals. Palmerston North, Taranaki Base, Tauranga and Invercargill Hospitals all opened their units in 1965 with Dunedin, Timaru, Masterton, Rotorua, and Nelson Hospitals all opening units from 1965 to 1970. This trend of small ICUs being established in regional hospitals continued on into the mid-1980s with Wanganui Hospital being the last to open its ICU in 1986. Of the larger hospitals, Dunedin opened its ICU in 1967 with ICU services provided at Christchurch's Princess Margaret Hospital from 1963. Trubuhovich and Judson note that Christchurch Hospital's ICU did not open until 1974 and was initially established as a holding ward for the Emergency Department and was mostly nurse driven. At best it was described as a High Dependency Unit, with the formal ICU opening in $1978 .^{100}$

It is difficult to establish exactly how many ICUs were in operation in NZ as there were many areas that were referred to as an ICU when in fact they were more of a high

\footnotetext{
97 Trubuhovich and Judson, Intensive Care, p.97 quoting Geoff Conley’s 'A Case History: The Hawkes Bay Hospital Board 1879 - 1989'.

98 Trubuhovich and Judson, Intensive Care, p.97.

${ }^{99}$ Trubuhovich and Judson, Intensive Care, p.108.

100 Trubuhovich and Judson, Intensive Care, pp.89 - 108.
} 
intensity nursing area. In 1978 The Department of Health published an occasional paper Intensive Nursing Care Units in Public Hospitals in New Zealand. ${ }^{101}$ In it Intensive Nursing Care Units (INCUs) were defined as "any area set aside specifically for patients of a high patient-nurse dependency requiring continuous, skilled nursing care." It was found that of the 29 hospital boards, 24 had some form of INCU whilst five either had no facilities or had facilities but no staff to service them. In this report it was represented that in the 24 boards there were 118 INCUs of 21 different types. This was the result of many hospitals identifying as having more than one unit. These various units encompassed coronary care (CCU), renal dialysis, burns, recovery, haematology and cardiothoracic units, in addition to combined acute admissions/ICU and CCU/ICU and general ICUs. ${ }^{102}$

\section{The Wellington Story}

A history of Wellington Hospital records that in mid 1938 a special respirator, commonly called an 'iron lung', was purchased for the treatment of anterior poliomyelitis cases. ${ }^{103}$ Additional iron lungs were imported from Sydney during the polio epidemic of the summer of 1947-48. Nonetheless Trubuhovich and Judson note that it was not until Dr Graeme Marshall (who whilst working in Adelaide had observed the development of the Royal Adelaide Hospital's ICU) returned to Wellington in 1962 as Director of Anaesthetics that the concept of intensive care began to become a possibility. In 1963 when Dr Cam Barrett returned from London, where he had helped to set up a two-bedded ICU, this gave impetus to setting up an ICU. Dr Marshall gave him the task of looking after various medical and surgical patients, who required ventilation in scattered wards around the hospital, utilising one Radcliffe and one Bird Mk8 ventilator. More importantly, he was able to pass on this knowledge and experience to specially trained

\footnotetext{
${ }^{101}$ The Department of Health New Zealand, Occasional Paper Number 7: Intensive Nursing Care Units in Public Hospitals, Management Services and Research Unit, Department of Health, 1978.

102 Occasional Paper Number 7: Intensive Nursing Care, p.1-3.

${ }^{103}$ L.H. Barber and R.J. Towers, Wellington Hospital 1847-1976, Wellington Hospital Board, 1976 as cited in Trubuhovich and Judson, Intensive Care, p.107.
} 
nursing staff. ${ }^{104}$ On August 24 1964, a six-bedded ICU opened in Ward 10 located at the end of the neurosurgical ward in the 2-10 Block. The first patient was admitted that day, a middle aged woman with head injuries. Sadly she died two days later of her injuries. ${ }^{105}$

Within the Wellington region there were only two hospitals; Wellington Hospital and Hutt Hospital in the 1960s. In 1968, Dr Andrew Cameron started an ICU at Hutt Hospital, as a Respiratory Unit located in the first two-bed room in Ward 7. At the time, it was for respiratory patients only and patients were nursed mainly by student nurses taken from the wards. In 1970 it closed down and re-opened three years later in 1973 in a specially adapted four-bedded cubicle with three beds in the middle of Ward 7. At this time its name was changed to the Intensive Care Unit. ${ }^{106}$ In 1980 Wellington Hospital Board opened a satellite hospital located in Kenepuru, Porirua, Wellington. It initially offered limited outpatient services, then latterly opened both surgical and medical wards, however there have never been any ICU facilities located here. ${ }^{107}$

\section{The Specialisation of Intensive Care Nursing}

The profession of nursing recognised early on that when nurses were providing care for certain patients or working in particular environments they were required to develop greater knowledge and skills in order to care for those patients. ${ }^{108}$ Smoyak discusses how in the early days of nursing the term specialty was only used to identify a particular field of nursing or a disease and she gives as example; tuberculosis hospitals and psychiatric nursing. As time went on the term specialist grew to mean doing something in nursing especially well, a notion that she believes is a far cry from the latter connotation of

\footnotetext{
${ }^{104}$ Trubuhovich and Judson, Intensive Care, p.105.

${ }^{105}$ Wellington Hospital Archive, WOW00200, Wellington Hospital Intensive Care Unit Patient Admission Books, 24 August 1964.

106 Trubuhovich and Judson, Intensive Care, p.98.

107 www.pcc.govt.nz

${ }^{108}$ Footner, 'Nursing specialism', p.219.
} 
expanded knowledge or clinical expertise. ${ }^{109}$ Peplau believes that specialisation within a profession often evolves from a division of a generic field or some recombination of aspects of different fields that occur along logical lines. ${ }^{110}$ Footner argues that it could be said that all qualified nurses working in a particular setting for any given period of time become specialists. Further to this she says that a nurse can only be deemed a specialist once they have successfully completed advanced studies and have had some degree of prolonged working in their chosen specialist field of nursing. ${ }^{111}$

Peplau considers that several trends tend to lead toward specialisation in nursing. Firstly, any significant increase in knowledge about phenomena of interest to a particular field results in specialty of those practitioners. Secondly, new knowledge in applied science inevitably leads to new technology which in turn calls for more complex technological skills and intellectual capabilities amongst practitioners working in that field. Lastly, when the attention or needs of others, such as hospital management, focuses on areas which have previously received scant attention, new areas of specialisation tend to be formed. These new fields usually have an initial shortage of personnel who have both the required knowledge and interest to develop the field further without the interest of others. ${ }^{112}$ Smoyak credits Peplau as hastening the move toward clinical specialisation by her identification in 1965 of eight possible categories for nursing specialisation. Within each of these eight categories were subcategories as shown in Table $1 .^{113}$ Smoyak succinctly sums up the idea of specialisation as a combination of the inevitable result of new knowledge within a field of medicine or nursing and a result of demands from the public for new services. ${ }^{114}$

\footnotetext{
${ }^{109}$ S.A. Smoyak., 'Specialization in nursing: From then to now', Nursing Outlook, 24, 11 (1976), p.676.

${ }^{110}$ H. Peplau, 'Specialization in professional nursing', Clinical Nurse Specialist, 17, 1 (2003), p.3.

${ }^{111}$ Footner, 'Nursing specialism', p.219.

112 Peplau, 'Specialization in professional nursing', p.3.

${ }^{113}$ Smoyak, 'Specialization in nursing', p.678.

${ }^{114}$ Smoyak, 'Specialization in nursing', p.678.
} 


\section{Table 1. Peplau's Eight Categories of Nursing Specialisation ${ }^{115}$}

Organs and body systems

- Renal, cardiac, metabolic nursing

Age of the client

- Premature, infant, adolescent, geriatric nursing

Degree of illness

- Intensive care, intermediate, self-care, long-term nursing

Length of illness

- Short or long-term nursing

Field of knowledge

- Nuclear, interpersonal, electronic, space nursing

Subrole

- The mother surrogate nurse, expert technical nurse, health teacher, nurse counsellor

\section{Professional Goal}

- Preventative, curative, rehabilitative nursing

Clinical service

- Medical-surgical, psychiatric, maternal-child nursing

Intensive care nursing began to evolve as a specialty with the advent of ICUs internationally. Although there is no one defining moment that represents the beginning of intensive care nursing, the nursing literature credits the phenomenon of "private duty nursing" for sick hospital patients and the start of "respiratory wards" set up during the poliomyelitis epidemics as the starting points. ${ }^{116,117}$

\footnotetext{
115 As discussed in Smoyak, 'Specialization in nursing', p.678.

116 Private duty nursing was a widespread practice within hospitals prior to the development of ICUs. It refers to nurses who were employed either by patients or their families to care for individual patients on a one-on-one basis. This was not a practice in New Zealand hospitals.

${ }^{117}$ Fairman, 'Watchful vigilance', p.56.
} 
Fairman and Lynaugh credit the origins of intensive care as evolving from an increasing demand for nurses and physicians services, together with hazardous care conditions and a continuously rising demand for more hospital care. It was as a result of these factors that nurses and physicians turned to the familiar, traditional system of intense observation and triage of the most seriously ill. These two very old ideas were combined and refined to form a new idea of intensive care. ${ }^{118}$ Hence the evolution of intensive care nursing as a specialty stemmed from the need to provide safe and effective care to those patients described by Fairman and Lynaugh as the "sickest and most helpless," with hospitals prioritising patient care according to their physiological stability. ${ }^{119}$

Lynaugh comments that the concept of differentiating intensive care nursing around a human condition, i.e. the concept intensive or critical, as opposed to differentiation around disease or organ systems which is the classic basis for medical specialisation is considered by some to be significant. ${ }^{120}$ According to Fairman and Lynaugh the main principle of ICUs in regards to delivering effective care to critically ill patients was the continuous presence of the nurse who was constantly on watch: ${ }^{121}$ "You were sitting right next to the patients... they could hear everything, they felt safe because you were right there. It scared them to death when the nurse left the room." 122 Though the beginnings of intensive care nursing may have been rudimentary, the principal concept proved sound. The parameters for monitoring the patient then were principally the measurement of vital signs, the level of consciousness, intake and output, and weight. In addition to

\footnotetext{
${ }^{118}$ Fairman and Lynaugh, Critical Care, p.12.

${ }^{119}$ Fairman and Lynaugh, Critical Care, p.12.

${ }^{120}$ J. Lynaugh, 'Moments in Nursing History', Nursing Research, 39 (1990), p. 255.

${ }^{121}$ Fairman and Lynaugh, Critical Care, p.15.

${ }^{122}$ Fairman and Lynaugh, Critical Care, p.15, citing a quotation from an interview with Shephard and Vaughan, 1989.
} 
this the nurse's sense of hearing, sight, touch, smell and sometimes her intuition were all utilised. $^{123}$

With intensive care nursing beginning to develop as a specialty, consideration was given to the physical and psychological aspects of the role. Several traits were considered essential for the intensive care nurse to possess:

Of paramount importance is the possession of both native intelligence and innate curiosity, enabling continued study and progress in the art and science of medicine, especially in extending diagnostic and therapeutic skills. Since there is little place in an intensive care unit for the nurse who does exactly what is ordered, no more and no less, initiative is a prime qualification. Age as such is probably not an important factor; on the other hand, good health is considered essential, because nowhere else in nursing are tasks more arduous. Other vital factors are the possession of emotional stability and empathy. Ideally the intensive care nurse should be quite stable because the almost continuous care of critically ill patients, many of whom are in a dying state, is bound to take an emotional toll. Empathy as displayed by a reassuring countenance, soft touch, and kind word of explanation to patients can make an immense contribution to these individuals. Certainly people in the critical or dying situation and their families deserve compassion more than in any other situation in the practice of medicine. Nonetheless, compassion and emotions should not be permitted to interfere with good judgement and logic. The nurse who becomes too deeply involved with the patient may be unable to render necessary life-saving service in the moment of crisis. The key to successful operation of the unit, regardless of the quality of the medical staff, is the kind, intelligent, well-informed, and observant nurse. This is true in no other branch of nursing as it is in the intensive care unit. $^{124}$

\footnotetext{
${ }^{123}$ Fairman and Lynaugh, Critical Care, p.16.

${ }^{124}$ Z.L. Burrell, Jr, and L.O. Burrell, Intensive Nursing Care, The C.V. Mosby Company, Saint Louis, 1969, pp.4-5.
} 
This critical care workforce developed for different reasons in various countries, but essentially each focused on the critically ill patients need for close, frequent and prolonged observation. ${ }^{125}$

\section{Nursing Staff - Why Work in ICU?}

Today the reasons for a nurse choosing to specialise in intensive care nursing are as varied and diverse as each nurse. However, Wiles and Daffurn describe how in the early years, many ICU nurses were hand-picked or chosen by matrons of the hospital or charge nurses to work in the ICU. The primary reason for this was that they were perceived to be 'good nurses'. 126 Initially most of the nurses who chose to work in this new field of nursing did so because they were "imaginative, interested and had a practical approach with an interest in technical things ". ${ }^{127}$ The reasons given by interviewees in the oral history interviews in my research are not dissimilar to those of nurses stories reported in the international literature and are discussed below.

Pauline started working in ICU in 1964 after returning from overseas.

I was overseas then I decided to come back to the hospital and the matron at that time... she wanted me to go onto night duty in ICU so I did a week with Dianna Latta [the then Ward Sister] on days and then went into night duty. ${ }^{128}$

Marie came to Wellington from the South Island wanting to get some acute nursing experience.

My first ICU experience was in 1967, I decided that I was going to be travelling in Canada. Having trained in a small hospital I thought that it was advisable to

\footnotetext{
${ }^{125}$ M.K. Robnett, 'Critical care nursing: Workforce issues and potential solutions', Critical Care Medicine, 34, 3 (2006), p.S25.

${ }^{126}$ Wiles and Daffurn, Bird and Bear, p.135.

127 Transcript of an interview with J. Cade as written in Wiles and Daffurn, Bird and Bear, p.135.

${ }^{128}$ Oral history interview with Pauline.
} 
get some training in some more emergency type patients so I applied to Wellington and I was accepted to come and work in the ICU there. ${ }^{129}$

Maureen trained in Wellington Hospital and was encouraged by a friend to apply to work in ICU.

I had a girlfriend who worked in Coronary Care and, I guess she saw something in me that I didn't see in myself, so she basically suggested why don't you think about it ... she basically encouraged me which I think was really good. So I went and asked if I could transfer to ICU, because that was the way you used to do it in those days, it was totally different then to how it is now, you'd make a phone call to a particular person and then they called you in and found out why you wanted to do it ... she asked me the appropriate questions and then that was it, off to ICU. $^{130}$

Maryanne first worked in the ICU at Hutt Hospital and was encouraged by the nurses there to come to Wellington to do the ICU course.

I actually trained at Hutt Hospital and in my first year as a staff nurse we had three or four rotations, I spent that in $\mathrm{A} \& \mathrm{E}$, a medical and a surgical ward and straight after that I went into ICU, that is the first ICU we had at Hutt Hospital. ${ }^{131}$ And it was just two girls who had done the ICU course at Wellington Hospital who came out and set it all up as part of the surgical ward. So I went in there [Hutt ICU] as one of the first staff nurses without an ICU qualification which was really exciting. And the women who had done the ICU course were fantastic and they thought it would be a good idea for me to do it and I got quite excited about

\footnotetext{
${ }^{129}$ Oral history interview with Marie.

${ }^{130}$ Oral history interview with Maureen.

${ }^{131}$ In fact as previously documented the ICU was started as a Respiratory Unit in 1968 for respiratory patients only. This unit closed down in mid-1970 when Andrew Cameron went overseas and re-opened in September 1973 as a specially adapted cubicle with 3 beds in the middle of Ward 7. It then became known as the intensive care unit as written in Trubuhovich and Judson, Intensive Care, p. 98.
} 
doing it. So within probably two years of graduating I came in to do the ICU course at Wellington Hospital with four others. ${ }^{132}$

Henny trained at Wellington Hospital but had always been a bit put off by the business of ICU. She was encouraged to try ICU by a former Charge Nurse who was now the Charge Nurse of ICU.

I was hospital trained so I always thought of ICU as a door that you looked in and closed very quickly because everybody looked quite busy and you didn't want to disturb them, and I started doing my training and did my 6 month rotation and was in a medical ward before coming to ICU. ${ }^{133}$

When asked what it was that made her brave enough to go through the doors and work in ICU Henny recalled:

Well Marg Ryan who was the charge nurse at that time, she was my Charge Nurse in medical and had moved to ICU, and she met me in the corridor and said Henny 'I've got a job for you,' and hence I started for a couple of years in 1977 and I think I left there in early $2000 .{ }^{134}$

Cheryl also trained at Wellington Hospital and completed her last four weeks of her training working as 'night float' in ICU. She was one of the first new graduate nurses to work in ICU.

As a third year student you always had to do night float, you all did it for 4 weeks. You were just like any other float staffing type situation and I spent my entire month in ICU because they were really busy at the time. 1980 was one of the first staff freezes with the Muldoon era, and there were 16 of us [hospital trained nurses] ... So we went to where the need was and for the first time ever new graduates went into the units. Essentially it was names out of a hat but because I had just finished my night float roster I was put straight back to where I had just

\footnotetext{
${ }^{132}$ Oral history interview with Maryanne.

${ }^{133}$ Oral history interview with Henny.

${ }^{134}$ Oral history interview with Henny.
} 
been, which was back into ICU. We had people... they went to intensive care nursing because they thought it was exciting and were really there for a lot of the glory, where I think that the glory of it was knocked out of me when I was a student. That wasn't why I went; I went because I actually enjoyed it, as opposed to thinking that it was something really fantastic. I really don't think that intensive care as a speciality is any more special than something like mental health. Mental health patients frighten the living daylights out of me, no intensive care patient frightens me. I don't think that we are better than anyone else. ${ }^{135}$

\section{Preparation to Work in ICU}

Hospital based training often was practical and task orientated. Fairman and Lynaugh argue that education in physiology, pathophysiology and pharmacology was usually rudimentary and the expectation was that nurses were to rely to some extent on the physician's knowledge rather than their own to solve complex clinical problems. Consequently nursing expertise usually developed on the job. ${ }^{136}$ With the development of intensive care nursing, Atkinson describes how the expectation became one of intensive care nurses confidently and competently providing care to the entire array of medical and surgical patients as well as those from across the age range from infancy to the very elderly. In order to accomplish this, the nurse needed to possess a broad range of clinical skills as well as an extensive knowledge base. ${ }^{137}$

\section{Orientation of Nurses to ICU}

It would appear that the experiences of those first ICU nurses in Wellington were no different to their international counterparts. Wiles and Daffurn describe the process of nurses' orientation as cursory, limited to a brief overview of the unit and an even quicker introduction to the ventilated patient. The reasons given for this were time constraints

\footnotetext{
${ }^{135}$ Oral history interview with Cheryl.

${ }^{136}$ Fairman and Lynaugh, Critical Care, p.8.

${ }^{137}$ B.L. Atkinson, 'Training Nurses for Intensive Care', Intensive Care Nursing, 6 (1990), p.174.
} 
and a lack of clinical teachers. ${ }^{138}$ Wiles and Daffurn claim that in Australian ICUs it was not uncommon for inexperienced nurses to be looking after an intubated ventilated patient on their first shift. The situation was generally even worse if the nurse's first shift was on night duty. ${ }^{139}$

The recollections of the nurses interviewed who started working in ICU in the 1960s was certainly one of on-the-job training, working alongside the charge nurse and it was very much a matter of watch, listen and learn, then take those skills and use them. Pauline describes how she spent a week working alongside the Ward Sister before starting night duty. Marie recalls that all of her instruction came from the Ward Sister.

The Ward Sister there was Dianna Latta. I had great admiration for her. I thought she was an extremely good manager but I was terrified of her...It was wonderful because having such a good Ward Sister she did all of the teaching and showing me. It was a matter of: you listen, you pick it up quickly and you do it... Yes it was only the Ward Sister who was the only one who ever instructed me. It was just, yes you can do it. ${ }^{140}$

Maureen recalls having no orientation or instruction and describes a sense of feeling very frightened.

My first day I can remember, this is a very vivid memory, I can remember I had no orientation as we would call it today. You were given a patient assignment if you can believe it, thrown in at the deep end ... I trained in the hospital so I did know a little bit about working there so it wasn't completely bizarre, but I remember vividly the Ward Sister handing me a syringe with Frusemide, telling me to give it intravenously and I looked at it and she said, 'just give it slowly'. I didn't know what slowly meant. I possibly gave it in half the time it was supposed to be given. And then I can remember being told off on not picking up

\footnotetext{
${ }^{138}$ Wiles and Daffurn, Bird and Bear, p.274.

${ }^{139}$ Wiles and Daffurn, Bird and Bear, p.274.

${ }^{140}$ Oral history interview with Marie.
} 
someone who was having problems on the ventilator, but it was like no one had showed me, so that was very different and in some ways frightening. ${ }^{141}$

By the 1970s the focus of orientating new nurses to the ICU environment had progressed to one of working alongside another nurse, sharing the care of a group of patients and learning from that nurse. Again this concept was similar to an Australasian trend described by Wiles and Daffurn where the needs of the nurse new to ICU were being increasingly recognised. Some hospitals in Australia had begun to plan staff intakes in order for new staff to be rostered onto day shifts initially in order to facilitate their learning the routines and the care of patients and their associated technology when there were more experience staff around to support them. ${ }^{142}$

In 1976 nursing staff in the Wellington ICU were given a questionnaire asking them about their educational needs. In this nurses were asked if they would like to see any changes in the orientation of new staff. The majority of responses were that there should be a personalised orientation where the new nurse worked with one senior nurse for at least two weeks and that set periods be devoted to supervised clinical teaching. It was also suggested that new staff should not be included in staffing establishments until a two to three week orientation had been completed. The 'buddy' system was advocated in many answers. ${ }^{143}$

In 1977 Kai Tiaki published a paper previously presented at a hospital study day for theatre and ICU staff by B.E. Collins (the Wellington Hospital intensive care course tutor of the time) on methods of clinical teaching in ICUs. ${ }^{144}$ In this she proposed the implementation of a 'buddy' system for orientating nurses new to the intensive care

\footnotetext{
${ }^{141}$ Oral history interview with Maureen.

${ }^{142}$ Wiles and Daffurn, Bird and Bear, p. 275.

${ }^{143}$ Wellington Hospital Archive, WOW00201, Summary of the Questionnaire Sent to ICU Nursing Staff by the Intensive Care Course Tutors to assist in the planning of staff training in 1977, circa 1976.

${ }^{144}$ B.E. Collins, 'Methods of clinical teaching', New Zealand Nursing Journal, June (1977), p.17.
} 
environment, whereby one member or the nursing staff would be responsible for the orientation of the new staff member to the unit over a set period of time. This one nurse would be accountable for ensuring that the new nurse was adequately taught, supervised and continually evaluated in their acquisition of the required knowledge and skills. In the event that the buddy and orientating nurse were to be assigned conflicting duties on the roster, then certain aspects of the orientation programme could be delegated to another member of the staff, but ultimately they still had to ensure that this was carried out to meet a specified standard. The advantage to the new staff member was one of feeling that they had one member of staff to relate to in this difficult and often stressful period and that their buddy was genuinely interested in their specific learning needs. With this one-to-one buddy system, individualised teaching could be assured and short and long term goals set. The new staff member was to be included in evaluating their learning needs, discussing their existing knowledge and together with their buddy could plan an individualised clinical teaching and learning programme. ${ }^{145}$

Henny spoke of a two week orientation to ICU in 1977 which would indicate that this proposed buddy system had been introduced. ${ }^{146}$ She recalls being buddied "for about two weeks" with a more senior nurse and sharing the workload: "Yes, you had about 3 or 4 patients each".

By 1980 the idea of a formal orientation process had been implemented and nurses new to ICU, as well as the one nurse interviewed that was returning to ICU from overseas were benefitting from a structured process of mentoring.

When we first went into the unit we were orientated for six weeks, with someone at all times. I was with a girl Fabian, she was really patient, very tolerant with me, and a very good buddy. In those days we had a six week orientation with one person. It was a great opportunity to learn. Unless there is some sort of personality clash you know where you stand and they know what you have been

\footnotetext{
145 Collins, 'Methods of clinical teaching', p.17.

${ }^{146}$ Oral history interview with Henny.
} 
doing, the consistency I think is very important. It's exhausting. As I went on and became experienced and orientated staff myself, it's an exhausting thing to do, but I still think that both sides benefit a lot from it. ${ }^{147}$

Maureen recalls a different orientation to the one mentioned earlier upon returning to Wellington ICU in the 1980s after working in Canada. "We got 6 weeks then, it was a full 6 week orientation". ${ }^{148}$

\section{Conclusion}

In NZ, as in the rest of the world, ICUs developed to provide one place with specially trained staff and the necessary equipment to provide care to the sickest patients. In initially developing these units it was recognised that the nursing staff were required to possess not only certain knowledge and skills but also certain personality traits. This resulted in nurses essentially being handpicked for the job, something that almost certainly contributed to the initial success of many units. The experience of the six nurses interviewed was similar, with most being encouraged by others to move to work in ICU. The process of orientating nurses to work in ICU developed over time from one of being instructed by the Ward Sister whilst caring for patients to a six week orientation process where nurses new to ICU worked alongside one of their more experienced colleagues in a supernumerary fashion. The orientation experiences of the nurses interviewed who started working in Wellington ICU in the 1960s is similar to the experiences of those early ICU nurses documented in the literature.

In the following chapter a snapshot of the demographic profile of the patients admitted to ICU during three time periods throughout the research period will be discussed. This will provide the context of practice experience by the ICU nurses during the period of this research.

\footnotetext{
${ }^{147}$ Oral history interview with Cheryl.

${ }^{148}$ Oral history interview with Maureen.
} 


\section{Chapter Four - Intensive Care Patients}

\section{Introduction}

In this chapter the demographic profile of the patients admitted to ICU during three phases of the research timeframe are presented. This will provide a glimpse of the types of patients admitted to the ICU and the variety of their diagnoses, length of stay, where they were admitted from and the mortality rates of those admitted. Excerpts from the oral history interviews relevant to the patients admitted are utilised in relation to these findings.

\section{Patient Demographics}

Despite all of the technology and supportive equipment available, the fundamental nature of the work of the ICU nurse is 'good' nursing care of the critically ill patient. Few other areas of nursing require the need to care for the diversity of patients spanning all age ranges and disease processes that are encountered in ICU. In exploring intensive care nursing at Wellington Hospital it is helpful to understand the demographic and clinical profile of patients who were being admitted. This information offers insight into the nursing care aspect of ICU work. The information obtained from the patient admission records provides a snapshot of patient demographics at three key points during this timeframe: 1965 being the first full year of operation of the ICU, 1977 being the midpoint and 1989 being the final year. Information gathered consisted of the patient age, admission diagnosis, length of stay, admission source and discharge destination including mortality rates. The data obtained from the patient admission records was reliant on the accuracy of the information entered into the records at the actual time of admission and discharge. In some circumstances, not all of the demographic information was available and was therefore unable to be recorded: this was most prevalent in 1977. Where there was missing data the denominator is specially noted. Table 2 presents the age and clinical profile of patients admitted to ICU during the three data subsets. 
Table 2: Patient Demographic and Clinical Profile

\begin{tabular}{|l|r|r|r|r|}
\hline & \multicolumn{1}{|c|}{$\begin{array}{c}1965 \\
\mathrm{n}=77\end{array}$} & \multicolumn{1}{c|}{$\begin{array}{c}1977 \\
\mathrm{n}=172\end{array}$} & \multicolumn{1}{c|}{$\mathrm{n}=235$} & \multicolumn{1}{c|}{$\begin{array}{c}\text { Total } \\
\mathrm{n}=484\end{array}$} \\
\hline Age (n = 480) & & & & \\
Mean (SD) in years & $44.82(22.99)$ & $43.61(22.42)$ & $43.52(22.42)$ & $43.76(22.47)$ \\
Range & $0-92$ & $0-84$ & $0-84$ & $0-92$ \\
$0-4$ years & $2(2.6 \%)$ & $8(4.7 \%)$ & $14(6.0 \%)$ & $24(5.0 \%)$ \\
$5-15$ years & $5(6.5 \%)$ & $9(5.3 \%)$ & $13(6.0 \%)$ & $27(5.6 \%)$ \\
$16-64$ years & $55(71.4 \%)$ & $116(67.8 \%)$ & $159(68.3 \%)$ & $330(68.8 \%)$ \\
$65-85$ years & $12(15.6 \%)$ & $38(22.2 \%)$ & $46(19.8 \%)$ & $96(20.0 \%)$ \\
$85+$ years & $3(3.9 \%)$ & $0(0.0 \%)$ & $0(0.0 \%)$ & $3(0.6 \%)$ \\
\hline Diagnostic Groups $(\mathbf{n}=\mathbf{4 7 9 )}$ & $19(24.7 \%)$ & $37(21.6 \%)$ & $87(37.7 \%)$ & $143(30.0 \%)$ \\
Medical & $14(18.2 \%)$ & $50(29.2 \%)$ & $52(22.5 \%)$ & $116(24.3 \%)$ \\
Surgical & $13(16.9 \%)$ & $36(21.1 \%)$ & $30(13.0 \%)$ & $79(16.6 \%)$ \\
Neurological & $17(22.1 \%)$ & $15(8.8 \%)$ & $41(17.7 \%)$ & $73(15.3 \%)$ \\
Trauma & $14(18.2 \%)$ & $33(19.3 \%)$ & $19(8.2 \%)$ & $66(13.8 \%)$ \\
Overdose & $0(0.0 \%)$ & $0(0.0 \%)$ & $2(0.9 \%)$ & $2(0.5 \%)$ \\
Obstetrics & &
\end{tabular}

Changes in the patient profile occurred over time as knowledge increased and newer treatments and surgical procedures were introduced.

As the complexity of surgery increased and the anaesthetists started doing much more complex cases, and taking people who historically might have been considered too high risk and not going forward for surgery, suddenly they were doing lots of those cases and suddenly we were getting lots of referrals from places like oncology where a lot of their pharmacological interventions were having high risk sort of consequences, so they were being sent to us for monitoring as well. As the technology increased and as surgical techniques increased and as pharmacology increased, our demographics changed hugely. We started seeing a lot more chronicity [of illness] as patients were being exposed to things that historically they wouldn't have been exposed to. So that evolved and 
of course it took quite a long time for us to be able to say to people like the renal surgeons, 'look we're not going to take the transplants any more, they are going to have to go to the ward', to the neurosurgeons 'we're not going to take the craniotomies any more, they are going to have to go to the ward'. So custom and practice was being challenged and that was an interesting time in terms of just moving or shifting the [patient] population, but you know the resources were very limited and you just had to do the very best you could with what you had. ${ }^{149}$

Other interviewees referred to the patients in general being less unwell than they may be in 2011. Maryanne recalls that "the acuity of patients was quite different". ${ }^{150}$ Mainly due to the fact that there were less treatment options available.

I think now we see a lot sicker patients surviving sepsis and the like. Patients with renal issues, because we only had the choice of haemodialysis which was not undertaken lightly, because you never had a blood pressure anyway, and the only other option was peritoneal dialysis, we used to do a lot of that ... so the patients that went into renal failure basically died because there wasn't an option like CVVH [continuous veno-venous haemodialysis]. ${ }^{151}$

Chronicity of illness and body habitus was also referred to: "people weren't so fat I suppose; you had the odd bariatric patient. I can remember one, but there weren't that many.' 152

People weren't as obese, and if you had been morbidly obese I don't think that you would have fitted the [admission] criteria. When I talk about criteria, there were a lot of people, if they had a lot of co-morbidities then they wouldn't get

\footnotetext{
${ }^{149}$ Oral history interview with Maryanne.

${ }^{150}$ Oral history interview with Maryanne.

${ }^{151}$ Oral history interview with Henny.

${ }^{152}$ Oral history interview with Henny.
} 
admitted into the ICU because they [the medical staff] knew they couldn't save them so what was the point of putting them through it. ${ }^{153}$

\section{Numbers of Patients Admitted to ICU}

The number of patients admitted steadily increased over the three time periods as demonstrated in Table 2. Greater numbers of patients at times meant that there was pressure on beds and resources. In 1980, with the move to the new ICU, physical bed numbers were increased from 7 to 14 . However, there would more than likely not have been enough resources, either nursing or equipment, to accommodate this number of patients. Anecdotally it would appear that a disproportionate ratio of patients to available bed numbers had been a facet of ICUs generally since their inception. In Wellington ICU, a member of the Intensive Care Unit Committee was routinely consulted to determine priority for patient admission and discharge when there was a particular problem regarding bed availability. ${ }^{154}$ Concern was raised in 1972 that the rapid rise in the number of post-operative and trauma patients requiring admission had reduced the available beds for medical cases resulting in the undesirable situation of critically ill patients being nursed in other parts of the hospital, particularly medical wards. ${ }^{155}$ The neurosurgical department had also on several occasions been affected by a lack of available beds for its patients who were unconscious or post-operative cases. ${ }^{156}$

\section{Age at Admission}

As Table 2 shows, patients across the whole spectrum of life from newborns to the very elderly were cared for in Wellington ICU, with nurses being required to have knowledge of the physiological and developmental differences between children and adults. The age

\footnotetext{
153 Oral history interview with Maureen.

${ }^{154}$ Wellington Hospital Archive, WOW00200, Wellington Hospital Intensive Care Unit Committee, First Report: Intensive Care Planning, 19 June 1972.

${ }^{155}$ Noted to comprise patients experiencing neurological, pulmonary and circulatory compromise.

${ }^{156}$ Wellington Hospital Archive, WOW00200, Wellington Hospital Intensive Care Unit Committee, First Report: Intensive Care Planning, 19 June 1972.
} 
range of patients admitted was 0 - 92 years in 1965 and $0-84$ in both 1977 and 1989 . The mean age of patients admitted changed very little over the 25 years with the mean age in 1965 being 44.8 compared with 43.6 and 43.5 in 1977 and 1989 respectively.

With Auckland's Starship Hospital, incorporating New Zealand's first specialist paediatric ICU not opening until December 1991, all of the region's paediatric patients requiring intensive care were admitted to Wellington ICU prior to this date. ${ }^{157}$ Children aged 15 and under made up $9.1 \%$ of admissions in 1965, rising to $9.9 \%$ in 1977 and $11.5 \%$ in 1989 . Most of the oral history interviewees referred to paediatric patients at some point throughout their interviews. Perhaps this is in part because caring for a critically ill child is an often stressful and emotional time and is therefore recollected more clearly than episodes of caring for a patient who is middle aged or older.

I think we used to get a lot of children because we didn't have Starship and that was a huge challenge because a lot of the nurses felt very uncomfortable, right out of their comfort zone. We did have some that did enjoy it and they became sort of the specialists for the unit! ${ }^{158}$

Maureen not only alluded to the number of children admitted to the unit, but also recalled that amongst these children "there were some sad cases". ${ }^{159}$ Further to this, Cheryl spoke of the challenges of caring for children in the 1980s.

A lot of it is pre Starship, it is also pre CPAP [continuous positive airways pressure]. ${ }^{160}$ In paeds they could do low flow oxygen, they could do half and quarter litres, and then they brought in these CPAP units and that made a huge difference. Ward 19 [children's ward, predominately children under 6 years of age] started taking sicker and sicker patients and as now they take the really sick

\footnotetext{
${ }^{157}$ Trubuhovich and Judson, Intensive Care, p.103.

${ }^{158}$ Oral history interview with Maryanne.

${ }^{159}$ Oral history interview with Maureen.

160 'CPAP' refers to continuous positive airway pressure, a form of non-invasive ventilation usually performed via nasal prongs in children and face masks in adults.
} 
patients and they do a damn good job. If a kid came rushing up from Ward 19 you knew you had to get the resus [emergency resuscitation] trolley because they were sick if they decided that they needed to come to us. That's something that has changed over time, we still get the odd bronchiolitis if they get too sick, but we used to get a lot more kids. ${ }^{161}$

Later in her interview Cheryl referred to the type of issues children presented with, in the 1980s.

We always have taken absolutely everything, every kind of patient except for neonates... we always had kids, bronchiolitis has been around for as long as I can remember. One thing that we don't see any more that we used to see a lot in the 80 s is Reyes Syndrome, that's the fatty liver as a result of children being given aspirin. We used to get so many kiddies through with it, they used to get encephalopathic, raised ICPs [intracranial pressures] ${ }^{162}$, low blood sugars and they either died or survived with severe brain damage. ${ }^{163}$

Conversely at the other end of the age spectrum those patients aged 65 years and over were represented in noteworthy numbers with $19.5 \%$ of patients in 1965 aged 65 or older, $22.7 \%$ in 1977 and $20.9 \%$ in 1989 . Maureen, who worked in the ICU in the late 1960 s, recalls that there was an age limit or age cut-off at which patients would not be admitted although this was not apparent in the data gathered. ${ }^{164}$

There were a lot tighter criteria about who could get in. There was an age factor for patients who could come and that sort of thing... there was a definite age cutoff, but in saying that we did have someone come in with what we would call Guillian-Barre now but what we called polyneuritis and he was above that age

\footnotetext{
${ }^{161}$ Oral history interview with Cheryl.

162 'ICP' refers to high intracranial pressures, or pressure within the brain measured by a pressure monitor inserted via the skull.

${ }^{163}$ Oral history interview with Cheryl.

${ }^{164}$ Human rights legislation preventing discrimination on the basis of age was not introduced in New Zealand until 1993.
} 
group. I can't remember what that [age limit] was, but he was still actually going to work, he was past retirement age but he was some manager or something, he possibly had associations or something, who knows? ${ }^{165}$

According to Maryanne, there was also a perceived ethical conflict experienced when the unit was occupied with older patients whilst a younger patient needed admission.

We often had quite an old population as well and we often used to not have quite enough beds and we used to be challenged with having a very old population around the unit and suddenly there were people begging admission that were very young and there were questions about the ethics of committing resources to the old when the young were needing it and all that sort of stuff. ${ }^{166}$

\section{Admission Diagnostic Groups}

Wiles and Daffurn describe the variety of conditions that patients are admitted to ICU with as vast, with every conceivable specialty and sub-specialty of both medicine and surgery represented. They argue that in no other field of nursing practice do nurses have to possess such a broad range of knowledge and skills. ${ }^{167}$

This is reflected in the variety of admission diagnoses in the data subsets sampled. Patients were coded into one of five diagnostic groups depending on their documented admission diagnosis as shown in Table 2, and within each of the five groups there were smaller diagnostic subgroups. The diagnostic group 'medical' comprised the greatest number of subgroups and these are demonstrated in Table 3. Five patients over the three data subsets had no admission diagnosis entered into the patient admission records.

\section{Medical admissions}

Admission diagnoses coded as medical make up the largest total group of admissions over the three years sampled. Within this group there are a number of subgroups, shown

\footnotetext{
${ }^{165}$ Oral history interview with Maureen.

${ }^{166}$ Oral history interview with Maryanne.

${ }^{167}$ Wiles and Daffurn, Bird and Bear, p. 255.
} 
in Table 3. The medical subgroup is comprised of patients with non-surgical, nontraumatic admissions but excludes those admitted following overdose and neurological or neurosurgical causes as these will be discussed separately later in this chapter.

Table 3: Medical Diagnoses Sub-Groups

\begin{tabular}{|l|r|r|r|r|}
\hline & \multicolumn{1}{c|}{$\begin{array}{c}1965 \\
\mathrm{n}=18\end{array}$} & \multicolumn{1}{c|}{$\begin{array}{c}1977 \\
\mathrm{n}=38\end{array}$} & \multicolumn{1}{c|}{$\begin{array}{c}1989 \\
\mathrm{n}=87\end{array}$} & \multicolumn{1}{c|}{$\begin{array}{c}\text { Total } \\
\mathrm{n}=143\end{array}$} \\
\hline Medical & $8(44.4 \%)$ & $10(26.3 \%)$ & $15(17.2 \%)$ & $33(23.1 \%)$ \\
GI Bleed* & $0(0.0 \%)$ & $2(5.3 \%)$ & $23(26.4 \%)$ & $25(17.5 \%)$ \\
Respiratory & $0(0.0 \%)$ & $7(18.4 \%)$ & $18(20.7 \%)$ & $25(17.5 \%)$ \\
Cardiac arrest & $4(22.2 \%)$ & $3(7.9 \%)$ & $7(8.0 \%)$ & $14(9.8 \%)$ \\
Seizures & $1(5.5 \%)$ & $5(13.2 \%)$ & $4(4.6 \%)$ & $10(7.0 \%)$ \\
Myocardial infarction & $0(0.0 \%)$ & $2(5.3 \%)$ & $7(8.0 \%)$ & $9(6.3 \%)$ \\
Heart failure & $1(5.5 \%)$ & $5(13.2 \%)$ & $2(2.3 \%)$ & $8(5.6 \%)$ \\
Renal failure & $1(5.5 \%)$ & $2(5.3 \%)$ & $4(4.6 \%)$ & $7(4.9 \%)$ \\
ENT** & $2(11.1 \%)$ & $1(2.6 \%)$ & $4(4.6 \%)$ & $7(4.9 \%)$ \\
Sepsis & $1(5.5 \%)$ & $1(2.6 \%)$ & $3(3.4 \%)$ & $5(3.5 \%)$ \\
\hline \multicolumn{2}{|r|}{$*$ Gastrointestinal bleeding. } & &
\end{tabular}

One group of patients who stand out are those admitted with gastrointestinal (GI) bleeds as demonstrated in Table 3; with a significant increase from $0.0 \%$ in 1965 to $26.4 \%$ in 1989. One possible reason may be that over time, as medical and pharmacological management improved, it was felt that there was benefit in admitting these patients to the ICU for care and treatment. Another reason is that there was recognition amongst medical staff that patients with acute gastrointestinal bleeding required careful monitoring and observation, hence the requirement that they were admitted to ICU. ${ }^{168}$

\footnotetext{
${ }^{168}$ The suggestion that patients with acute GI bleeds require close observation and monitoring was put forward as a possible reason for the increase in numbers by Dr Peter Hicks, Intensive Care Consultant and former medical director . Personal email correspondence, February 2011.
} 
This second theory is given further credence as in 1989 a three year research study was undertaken by Wellington Hospital's then hepatobiliary and upper gastrointestinal surgeon Dr Richard Stubbs along with co-investigators Dr Peter Roberts and haematologist Dr John Carter. ${ }^{169}$ The purpose of the research was to study the management of patients with acute upper GI bleeding. Prior to this a 12 month retrospective study looking at all patients with acute upper GI bleeding in Wellington Hospital had identified that the mortality rate of this patient group was high at $12.6 \%$. Patients with conditions deemed to be more serious were required to be admitted to the ICU with the admission criteria being a heart rate greater than 100 beats per minute or a systolic blood pressure less than $100 \mathrm{mmHg} .{ }^{170}$

Respiratory admissions comprised adults with chronic respiratory conditions, both adult and paediatric patients admitted with asthma, and paediatric patients admitted with either bronchiolitis or croup. ENT admissions were made up of patients with epiglottitis and children admitted with ingestion of foreign bodies.

\section{Surgical admissions}

The admission diagnostic group of surgical admissions included all patients admitted following a surgical procedure with the exception of neurosurgery. Over the three data subsets a total of $66(57.1 \%)$ were admitted following vascular surgical procedures, 48 (41.2\%) were admitted following general surgical procedures whilst 2 (1.7\%) patients were admitted from the cardiothoracic ICU following complications after cardiac surgery. ${ }^{171}$

\footnotetext{
${ }^{169}$ Dr Peter Roberts was the medical director of the ICU at this time.

${ }^{170}$ Information of the details of this study was obtained from Professor Richard Stubbs, Wakefield Gastroenterology Centre, former hepatobilary surgeon at Wellington Hospital. Personal e-mail correspondence, February 2011.

${ }^{171}$ The cardiothoracic ICU was a Monday-Friday unit admitting patients who had undergone cardiothoracic surgery. Any patients who were not suitable for discharge to the cardiothoracic ward at the end of the week were transferred to the general ICU.
} 


\section{Neurological admissions}

The diagnostic group neurological, is comprised of patients who were admitted following a neurosurgical procedure and patients admitted with subarachnoid haemorrhage. Patients with traumatic head injuries were excluded from this group as they were coded as having been admitted with a diagnosis of trauma. Of the 79 patients admitted in this diagnostic group over the three time periods, post operative neurosurgical admissions accounted for 72 patients $(91.1 \%)$, with subarachnoid haemorrhages making up the other 7 patients $(8.9 \%)$.

\section{$\underline{\text { Trauma admissions }}$}

This group includes all patients who were admitted to the ICU as a result of some sort of trauma and includes head injuries, motor vehicle trauma, burns, and stabbings. Table 4 demonstrates the numbers of patients admitted in each of these diagnostic subgroups.

\section{Table 4: Trauma Admissions}

\begin{tabular}{|l|r|r|r|r|}
\hline & \multicolumn{1}{|c|}{$\begin{array}{c}1965 \\
\mathrm{n}=17\end{array}$} & \multicolumn{1}{c|}{$\begin{array}{c}1977 \\
\mathrm{n}=15\end{array}$} & \multicolumn{1}{c|}{$\begin{array}{c}\text { Total } \\
\mathrm{n}=41\end{array}$} & \multicolumn{1}{c|}{$\mathrm{n}=73$} \\
\hline Trauma & $6(35.3 \%)$ & $9(60.0 \%)$ & $22(53.6 \%)$ & $37(50.7 \%)$ \\
Head injury & $9(53.0 \%)$ & $6(40.0 \%)$ & $19(46.3 \%)$ & $34(46.6 \%)$ \\
Burns & $2(11.8 \%)$ & $0(0.0 \%)$ & $0(0.0 \%)$ & $2(2.7 \%)$ \\
\hline
\end{tabular}

The absence of any patients with an admission diagnosis of burns in the years 1977 and 1989 is probably a consequence of the opening of the ICU at Hutt Hospital in 1973. Hutt Hospital is the location of the Wellington region burns and plastics unit. Maryanne made reference to the number of patients referred requiring tertiary level care from Hutt Hospital.

We did have a lot of transfers in from the Hutt Hospital, perhaps because their ICU was very low key, they had all of the big burns, we used to get more of that and then that sort of tapered off. ${ }^{172}$

\footnotetext{
${ }^{172}$ Oral history interview with Maryanne.
} 
In contrast, Maureen specifically mentioned that because "Hutt didn't have a functioning ICU at that time so we got the burns patients who required ICU type treatment". ${ }^{173}$

\section{Overdose admissions}

As a single diagnostic group, overdoses or accidental poisonings were the fifth largest group in number. Within this group many patients were recorded as having taken a combination of drugs with or without alcohol where others were simply recorded as "overdose". However, when the substance or substances that the patient overdosed on are referred to, the most prevalent drugs were barbiturates, benzodiazepines and tricyclic antidepressants. In regards to commonly available analgesia taken in overdose, the ingestion of aspirin was more prevalent in 1965 and 1977 with paracetamol more commonly taken in 1989. Agents associated with poisonings were toadstools and organophosphates.

Included in this data subset are children admitted following overdoses. ${ }^{174}$ This was comprised of two children in 1965, eight in 1977 and nil in 1989. This may in part be due to the introduction of legislation in 1984 requiring the use of child safety caps or strip or blister packaging that were "reasonably resistant to attempts of young children to gain access." $" 175$ These deterrents were required to be used on several medications including, but not limited to aspirin, paracetamol, barbiturates and antidepressants. ${ }^{176}$ The snapshot of data indicates that these groups of medications were those most commonly taken by children admitted with a diagnosis of overdose in this research.

\footnotetext{
${ }^{173}$ Oral history interview with Maureen.

${ }^{174}$ Children were patients admitted under the age of 15 .

175 Section 37, Medicine Regulations (1984). www.safekids.org.nz.

${ }^{176}$ Child resistant packaging for medications, Position Paper 1, 2001. www.safekids.org.nz
} 
In a 1976 memorandum sent to medical staff within Wellington Hospital regarding the management of patients presenting to hospital after self-harm attempts from drug overdose, the following recommendations were made:

Patients presenting in coma or with major impairment of their level of consciousness be admitted to the ICU following emergency resuscitative treatment in the A\&E department and following consultation with the medical staff in charge of the ICU. ${ }^{177}$

In the same memorandum it was also suggested that: "On many occasions transfer of such patients would be a matter of urgency and that they should not be left to be managed for any period of time in A\&E". Once the patient regained consciousness and was assessed as suitable for psychiatric consultation a member of staff from the psychiatric unit would see the patient and make a plan for further psychiatric management. ${ }^{178}$

Henny specifically referred to the prevalence of patients who had overdosed during the late 1970 s and 1980 s.

There were lots of overdoses. I don't know what it is like now but every Friday you would have a couple and they were great because you would charcoal and lactulose them and they would be puking and pooing, but it wasn't the basic stuff like these days people take panadol, you still had panadol but it was more the antidepressants type of things, cardiac problems with overdoses that needed monitoring. They all came to ICU because there was not room on CCU [coronary care unit] because CCU only had four acute beds; there wasn't a lot of room there so they came to us. ${ }^{179}$

\footnotetext{
${ }^{177}$ Wellington Hospital Archive, WOW00201, Memorandum from Acting Director of Medical Services to Medical Consultants, Medical Registrars, Psychiatric Staff, A\&E Department, and House Surgeons, Memorandum RE: Management of Drug Overdose Patients, 8 March 1976.

${ }^{178}$ Wellington Hospital Archive, WOW00201, Memorandum from Acting Director of Medical Services to Medical Consultants, Medical Registrars, Psychiatric Staff, A\&E Department, and House Surgeons, Memorandum RE: Management of Drug Overdose Patients, 8 March 1976.

${ }^{179}$ Oral history interview with Henny.
} 


\section{Patient Admission Source}

Patients admitted to Wellington ICU came from five areas as shown in Table 5.

Table 5: Admission source

\begin{tabular}{|l|r|r|r|r|}
\hline & \multicolumn{1}{c|}{$\begin{array}{c}1965 \\
\mathrm{n}=77\end{array}$} & \multicolumn{1}{c|}{$\begin{array}{c}1977 \\
\mathrm{n}=172\end{array}$} & \multicolumn{1}{c|}{$\begin{array}{c}1989 \\
\mathrm{n}=235\end{array}$} & \multicolumn{1}{c|}{$\mathrm{n}=484$} \\
\hline A\&E & $20(26.0 \%)$ & $48(28.0 \%)$ & $67(28.5 \%)$ & $135(27.9 \%)$ \\
Wards & $27(35.0 \%)$ & $42(24.5 \%)$ & $43(18.0 \%)$ & $112(23.1 \%)$ \\
Theatre & $25(33.7 \%)$ & $78(42.5 \%)$ & $81(33.5 \%)$ & $184(36.5 \%)$ \\
Other hospitals & $4(5.2 \%)$ & $9(5.0 \%)$ & $43(18.0 \%)$ & $5611.6 \%)$ \\
Direct admissions & $0(0.0 \%)$ & $0(0.0 \%)$ & $4(2.0 \%)$ & $4(0.8 \%)$ \\
\hline
\end{tabular}

The reason there were direct admissions in 1989 is a result of the establishment of an assessment room in the ICU for initial assessment and treatment of patients, usually victims of multiple trauma, transported to hospital via helicopter. With the opening of the Clinical Services Block (CSB) at Wellington Hospital in the early 1980s a helicopter landing pad was located on the roof allowing rescue and medical transport helicopters to land there rather than on the previous landing pad located at road level in the grounds of the hospital. The distance from this new landing pad to the A\&E department was then greatly increased, requiring a journey via a labyrinth of corridors. With the ICU located in the CSB, it was quicker and more direct to take the critical or unstable patients directly there for their initial triage and assessment than undertake the circuitous journey to A\&E. They were then assessed by a team of medical staff including those from ICU, anaesthetics, general surgery and orthopaedics depending on their injuries. It was at this stage that a treatment plan was made depending on the nature and severity of their injuries.

\section{Length of Stay}

As shown in Table 6, in all three data subsets the majority of patients stayed in the ICU for between one and three days with 39\% in 1965, 44.2\% in 1977 and $35.7 \%$ in 1989 . 
Length of stay data was missing for 18 patients in 1977. The numbers of patients being admitted for fewer than 24 hours steadily increased over the three time periods from $18.2 \%$ in 1965 to $32.5 \%$ in 1977 and up to $48.1 \%$ in 1989 . Examination of the data found that in 1977 and 1989 patients admitted to the ICU following surgery generally had shorter stays than in 1965. In contrast to the increased proportions of people having very short lengths of stay, there was also a change in those who stayed for longer.

Table 6: Length of Stay in ICU

\begin{tabular}{|l|r|r|r|r|}
\hline & \multicolumn{1}{|c|}{$\begin{array}{c}1965 \\
\mathrm{n}=77\end{array}$} & \multicolumn{1}{c|}{$\begin{array}{c}1977 \\
\mathrm{n}=154\end{array}$} & \multicolumn{1}{c|}{$\begin{array}{c}1989 \\
\mathrm{n}=235\end{array}$} & \multicolumn{1}{c|}{$\begin{array}{c}\text { Total } \\
\mathrm{n}=466\end{array}$} \\
\hline Mean (SD) in days & $5.68(8.93)$ & $1.86(2.25)$ & $2.27(3.71)$ & $2.70(4.84)$ \\
Range* & $0.25-52.0$ & $0.25-13.0$ & $0.25-31.0$ & $0.25-52.0$ \\
13 hours & $8(10.4 \%)$ & $29(18.8 \%)$ & $60(25.5 \%)$ & $97(20.8 \%)$ \\
$1-3$ days & $6(7.8 \%)$ & $27(17.5 \%)$ & $53(22.6 \%)$ & $86(18.4 \%)$ \\
$4-6$ days & $30(39.0 \%)$ & $76(49.3 \%)$ & $84(35.7 \%)$ & $190(40.8 \%)$ \\
$7-28$ days & $17(22.1 \%)$ & $13(8.4 \%)$ & $17(7.2 \%)$ & $47(10.1 \%)$ \\
$\geq 29$ days & $12(15.6 \%)$ & $9(5.8 \%)$ & $20(8.5 \%)$ & $41(8.8 \%)$ \\
& $4(5.2 \%)$ & $0(0.0 \%)$ & $1(0.4 \%)$ & $5(1.1 \%)$ \\
\hline
\end{tabular}

*0.25 was used when it was reported that patients were in ICU fewer than 6 hours.

\section{Discharge Destination}

Of the $415(85.7 \%)$ patients who survived in ICU (Table 7), most were discharged to wards within Wellington Hospital with only 3-5\% of patients each year being transferred to other hospitals. The majority of these patients were transferred back to their referring hospital with a small number of patients each year being transferred to the spinal unit in Christchurch, psychiatric facilities at Porirua Hospital, the prison service or the Chest Hospital at Ewart Hospital in Wellington. Each year, there were also one or two patients who were discharged directly home from the ICU following admission for an overdose and they were all discharged within 24 hours of admission. 


\section{Mortality Rate}

Table 7: ICU Mortality Rates

\begin{tabular}{|l|c|r|r|r|}
\hline & \multicolumn{1}{|c|}{$\begin{array}{c}1965 \\
\mathrm{n}=77\end{array}$} & \multicolumn{1}{c|}{$\begin{array}{c}1977 \\
\mathrm{n}=161\end{array}$} & \multicolumn{1}{c|}{$\begin{array}{c}1989 \\
\mathrm{n}=235\end{array}$} & \multicolumn{1}{c|}{$\begin{array}{c}\text { Total } \\
\mathrm{n}=473\end{array}$} \\
\hline Died in ICU & $15(19.5 \%)$ & $16(9.9 \%)$ & $27(11.5 \%)$ & $58(12.3 \%)$ \\
Yes & $62(80.5 \%)$ & $145(90.1 \%)$ & $208(88.5 \%)$ & $415(87.7 \%)$ \\
& & & & \\
\hline
\end{tabular}

Wiles and Daffurn discuss how with better understanding of the needs of the ICU patient, and improved knowledge and technology, patient survival rates began to improve. As a result of this, outcomes were better and mortality in intensive care was seen to decrease from $20 \%$ to around $12 \% .{ }^{180}$ The information in Table 7 , in regard to the mortality of patients at Wellington Hospital ICU, is consistent with the above international statistic with the mortality rate decreasing from $19.5 \%$ in 1965 to $11.5 \%$ in 1989 . I have been unable to find reference to national and international mortality rates within the literature to provide a benchmark to other ICUs. ANZICS advised that they didn't begin to keep information on mortality rates until the 1990 s. ${ }^{181}$

\section{Conclusion}

In this chapter the demographic data of the patients admitted to Wellington ICU in 1965, 1977 and 1989 in three selected data subsets was discussed. The clinical profile of patients was compared over these three time periods and each admission diagnostic group was discussed. All age ranges and diagnostic codes were represented throughout each of the three data subsets. The five sources of admission, namely A\&E, hospital wards, operating theatres, other hospital and direct admission via the helipad were outlined. Length of stay varied from hours to several weeks in all three data subsets with most patients' length of stay ranging from 1-3 days. It was found that in regards to mortality

\footnotetext{
${ }^{180}$ Wiles and Daffurn, Bird and Bear, p.161.

${ }^{181}$ Personal email correspondence, the ANZICS records administrator. February 2011.
} 
rates, Wellington ICU were comparable with the numbers presented in the international literature.

The key personnel involved in the care of these ICU patients are the nurses and doctors. The following chapter discusses the hierarchical nature of the working relationships between the nursing and medical staff within the context of the ICU and how that evolved over time. 


\section{Chapter Five - Doctor-Nurse Working Relationships}

\section{Introduction}

Wiles and Daffurn describe how with the development of intensive care units it became necessary for both doctors and nurses to learn about this promising field of patient care together. As a result of this it was necessary for each discipline to work in a partnership from the beginning. ${ }^{182}$ Wiles and Daffurn discuss how with the development of ICUs, working relationships by necessity were required to become less formal and more collegial. ${ }^{183}$ The evolution of these working relationships is discussed in this chapter and nurses' recollections are utilised to help describe this process. The nursing and medical hierarchy within the greater hospital will not be discussed in this chapter.

In the 1960s relationships between nursing and medical staff were, on the whole, hierarchical and very formal. Research into the hierarchical nature of these relationships and the psychology of communication and interaction between each discipline was the basis of several studies between the 1960s and the 1990s. ${ }^{184}$ Of these, Stein's seminal work in 1967 on the doctor-nurse game is the most widely recognised and cited. In 1990 Stein, Watts and Howell revisited Stein's original research to see if these relationships had altered over the preceding 23 years. ${ }^{185}$ Aspects of the findings of Steins research, likened to a game where both parties "utilise subtle nuances in order to achieve a

\footnotetext{
${ }^{182}$ Wiles and Daffurn, Bird and Bear, p.141.

${ }^{183}$ Wiles and Daffurn, Bird and Bear, p.141.

${ }^{184}$ L.I. Stein, 'The doctor-nurse game', Archives of General Psychiatry, 16 (1967); L.I. Stein, D.T. Watts, and T. Howell, 'The doctor-nurse game revisited' Nursing Outlook, 38. 6 (1990); D. Hughes, 'When nurse knows best: Some aspects of nurse/doctor interaction in a casualty department' Sociology of Health and Illness, 10, 1 (1988); D. Allen, 'The nursing-medical boundary: A negotiated order?' Sociology of Health and Illness, 19, 4 (1997); R. Svensson, 'The interplay between doctors and nurses - a negotiated order perspective' Sociology of Health and Illness, 18, 3 (1996); and M. Tellis-Nayak and V. Tellis-Nayak, 'Games that professionals play: The social psychology of physician-nurse interaction', Social Science Medicine 18, 12 (1984).

${ }^{185}$ Stein, Watts, and Howell, 'The doctor-nurse game revisited'.
} 
favourable outcome from the interaction", are demonstrated in both the literature on relationships in ICU and also in the interviews conducted for this research. ${ }^{186}$

\section{The Doctor - Nurse Game}

Stein described the interactions between nursing and medical staff as being traditionally formal with both parties agreeing that the relationship was a hierarchical one with doctors being superior to nurses. The doctor had total responsibility for making decisions regarding the management and treatment of his/her patients. To guide decision making the doctor considered data gathered from the medical history, physical examination, laboratory findings and at times recommendations from other doctors. Another key factor in this decision making was the recommendations received from the nurse. The way that these nursing recommendations were communicated was distinctive, and when observed using an interactional framework, the rapport between the doctor and the nurse was seen to take on a special quality that fits a game model. ${ }^{187}$ Further to this, in the follow up research, Stein, Watts and Howell describe each interaction as being carefully managed according to the rules of the game, with both parties endeavouring not to disturb the hierarchy, maintain mutual respect and foster the interdependence that is so characteristic of their relationship. This game was an intricate interaction carefully developed over time in which both players were willing participants. ${ }^{188}$

\section{Doctor - Nurse Relationships in ICU}

There is acknowledgement amongst some of the literature that relationships between nursing and medical staff in specialised areas such as ICUs evolved much more quickly than those in general areas due to the nature of their work. ${ }^{189}$ Tellis-Nayak and TellisNayak found that the situational demands of an area such as the ICU overrode the status

\footnotetext{
${ }^{186}$ Stein, 'The doctor nurse game', p.699.

${ }^{187}$ Stein, 'The doctor nurse game', p.699.

${ }^{188}$ Stein, Watts, and Howell, 'The Dr - Nurse game revisited', p.264.

189 Stein, Watts, and Howell, 'The Dr- Nurse game revisited', p.264; Tellis-Nayak and Tellis-Nayak. 'Games that Professionals play: The social psychology of physician nurse interaction',; and S. Snelgrove and D. Hughes, 'Interprofessional relations between doctors and nurses: Perspectives from South Wales', Journal of Advanced Nursing, 31, 3, (2000).
} 
considerations and somewhat diminished the associated social rules. ${ }^{190}$ Doctors increasingly depended on the expertise of nurses in prestigious settings such as ICUs where the nurses received specialty training and had independent duties and responsibilities to their patients. ${ }^{191}$

Wiles and Daffurn describe how the establishment of ICUs and the development of critical care nursing as a specialty resulted in an environment where nursing and medicine grew together and became jointly supportive. It was a time of immense change in both medicine and nursing. Doctors helped to develop ventilators, artificial kidneys and cardiac monitors, which nurses learnt to operate whilst providing 24-hour care for the patients attached to them. Without the involvement of the nurses the medical staff could not have achieved what they did. ICUs were the environment in which both groups grew and came of age. ${ }^{192}$

Fairman and Lynaugh write that the ICU became the perfect setting in which medical and nursing staff could share knowledge. It also provided an ideal environment in which to test a new model of collaborative patient care. Further, Fairman and Lynaugh describe how doctors were encouraged to discard traditional beliefs about the expertise and abilities of nurses, and the familiarity between doctors and nurses as a result of having to work closely together helped bridge any discrepancies in knowledge and professional class. Concentration of their sickest patients in one area with the experience and knowledge of the ICU nurse provided reassurance to doctors and the opportunity for them to work with nurses in a less authoritative manner. The overall result was therefore that both doctors and nurses were able to concentrate all of their time and energy on the care of the critically ill patient. ${ }^{193}$

\footnotetext{
190 Tellis-Nayak .and Tellis-Nayak, 'Games that professionals play', p.1064.

${ }^{191}$ Stein, Watts, and Howell, 'The doctor - nurse game revisited', p.264.

192 Wiles and Daffurn, Bird and Bear, p.80.

${ }^{193}$ Fairman and Lynaugh, Critical Care, pp.77-78.
} 
Fairman and Lynaugh describe how this collaborative patient care model created a triangle of safety for doctors, nurses and patients. ${ }^{194}$ They explain this triangle of safety as including three zones: a zone of security, a zone of authority and a zone of safety.

ICU provided a 'zone of security' for doctors worried about their critically ill patients. In general, hospital doctors were not always available in emergencies and many did not have the time to personally monitor complex medical therapies or critically ill patients on the wards. In order for this zone of security to be realised, doctors had to acknowledge a partnership with nurses. In turn, nurses providing the care for these patients needed the expertise, skills and authority traditionally considered the domain and privilege of doctors. This included nurses assessing the physical stability of the patient and making critical decisions and treating patients according to protocols in the absence of the doctor. With this nurses gained a 'zone of authority' to work within a sphere of competence in which their skills and expertise were respected. With this authority came the responsibility to learn more about the care of the physically unstable patient. This required the acquisition of skills not traditionally taught in the usual nurse training curriculum but learned on the job from self-education, experience and physician teachers. For patients, being cared for in the ICU environment provided a 'zone of safety' in which all caregivers pooled their knowledge about the treatment of the critically ill patient. Concentrated nursing and medical presence, shared knowledge and rapid responses to changing patient physiology gave the ICU patient greater protection. ${ }^{195}$

In the early years there continued to be a distinct hierarchy with nurses and doctors communicating via the ward sister.

As a Staff Sister you stood back and the Ward Sister did all of the talking ... you weren't paid to think much, you did what you were told ... there was tremendous

\footnotetext{
${ }^{194}$ Fairman and Lynaugh, Critical Care, pp. 77-78.

${ }^{195}$ Fairman and Lynaugh, Critical Care, pp.78-79.
} 
discipline, no backward chat or jokes, there was no laughter, it was just very serious. ${ }^{196}$

As was apparent in the literature internationally, the nursing relationships with the specialist ICU medical staff in Wellington ICU developed overtime into one of shared knowledge and information and a sense of working together as a team.

I believe that from my own personal perspective anyway that I had a very good working relationship with the medical staff and the medical staff worked very much hand in glove with us and I didn't ever really have a sense of them being the boss and me being a subordinate at all. And I think that it was a very healthy and a very synergistic type relationship and we did quite a lot as teams and I think that it worked very well ... By the time we had got into the 1970s and the 1980s the medical staff had a hugely respectful attitude to nursing and nursing's contribution to patient care and that was something that they were very open about at conferences and things like that and I hope that that hasn't changed because it was phenomenally supportive of each other. ${ }^{197}$

Maryanne referred again to this notion of teamwork and working together collaboratively. "It is a team ... I think that that is partly as a specialty we do work very closely together and through lots of very serious situations". ${ }^{198}$ However, whether this was an opinion shared by the doctors in the wider hospital setting is questionable. Most of the nurses interviewed have recollections of doctors visiting the ICU with an air of superiority to them and the relationships remaining somewhat formal.

It was fairly formal. The surgeon we had the most to do with was a Mr James [neurosurgeon]. He had a good sense of humour which helped. And we had $\mathrm{Mr}$

\footnotetext{
${ }^{196}$ Oral history interview with Marie.

${ }^{197}$ Oral history interview with Maryanne.

${ }^{198}$ Oral history interview with Maryanne.
} 
Barrett, he was quite relaxed too. ${ }^{199}$ Again I had minimal involvement with him personally. There were definitely no first names. ${ }^{200}$

As a consequence of hierarchical behaviours outside of ICU many nurses found it difficult to forge relationships with senior medical staff in the ICU environment.

I think that the relationships evolved over time. I can remember when I first came into Wellington I was very much in awe of the tertiary aspect of things, and certainly at that time in the very early stages we had some very strong individuals who were running units, like the cardiothoracic surgeon Jimmy Baird was a force to be reckoned with. All of these people were senior and there was very much a power dynamic and you were very aware of that power dynamic. ${ }^{201}$

Because of the need for both the medical and nursing staff to work collaboratively the working relationships in ICU became less formal than those in the general wards.

The relationship between doctors and nurses was a lot more formal than it is now, because of course we didn't have registrars. You only had consultants who worked in ICU so you had to worship the ground that they walked on really. But it was a lot less formal than if you met them in the ward where you almost kissed the floor before they walked on it ... and slowly over the years that got a lot less formal, but that was only in the unit, not so much in the wards, it was still very much 'oh Dr God'. ${ }^{202}$

In 1977 the first intake of fourth year medical students began in Wellington Hospital. This came about as the result of a combined contract between the University of Otago (in Dunedin) and Wellington Hospital Board and the development of the Wellington Clinical

\footnotetext{
${ }^{199}$ Referring to Dr Cam Barrett, the medical director of the ICU.

${ }^{200}$ Oral history interview with Marie.

${ }^{201}$ Oral history interview with Maryanne.

${ }^{202}$ Oral history interview with Henny.
} 
School. ${ }^{203}$ From then on more junior doctors were to be seen in the wards and would visit ICU with their more senior colleagues from the wards. Although there were still formal hierarchical relationships between the nursing staff and the surgeons it would appear that the more junior the doctor the more acceptable it was to speak to the nursing staff. According to Cheryl "You never spoke to surgeons; you'd speak to the house surgeons. The registrars never acknowledged you but the house surgeons and the trainee interns did. They were the underlings and we were the underlings". 204

The doctor - nurse partnership in ICU became one of working together towards a common goal; that of supporting the critically ill patient towards wellness, and also of learning together in those early days. Whether this occurred because of the desire of both medical and nursing staff to improve patient care or simply as a need for the sharing of information in order to deliver patient care is not clear.

I think that compared to the other areas it was possibly a better relationship. There still was a hierarchical relationship within the medical staff and with nurses, a little bit of 'them and us', and if you compared it to today it was miles apart. There was some autonomy there but possibly ... it was harder to argue your point if you weren't happy but you would still do it sometimes, it wasn't quite as it is now when there is more discussion, it was still kind of coming to them with the information. ${ }^{205}$

Outside medical staff soon learnt that in order for their patients to receive care within the ICU it was necessary for them to engage with the nursing staff. Also "In the unit [if] they wanted information from you and they wanted you to treat their patient they did [have to] talk to you". 206

\footnotetext{
${ }^{203}$ www.wnmeds.ac.nz/about/historical_note.html.

${ }^{204}$ Oral history interview with Cheryl.

${ }^{205}$ Oral history interview with Maureen.

${ }^{206}$ Oral history interview with Henny.
} 
Just as discussed in the literature regarding the development of ICUs overseas, learning and working together as a team was prevalent in Wellington ICU with senior medical staff role-modelling this collaborative partnership to newer less experienced doctors.

The autonomy that we have today was already starting to come into place [in the 1980s] and there were some doctors who were better than others. In fact the Director at the time was very keen and he would tell the doctors to be looking at the charts, so we would work quite closely with the registrars and often when they first started out there was an understanding that we would have to guide them. ${ }^{207}$

However, even though it was a time of teaching for the medical staff, the nursing staff often felt threatened when questioned by the medical staff about their practice.

The nurses were certainly good at challenging the medical staff and the medical staff would respond appropriately but they wouldn't cope with the medical staff challenging the nursing staff. All that stuff about critical reflection, critical analysis, we had a huge bridge to cross and I guess it was early days as it was before evidence based practice and it was something we were really aware of and very keen to try and break ... one thing that is really pertinent in terms of ICU nursing is that nurses tend to be very defensive in their demeanour. I would go around on the medical ward rounds every day and the medical staff would think nothing of saying to the registrars 'why did you do that?' and 'why did you do this?' and 'how come that happened?' and question them about their practice. Now, if that consultant turned around and said to the nurse 'why did you do that' the nurse would automatically become terribly defensive and 'how dare they question my practice' etc. They weren't nearly as confident and didn't like to be challenged. $^{208}$

Dealing with stressful 'cases' is part of working in an environment such as ICU. Working collaboratively and having informal debriefing are both common methods

\footnotetext{
${ }^{207}$ Oral history interview with Maureen.

${ }^{208}$ Oral history interview with Maryanne.
} 
utilised by the nursing staff to deal with these situations. One informal way that staff ensured morale remained high was to relax together at the end of the week.

Friday nights were always good. Friday nights the relatives would be kicked out of the visitor's room if it wasn't occupied by patients and we would have our brown paper bag with our box of wine and we would all sit and socialise. ${ }^{209}$

When asked if it was just the people who were working or whether others came in specifically, Henny recalls it was just "the ones who had finished working, at the end of the shift because you finished at $3.30 \mathrm{pm}$ and it wasn't a worry about drink/driving in those days".

When asked what the relatives were told when they were moved from the relatives room Henny was not sure but recalled that there were often no relatives using the room.

They were just asked to leave, often there wasn't anyone there because it wasn't encouraged, so often it was empty anyway, so we just sort of, I don't know someone just obviously closed the door when it was empty so no one else would come in. ${ }^{210}$

\section{Conclusion}

In this chapter the hierarchical nature of the working relationships between nursing and medical staff in the early years of intensive care was discussed. The work that most adeptly describes this relationship within health care is Stein's work entitled the DoctorNurse game. Aspects of this game playing were evidenced in the references to doctornurse working relationships in the oral history interviews. As evidenced in the literature on the nature of doctor-nurses relationship both in ICU and the wider hospital the interactions between these two groups became less formal over time. Whether this was initially due to the need to learn the intricacies of this new specialty together or the formation of a more collegial relationship in order to ensure that the patients received the

\footnotetext{
${ }^{209}$ Oral history interview with Henny.

${ }^{210}$ Oral history interview with Henny.
} 
level of care required is not absolutely certain but is most likely a combination of both factors.

The physical working environment along with the technology and equipment that both the nursing and medical staff required to care for these patients is presented in the following chapter. Additionally, delivery of patient care and daily routines are described. 


\section{Chapter Six - ICU Design, Technology and the Rituals of Caring in ICU}

\section{Introduction}

The idea of grouping the sickest patients into one area to provide skilled nursing care and close observation was the fundamental impetus to the development of ICUs. Along with this the introduction of technology to facilitate the gathering of vital signs, monitor the patient and assist with respiration became part of the territory. Much of this initial technology was rudimentary and evolved over time to meet the needs and demands of both the patients and the medical and nursing staff responsible for its use. Margarete Sandelowski is noted to have said that nurses played a key role in the technological transformation of hospital care, but she also argued that nursing gave much more to technology than technology ever gave to nursing. In fact she emphatically concludes that "although nurses certainly acquired new knowledge and skills, what nurses gained most of all was new and arguably more work to do". ${ }^{211}$

In this chapter the layout and design of both the first and the second ICUs at Wellington Hospital will be described. In addition, the technology which was commonly used is described and excerpts from the oral history interviews are utilised to demonstrate how the nurses utilised this equipment. In the interviews the nurses described rituals of care involving regular treatments and actions that were performed by the nurse in lieu of the patient being able to do these for themselves. Such rituals included regular suction of secretions via the patient's endotracheal tube, eye and mouth care and routine position changes.

\section{ICU Design}

Many ICUs internationally were developed out of postoperative recovery rooms and respiratory care units rather than being purpose built. As a result space was often

\footnotetext{
${ }^{211}$ As cited by Lewenson and Herrmann, Capturing Nursing History, p.15.
} 
inadequate with planners and hospital administrators not anticipating the soon to be rapid introduction of large and complex machinery. ${ }^{212}$ Several important recommendations were put forward when establishing an ICU. Wiklund writing in 1969, described how when planning the layout of an ICU it was recommended that each bed space be sufficient in size to accommodate the array of equipment required. ${ }^{213}$ The patient bed space should be made as flexible as possible in order to meet the needs of widely differing patients and be approximately two to three times as big as that of a general patient care area. Wiklund also described how the nurses' station (which also frequently served as the place where doctors worked) should be arranged so that all of the patients could be constantly observed. The desk should also be large enough to provide sufficient workspace for several people, as well as being able to accommodate the central monitoring equipment. Another of the recommendations was that isolation rooms for patients liable to infection or those already infected were essential as a first step to control cross infection. Isolation rooms could also be used for the conscious ICU patient who would otherwise be disturbed by the activity, light and noise in the open unit. These rooms might also be utilised to cater for the conscious patient who might be experiencing psychological implications from knowing that they were so seriously ill that they required treatment in the ICU; nursing care could then be given to such a patient in isolation so that the psychological distress of one patient did not affect the others. ${ }^{214}$ Burrell and Burrell writing at the same time, argued that the overall ICU design should allow the critically ill patient a measure of privacy whilst simultaneously allowing their constant observation by nursing and medical personnel. They also recommended that wall mounted equipment be utilised wherever possible to cause minimal interference with direct patient care. ${ }^{215}$

\footnotetext{
${ }^{212}$ Fairman and Lynaugh, Critical Care, p.15.

${ }^{213}$ Wiklund, 'Intensive care units', p.123.

${ }^{214}$ Wiklund, 'Intensive care units', p.151.

${ }^{215}$ Burrell and Burrell, Intensive Nursing, p.254.
} 
During the planning phase of Wellington's first ICU, the first intensive care unit committee members worked with staff from various hospital departments and potential users of the unit to get advice on the process of ordering equipment, structural alterations and staffing. ${ }^{216}$ Integral to these discussions was the Department of Anaesthesia. ${ }^{217}$ The initial ICU, known as Ward 10, was a seven-bedded unit and was located in the 2-10 Block alongside the neurosurgical ward. Marie recalls her first impressions of the ICU.

Well I was impressed. I had actually never been in an ICU before at any stage... I have been trying to think of how many beds we had and I've been visualising it and I think we might have had 6-8 but I can't be sure... In those days we walked through a small neurosurgical ward into the ICU, where we entered slightly to the left there was a nurse's station area. ${ }^{218}$

Others, including Marie recalled being able to place patients into rooms not necessarily designated as patient bed spaces.

I'm trying to think of the layout. I have a funny feeling that we occasionally did go up above $7 \ldots$ we had isolation rooms or burns rooms one or the other but I think there was another room that we occasionally had patients in. ${ }^{219}$

And at times, staff even resorted to using the relatives' waiting area to accommodate an additional patient. "You could squeeze one more in if you had to, then you could kick the relatives out of the waiting room and squeeze another one in there". 220

The physical layout of the ICU as shown in Figure 1 was comprised of a desk with patient bed spaces positioned around this.

\footnotetext{
${ }^{216}$ I was unable to ascertain who made up the membership of this committee.

${ }^{217}$ Wellington Hospital Archive, WOW00201, Wellington Hospital Intensive Care Unit Committee, First Report: Intensive Care Planning, 19 June 1972.

${ }^{218}$ Oral history interview with Marie.

${ }^{219}$ Oral history interview with Maureen.

${ }^{220}$ Oral history interview with Henny.
} 
There was the central nursing bench and the cubicles were in an arc around that. There were two that were fully enclosed to my memory. One was totally enclosed, you couldn't see inside it and the other one was a glass room as I recall it ... All of the supplies were behind the nurses' station in the sterile area ... there were a few windows, just down one side otherwise it was a straight wall. Patients who were in isolation, in that glass room, if the curtains were closed they saw nothing. ${ }^{221}$

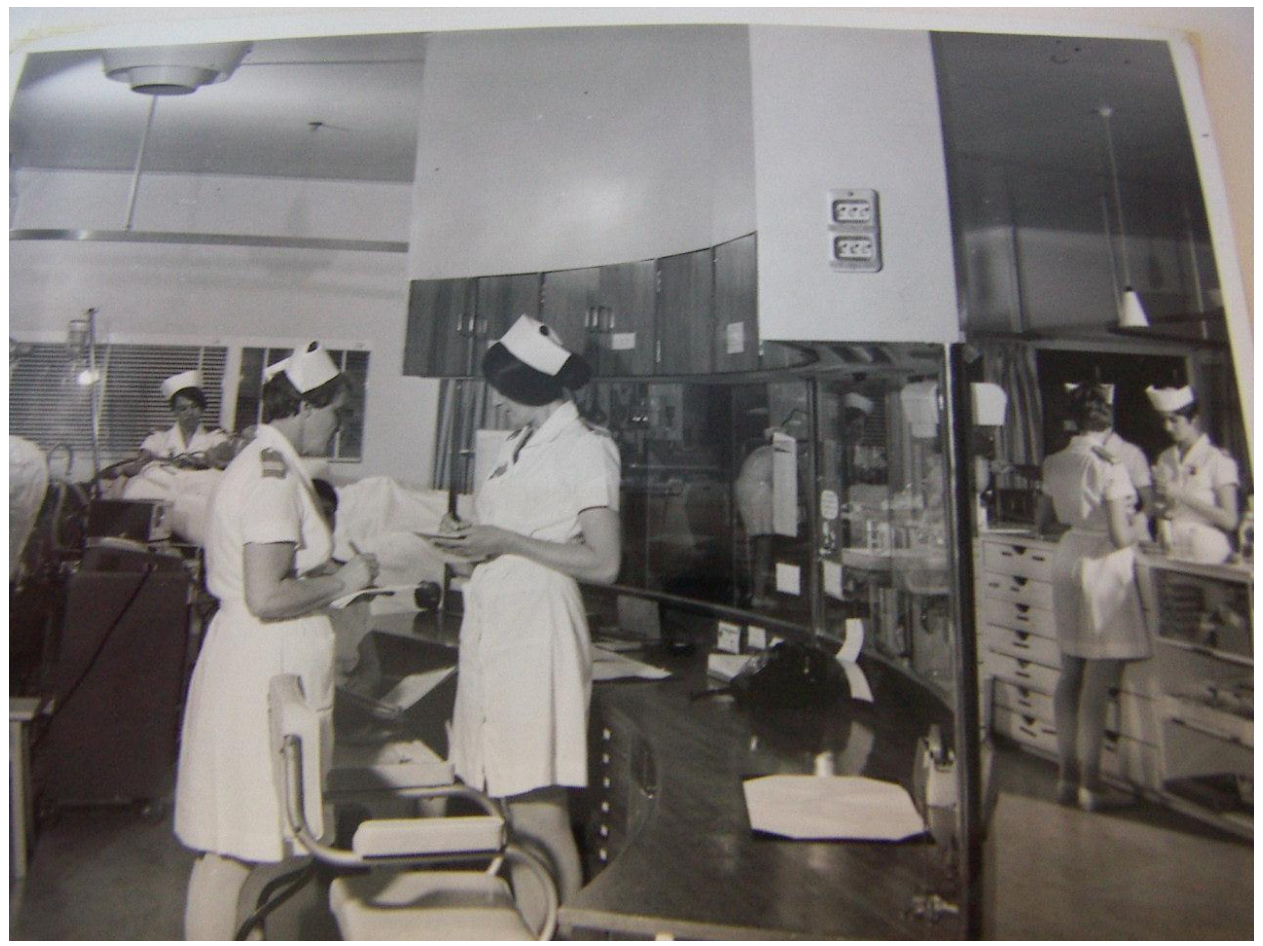

Figure 1: Wellington ICU Layout c.late 1960s*

*Source Archives New Zealand, Wellington Archives, ABRR 7563, W4990, 10, Nursing Staff, Wellington Hospital, 1960-1970, Envelope of photographs. Reprinted with permission.

Two years after the unit opened, planning began for the design of a new ICU to be built in what was then described as Block B Wellington Hospital. ${ }^{222}$ Block B was considered to be ideal as it was to be sited in close proximity to the operating theatres and the

${ }^{221}$ Oral history interview with Cheryl.

${ }^{222}$ Block B later became known as the Clinical Services Block. However, it could not be determined from the documents available when this change in name occurred. 
associated recovery areas, both of which by necessity had important functional relationships with the ICU. This planning finally reached a more definitive stage in 1972 when it was proposed that the current 7 bedded unit was significantly lacking in storage, office space and teaching amenities and that these factors seriously impaired the functioning of the unit. It was decided that for Wellington Hospital to continue to compare favourably with other hospitals in standards of patient care there should be no further indecision in planning. ${ }^{223}$ It was time to move on to bigger and better things.

This 1972 report states that all members of the ICU Committee were involved in the planning and design of the new unit, together with the Sister-in-Charge of the unit and the Sister from the Intensive Care nursing course. ${ }^{224}$ Also attending planning meetings were representatives from the Planning Department and the Department of Electronics. As with the planning of the first unit, advice was also sought from other users of the ICU and staff from various hospital departments. During these planning meetings topics of discussion included the administration, size and design of the ICU, along with its location in relation to other internal and external units, both at present and in the future. ${ }^{225}$ Future trends in patient monitoring equipment and the future effect that these developments would have on patient care were also assessed, including monitoring, computer storage and relay of the various parameters to both the bedside and within the greater confines of the ICU. The report also notes that members of the committee agreed that an ICU comprised of at least 14 beds was required based on the limitations imposed on the bed numbers of the current unit together with recommended bed numbers from experience of other hospitals both in New Zealand and overseas. Along with an increase in bed numbers it was agreed that provision be made for adequate storage, administrative offices staff accommodation and teaching facilities and that the floor area of such facilities

\footnotetext{
${ }^{223}$ Wellington Hospital Archive, WOW00201, Wellington Hospital Intensive Care Unit Committee. First Report: Intensive Care Planning, 19 June 1972.

${ }^{224}$ Wellington Hospital Archive, WOW00201, Wellington Hospital Intensive Care Unit Committee. First Report: Intensive Care Planning, 19 June 1972.

${ }^{225}$ Internal referred to the cardiothoracic, renal dialysis and coronary care units and the premature baby unit. External referred to the relationships with other Hospitals and ICUs from Hutt Hospital, and the lower part of the North Island as well as the northern parts of the South Island.
} 
should be at least equal to that of the patient treatment area. In addition to this, storage and administrative space, a minimum of 200 sq.ft per patient bed space would be required. $^{226}$

The final location of the new ICU was on Level 5 of the Clinical Services Block (CSB) with operating theatres located on Levels 6 and 7, each with their own recovery areas situated alongside the theatres. The new ICU opened in 1980 and was designed to eventually accommodate 14 patients. There were two four-bedded bays situated beside each other with a central preparation area with storage for IV fluids, syringes, needles and other equipment between the two bays. Facing these bays was a central desk for both nursing and medical staff to use with a raised central console area that housed a central monitoring system whereby each patient's monitor could be viewed (Figure 2). ${ }^{227}$

It was a six-bedded unit when I first started, then it became eight then ten, and up it went. But we always had equipment for at least eight patients and we never used to have more than eight patients ... there were about eight separate monitors [in the central raised console] and every monitored patient would come up on one of those screens, it was like working in air traffic control. ${ }^{228}$

This central monitoring console was used for many purposes and on the evening and night shifts it was where the nurses were to be found.

We used to sit up there; we used to have handover up there for afternoon and night duty as well. Everyone would sit on the bench and whoever was in charge would come up and tell the story. ${ }^{229}$

\footnotetext{
${ }^{226}$ Wellington Hospital Archive, WOW00201, Wellington Hospital Intensive Care Unit Committee. First Report: Intensive Care Planning, 19 June 1972.

227 This area later became the ward clerks' station.

${ }^{228}$ Oral history interview with Cheryl.

${ }^{229}$ Oral history interview with Cheryl.
} 


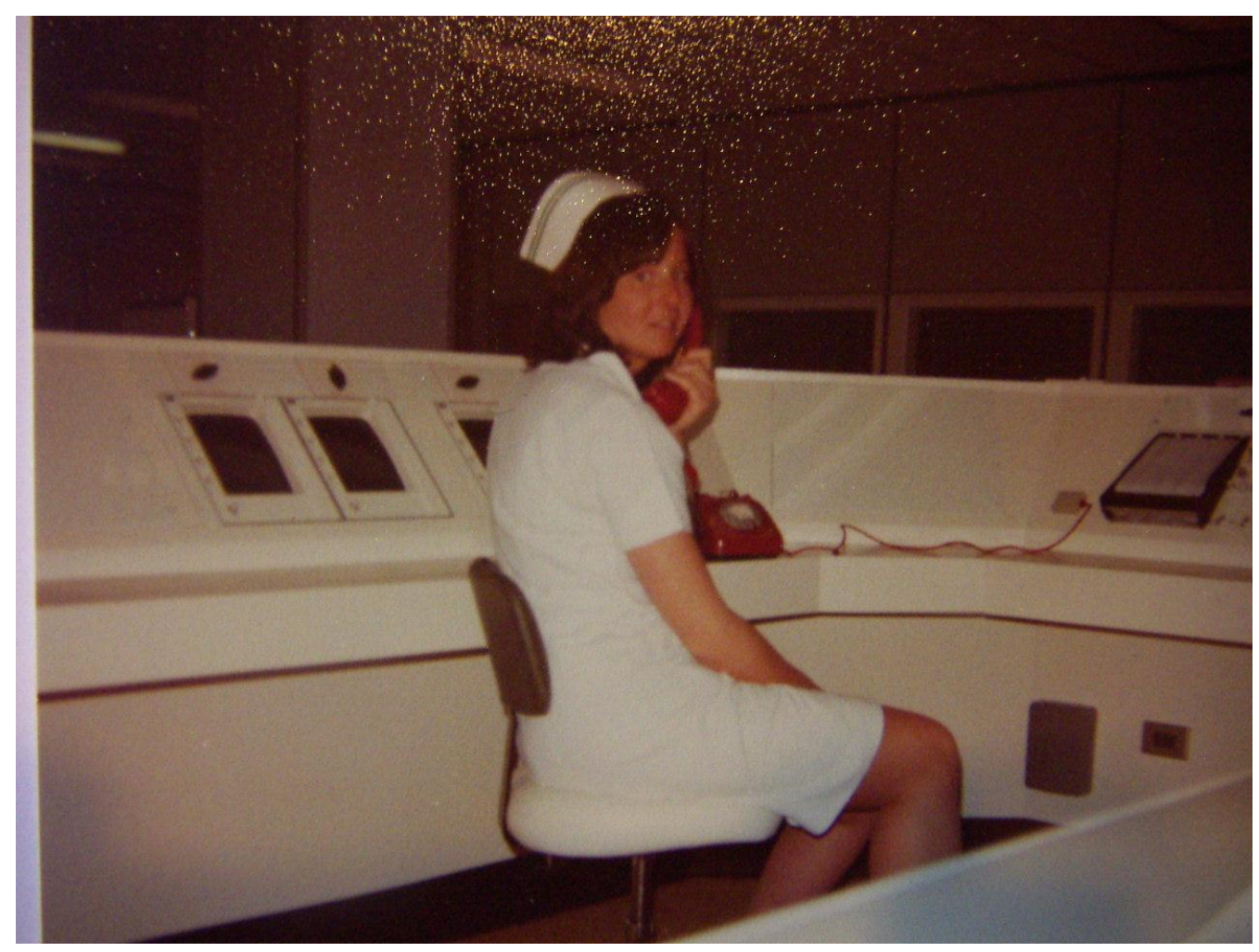

Figure 2: The New ICU Central Monitoring Console c.1980

Source: Wellington ICU Staff Photo Album. Name of nurse in photo unknown, date unknown Reprinted with permission.

As well as the two four-bedded bays there were four single rooms that doubled as isolation rooms, two on either side of the unit. Two of these rooms were negative pressure rooms for respiratory isolation of patients who were suspected of having, or diagnosed with, airborne spread diseases such as tuberculosis. There was also a two bedded room used for paediatric patients located beside the central area. In addition to this patient care area, there were also several offices, storage areas and a staff tearoom located along a corridor behind the patient area.

\section{Nursing the Patient or Nursing the Technology?}

Wiles and Daffurn portray how with the advent of this new field of nursing came the introduction of unfamiliar equipment and technology. They describe how before 1960 nursing care was challenging, uncluttered and uncomplicated by technology. The most sophisticated equipment in the nurse's repertoire was a mercury thermometer, a manual 
sphygmomanometer and a stethoscope. ${ }^{230}$ Then, during the mid-1960s developments in science and medical technology revolutionised the care of patients.

Doctors and nurses were confronted with artificial kidneys, expired air resuscitation and external cardiac massage, external defibrillators, cardiac monitors, and the widespread use of increasingly sophisticated ventilators and monitoring systems. These burst upon unsuspecting staff with the impact of a meteorite: unforeseen, unplanned, unbridled, unevaluated and barely understood by those responsible for their operation. ${ }^{231}$

The essential premise of intensive care nursing is one of total care of the patient who through illness, injury or as a means of pharmacological intervention is unable to participate either partially or completely in their care. Much of this nursing care was focused around the information gathered from close monitoring of the patients' vital signs and as the concept of intensive care evolved, more machinery was introduced in order to facilitate the gathering of this data. In essence, the nurse was no longer just nursing the patient and there were concerns that with the introduction of more equipment, nurses would begin to practise nursing the technology rather than making their primary focus that of excellent nursing care of the patient.

This concern was discussed by Fairman who describes how with the number of intensive care units growing and hence greater numbers of patients benefitting from the care and skill of the ICU nurse the lessons of those pre-ICU years were forgotten. The vigilance and careful observation of patients of the past was overshadowed by eagerness on the part of the ICU nurse for machinery as intensive care increasingly became the domain of technology; the care of the critically ill patient became focused on the data gathered from machines which in turn overrode the intense observation of nurses and their expertise. ${ }^{232}$

\footnotetext{
${ }^{230}$ Wiles and Daffurn, Bird and Bear, pp.xix-xx.

${ }^{231}$ Wiles and Daffurn, Bird and Bear, p.xix-xx.

${ }^{232}$ Fairman, 'Watchful Vigilance', p.58.
} 
Sister B. Mercer, who studied in the ICU course at Wellington Hospital also wrote of her concerns of such an occurrence.

The purpose of the post basic course in Intensive care nursing at Wellington Hospital as concerned with electronic monitoring equipment is to train nursing staff, so that in managing patients requiring this form of treatment, the patient may be given the optimum care and attention, while the equipment surrounding the bed is of secondary importance and only used as a guide to the patients' condition. This patient care can only result if you have specially trained nursing staff who are familiar with the function of the equipment, and it is my opinion that insufficient training of staff in these areas may result in too much attention being paid to the equipment, and too little to the patient. ${ }^{233}$

\section{Equipment}

The equipment in early ICUs could be considered rudimentary by 2011 standards; however, the essential tools of patient care have remained unchanged since the inception of ICU as a specialty. In Wellington ICU the majority of the specialised respiratory and electronic monitoring equipment was provided by the Department of Anaesthesia who also organised its maintenance and provided instruction to both medical and nursing staff in its correct use. ${ }^{234}$ Burrell and Burrell explained that several pieces of equipment were deemed mandatory for the essential function of the intensive care unit. They described these as "a mechanical means of supporting respiration, electronic equipment for patient monitoring, specific sterile supplies and certain drugs". ${ }^{235}$ Along with these items they list various additional pieces of equipment considered necessary including, but not limited to: adult and paediatric sphygmomanometers, stethoscopes, an intermittent

\footnotetext{
${ }^{233}$ Mercer, 'Intensive Care', p. 22, in an article written whilst a student completing the Post-Basic course in Intensive Care Nursing at Wellington Hospital.

234 Wellington Hospital Archive,WOW00201, letter from the Wellington Hospital Intensive Care Committee to Mr. C.L. Tucker, Chairman Detailed Planning Committee, Wellington Hospital, 7 June 1972.

${ }^{235}$ Burrell and Burrell, Intensive Nursing, pp.255-257.
} 
suction machine, portable intravenous stands, an ample supply of linens, charting forms and necessary stationary supplies. ${ }^{236}$

In Figure 3 it can be seen that much of this equipment was stored at the head of a bed. The sphygmomanometer is attached to the wall to ensure that it is always readily available, the glass suction bottle and metal IV pole are all evident along with two oxygen flow meters, ample power plugs for equipment to be plugged into and a mobile light source.

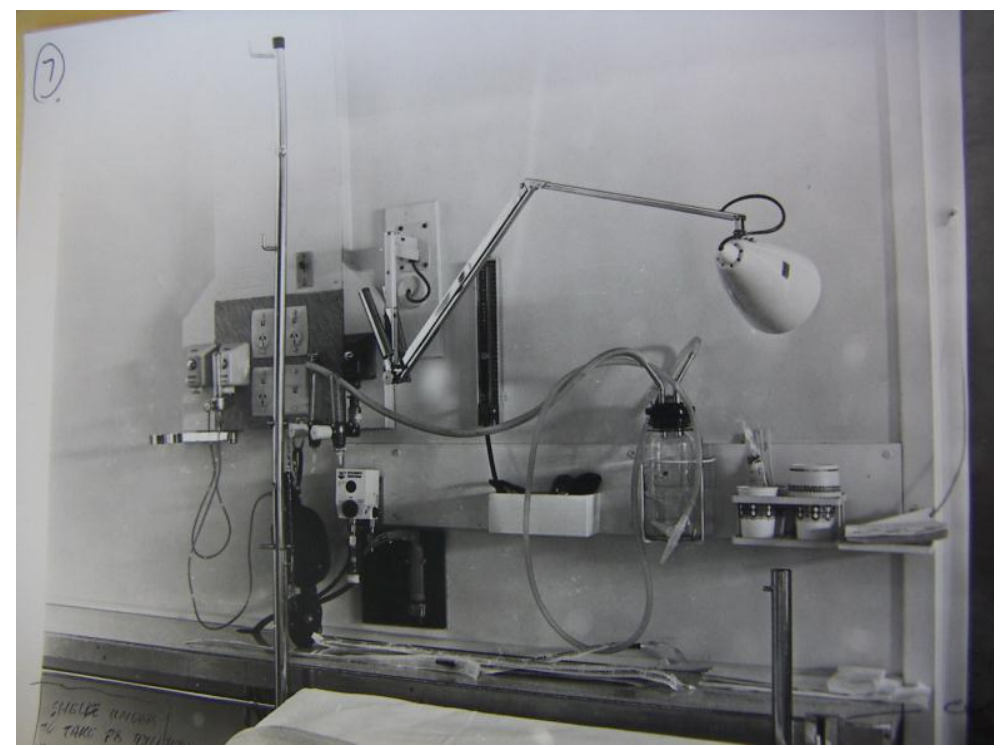

\section{Figure 3: Bedside Equipment Wellington ICU c1970s}

*Source: Archives New Zealand. Wellington Archive, ABRR, 7563, W4990. Reprinted with permission.

\section{Emergency Equipment}

Burrell and Burrell described a portable resuscitation trolley that could be taken to the bedside in an emergency situation as an essential feature of an ICU. ${ }^{237}$ It was recommended that each trolley be equipped with the following: defibrillator with synchroniser, portable resuscitators, ${ }^{238}$ airways and endotracheal tubes, intracardiac

\footnotetext{
${ }^{236}$ Burrell and Burrell, Intensive Nursing, pp.255-257.

${ }^{237}$ Burrell and Burrell, Intensive Nursing , p. 257.

${ }^{238}$ Bag mask breathing bags used in emergency situations to assist the patient with respirations. Also known as ambubags.
} 
needle, arm boards, tourniquets and alcohol sponges, cardiac arrest tray, and emergency drugs. Such emergency equipment was readily available in the clinical area at Wellington ICU (see Figure 4). According to Marie, "there were ambubags near every bed. There was a trolley with emergency equipment there". ${ }^{239}$

In line with international practice in 1967, the Wellington ICU resuscitation trolley contained the following equipment, not dissimilar to the above list: ${ }^{240}$

Ambubag (adult and child), cuffed endotracheal tubes, rubber dressed spencer wells forceps, laryngoscopes (adult and child), metal yanker suction, tape (TNC and sleek), cocaine $2 \%$ spray and sprayer, ${ }^{241}$ oxygen mask and tubing, suction catheter, syringes, intracardiac syringe, needle and blade, aminophylline, alupent, $\mathrm{KCl}$ and $\mathrm{CaCl}^{242}$

In the ICU environment the black resuscitation ambubag with black rubber mask connected to one of the two oxygen flow meters and laryngoscope and blade are considered permanent fixtures.

\footnotetext{
${ }^{239}$ Excerpt from oral history interview with Marie.

${ }^{240}$ A list of the equipment kept on the emergency trolley written by oral history interviewee Maire during her orientation period to Wellington ICU in 1967. This list was contained within a notebook kept by Marie containing both useful and essential to know information.

${ }^{241}$ Cocaine spray was used as a topical anesthetic, probably in this instance used to numb the airways prior to intubation.

${ }^{242}$ Both aminophylline and alupent were used as bronchodilators. The other medications are electrolytes: $\mathrm{KCl}$ is potassium chloride and $\mathrm{CaCl}$ is calcium chloride.
} 


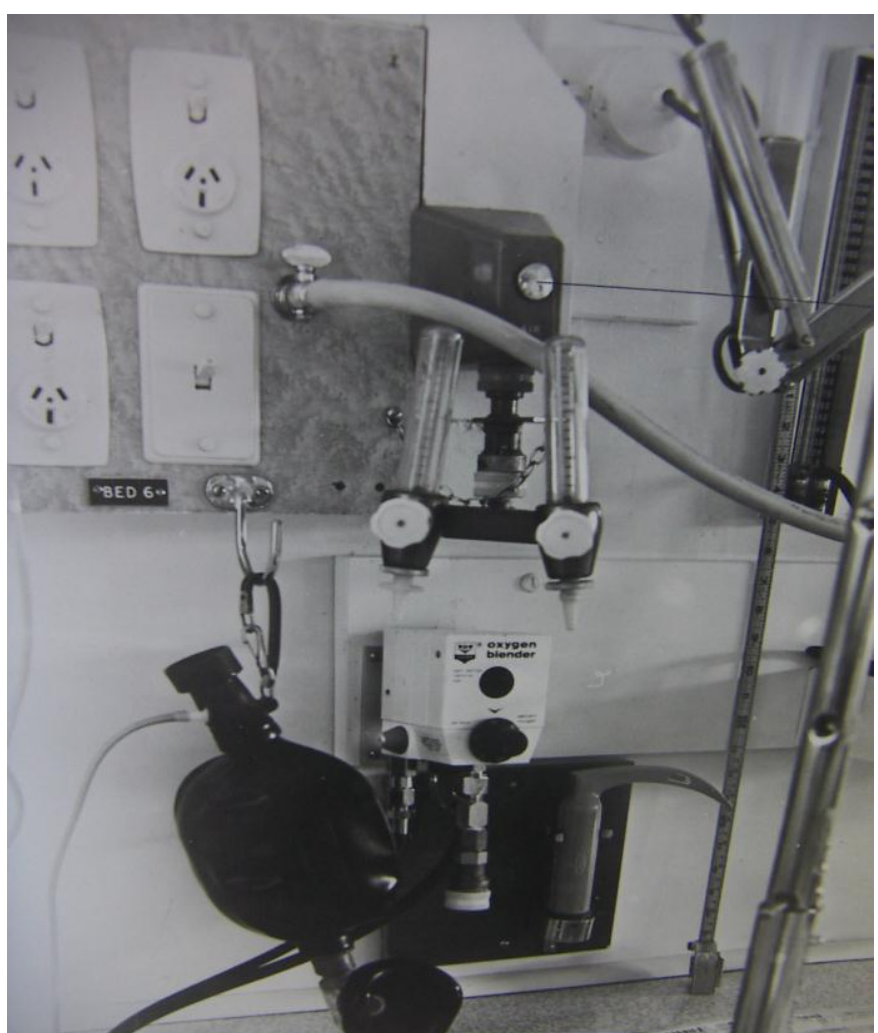

Figure 4: Emergency equipment kept at the head of a bed space - Wellington ICU c1970s

*Source: Archives New Zealand. Wellington Archive, ABRR, 7563, W4990 Reprinted with permission.

\section{Ventilators and Patient Ventilation}

Many of the nurses interviewed recalled that the ventilators used in Wellington ICU were predominantly the Bird Mark 8. Wiles and Daffurn describe the Bird Mark 7 and 8 as the most commonly used ventilators in many ICUs. Bird ventilators were considered the backbone of ICU, however they required attention in order to get good ventilation from them. If nurses did not pay attention or did not understand them they could poorly ventilate the patient. ${ }^{243}$

The bird respirator was the only respirator we had. They took a lot of skill to use ... when we had to turn the patients over we had to put them on the bag [ambubag] and turn them and then take the machine around to the other side of

${ }^{243}$ Wiles and Daffurn, Bird and Bear, p.217. 
the bed and put them back on again. The machine, it wasn't very flexible and you couldn't really get it around the back of the bed. ${ }^{244}$

Nurses required significant skill and knowledge to operate the Bird ventilators and their lack of safety features. They also embraced the changes that were associated with some of the newer technology when it came along. Maryanne who had worked at the ICU from 1974 into the 1990s recalled the changes she had observed over time.

I first started with the Bird ventilator which is a ventilator that is incredibly historic and I think that you needed an enormous amount of skill to operate those ventilators. They didn't have any of the safety measures built into them that some of the newer ones had. They were hugely challenging. I remember that we went from them, which were very much a pressure ventilator, to things like the Bennett and Bourne ventilators, the volume ventilators, and that was a really exciting time because there was this explosion of technology ... its implications for the patients and physiology and things. ${ }^{245}$

The differences in the sounds of individual machines was an understandably valued, and even endearing quality to nurses of that era, because these machines did not have alarms to signal detachment from the patient, much less alarms for changes in ventilation or malfunction. ${ }^{246}$ Many of the oral history interviewees recalled the particular quirks and difficulties associated with using the Bird ventilators.

Because all of the alarms were audible you sat behind the glass screen and you could actually hear your patient so you knew when things changed very quickly, even before any alarms went off, you could hear the ventilator working. ${ }^{247}$

\footnotetext{
${ }^{244}$ Oral history interview with Pauline.

${ }^{245}$ Oral history interview with Maryanne.

${ }^{246}$ Wiles and Daffurn, Bird and Bear. p.215.

${ }^{247}$ Oral history interview with Henny.
} 
In addition to being able to hear the ventilator functioning interference associated with movement of the patient required the nurses to have to regularly readjust the settings.

I remember predominantly the Bird ventilator. They were nasty things; you had to watch it like a hawk, every time you moved your patient or every time they coughed you had to reset everything. It was just a nuisance ... you knew from the sound it made, and just looking at your patient, what you were hearing you knew whether you had it in sync or not... the baby Bird [for paediatric patients] ventilator, that was a nightmare. It was a ghastly ventilator, worse than the pressure cycled adult Bird, again its alarm was an add-on. ${ }^{248}$

Henny recalls the Bird ventilators as being tricky but also reflects on using the Bourne ventilators.

The Bird was a pretty tricky thing to set up ... the other ones with the bellows, Bourne ventilators, you could see the bellows going up and down so you knew the patient was breathing because the bellows were going up and down and there wasn't a leak because it hit the mark. ${ }^{249}$

It was often necessary to paralyse many patients whilst they were ventilated to facilitate adequate ventilation.

We controlled ventilators and patients with tubocurare which lasted 20 minutes, then we used to use pancuronium all of the time ... every patient in the early 1980s got paralysed, all of them. Serious head injuries, high oxygen requirements, they all got paralysed. ${ }^{250}$

By 2011 standards, these early ventilators were decidedly basic and not particularly attuned to the needs of the patients.

\footnotetext{
${ }^{248}$ Oral history interview with Cheryl.

${ }^{249}$ Oral history interview with Henny.

${ }^{250}$ Oral history interview with Cheryl.
} 
The ventilators had no alarms and they were very basic, they would just push air in. If the patients tried to take a breath it was very hard, if you wanted to slow your patient's breathing down you increased the sensitivity and made it harder for them to breath. All you were doing was making them work so hard they wouldn't bother and then you paralysed them so it was pretty awful ... the ventilators were not very patient friendly, and so you either paralysed them [the patient] or they were so unconscious that they didn't care, or they were overdoses so they were drugged anyway. ${ }^{251}$

Nursing the ventilated patient was demanding with routine cares being associated with managing their respiratory function.

We didn't understand the dangers of barotrauma and we used to hyperventilate our patients. When I first started working in ICU we didn't hyperventilate them constantly, we didn't run them on high volumes, but every two hours we hyperventilated them. You bagged them and suctioned them and bagged them whether they needed it or not, and then later on it came in that we ran them on high volumes so that we were increasing their minute volume but we were doing it with volume rather than rate ... and often unless you got someone fairly quickly off the ventilator it would be a really slow wean. I'm talking about over a few days and your options of oxygenation were quite limited as well. It was very hard to switch [the concentration of oxygen], it was 100\%, something in between, and $21 \%$. You didn't have a lot of choices, and we didn't understand about the effects of oxygen on adults. We did on children but not on adults. ${ }^{252}$

With these early ventilators the ability to individually titrate the ventilation to meet the patient's physiological needs was not possible and therefore each patient was ventilated in an identical fashion.

\footnotetext{
${ }^{251}$ Oral history interview with Maureen.

${ }^{252}$ Oral history interview with Maureen.
} 
You paralysed your patients because the ventilators were quite basic, they didn't sigh or change volume or anything ...when I first started working in ICU we ventilated patients on rates like $8 \times 1200 \mathrm{mls}$ because that was what they thought was best for the patient and that was what ventilators delivered ... then it all changed, but not for years after I started working in ICU, to lesser volumes and the higher rate. ${ }^{253}$

However, attempts were made to normalise patient physiology whilst they were on the ventilator.

We used to sigh patients too back in the olden days. ${ }^{254}$ We would give four sighs per hour and they would be set on 1000mls generally, because that's what you normally do, you sigh all of the time, we thought we were normalising them. ${ }^{255}$

The use of positive end expiratory pressure (PEEP) was unheard of at first and was not an inbuilt function of those initial ventilators.

We didn't have PEEP to start with. PEEP was just a tube in a bottle of water and you had to measure how far that tube went in as to what your PEEP was ... so if you had to do that [give the patient PEEP] it was another lot of tubing and whatnot that you had to get the tech to come and sort out and fix for you and make it work. ${ }^{256}$

Many of the oral history interviewees recalled the sophistication of these newer machines as technology improved. But not all of the new machines were favoured.

\footnotetext{
${ }^{253}$ Oral history interview with Henny.

${ }^{254}$ Sigh breaths during mechanical ventilation were commonly used in the 1970s but then became less common. The sigh breath is a deliberate increase in tidal volume for one or more breaths at regular intervals. D. Hess and R.M. Kacmarek, Essentials of Mechanical Ventilation, $2^{\text {nd }}$ ed., McGraw-Hill Companies Inc, United States of America, 1996, p.67.

${ }^{255}$ Oral history interview with Cheryl.

${ }^{256}$ Oral history interview with Henny.
} 
Ventilators changed over time, they got smaller, more compact and more patient friendly ... Once we got rid of the old Bird ventilators we got the Bennett's that had the bellows and the Bull and Bear ventilators. The Bull and Bear, that was a nice one because that was a synchronised IMV [intermittent mandatory ventilation] whereas the Bennett was an IMV that we attached an H-shaped thing to with humidified oxygen from the wall. The patient could breathe sideways or the ventilator could breathe for them. Of course it was not synchronised [with the patient's own breathing pattern]. The bellows had a little alarm on the top that had a pressure monitor attached to it. But the Bull and Bear, that was nice, it had little dials attached to it. They looked like little old fashioned robots, they were so funny but they were the ventilators at the time. Then the Enstrom came in, it had pressure support, that was such an amazing mode and it was such a good weaning mode ...when we used to wean we just reduced the rate of SIMV [synchronised intermittent mandatory ventilation] and once the patient was on an SIMV of four they got a T-piece trial. There was CPAP modes on the ventilators but boy did you have to breathe hard against the resistance. ${ }^{257}$

So important was the technology, by the end of their orientation period to ICU it was expected that nurses would be able to dismantle and reassemble the equipment routinely used.

Part of your orientation was to learn how to take a ventilator apart, clean it and put it back together again from scratch. Also an ambubag, take it to pieces and as a new employee you had to know how to put it back together again in working order ... a lot of the ventilator circuits are very simple now, the old Bird came apart into about 20 pieces, but I could do it blindfolded. ${ }^{258}$

${ }^{257}$ Oral history interview with Cheryl.

${ }^{258}$ Oral history interview with Cheryl. 


\section{Monitoring the Patient}

Much of the equipment commonly used in 2011 was previously only used on selected patients as determined by their degree of illness. Additionally some skills that were developed and considered routine during the early days of ICU nursing are now no longer used, for example inserting IV cannuale. Without the routine use of central venous lines, peripheral IVs were usual and inserted by the nursing staff. "Nurses could cannulate but in saying that sometimes critically ill patients aren't that easy". ${ }^{259}$

Arterial lines were not considered commonplace and central lines were only able to be used in patients in ICU.

We took blood gases. We did it ourselves with glass syringes and 21 gauge needles and a smidge of heparin in the bottom. We were very good at taking arterial blood gases from radial arteries, and in those days everyone who got septic with multi organ dysfunction got DIC [disseminated intravascular coagulation] and they were the patients who got arterial lines. Not every patient got an arterial line. They all got central lines, but they had to be replaced with peripheral lines before they left the unit. Central lines did not go to the ward; they were very special, as were intercostal drains, they were very special too. ${ }^{260}$

Cardiac monitoring was initially the predominant method of monitoring a patient's haemodynamic state, but the equipment was large and awkward. "When cardiac monitoring came in, the machines were so cumbersome". ${ }^{261}$ Types of monitoring specifically used in the assessment and monitoring of certain patient groups were more commonly seen in other departments and nurses would usually only be exposed to them whilst working in the other units during their course rotations.

Our main method of monitoring was purely heart. They arterially monitored in the cardiothoracic unit but we didn't ... very occasionally had an arterial line but

\footnotetext{
${ }^{259}$ Oral history interview with Maureen.

${ }^{260}$ Oral history interview with Cheryl.

${ }^{261}$ Oral history interview with Pauline.
} 
mostly they were in cardiothoracics, and the monitor... it would have been the height of this room and quite temperamental. Very temperature related and atmospheric related and had to be grounded. ${ }^{262}$

Henny also recalls the immense size of the equipment required to monitor arterial blood pressure.

You certainly didn't have anything like arterial lines, that was a huge machine that was, I imagine a good 5 foot high, and 2-3 foot wide as a box and it had a tiny little screen on it which was about 6-8 inches round which would have a couple of complexes going and if you wanted to do blood tests the tech from theatre had to be called, and he had to come up and do the blood tests because we weren't allowed to. And then it would get run to the lab on ice because we didn't have a machine. It was quite a big deal. ${ }^{263}$

As equipment such as arterial lines became more common in the 1980s the technology became smaller and more accessible, although perhaps still time consuming and not so user friendly.

The arterial transducers, you used to have to put a drop of water in the middle and then put the top on and screw it down. Any air bubbles would interfere with the transmission of your data, you had to be so careful. The actual sets for the transducers were so badly designed and you always got two rims of bubbles at the bottom ... you had to spike a bag of normal saline and fill the air trap up, the more you did it you got really good at it and you would hold them at a certain angle, you'd slowly tip them up and you'd get no air, you got so good at it but they took forever ... we used to have a technician at the time and if you had an arterial line that came out you had to take the transducer out [of the monitor], because if you had a straight line going across the screen he used to go berserk; he believed that

\footnotetext{
${ }^{262}$ Oral history interview with Maureen.

${ }^{263}$ Oral history interview with Henny.
} 
it damaged the monitors, he gave images of it causing some sort of heat thing causing the screen to explode or something. Of course it never happened. ${ }^{264}$

As ICUs became more established the equipment started to become more sophisticated.

We had no ETCO2 [end tidal $\mathrm{CO}_{2}$ monitoring], that was all done by blood gases. You had sats [oxygen saturation] and ECG [electrocardiograph] and CVP [central venous pressure] lines the old fashioned way, you know, with a spirit level, and the ICPs [intracranial pressure] we had which were once again with a spirit level type of thing, not many of them though ...slowly we had things like cardiac output introduced once we started having more cardiac throughput, up in the cardiac theatres especially they had that. ${ }^{265}$

\section{Daily Routines and Delivery of Patient Care}

Automatic blood pressure cuffs, electronic thermometers and infusion pumps for delivering fluids and medication were unheard of initially with the ICU nurse manually recording and monitoring everything.

There were patients with tracheotomies to be cleaned... And the different IVs and blood products, there were no infusion pumps of course, you had to calculate and count the drop rates. ${ }^{266}$

Without electronic infusion pumps nurses became adept at knowing exactly how many drops per minute equated to the required amount of medication being delivered per hour. Other medications were given as an IV bolus rather than infusion as there were no pumps to enable constant delivery of medications.

Everything was counting drips. Lignocaine infusions were the most common ones we used and that was because in those days if a patient had more than six PVCs [premature ventricular contractions] in a minute you treated it and started a

\footnotetext{
${ }^{264}$ Oral history interview with Cheryl.

${ }^{265}$ Oral history interview with Henny.

${ }^{266}$ Oral history interview with Marie.
} 
lignocaine infusion. You used to know how many drops you would have for each one. You gave IV morphine as a push. We used IV diazepam in those days, it was a push. We paralysed just about everybody and that was a push ... and this was mostly peripheral IVs. ${ }^{267}$

The daily work routine of the ICU nurse was centred on the delivery of excellent patient care and the doctors' ward rounds where the plan of care for the coming day would be decided. The importance of regular accurate recording of observations was paramount.

[After coming on duty] we got report and then you went straight to your patient, and you got on with the routine of the tasks that needed to be done, the recordings that needed to be done. The tremendous importance of accurate records, that was essential, and of course it was all by hand. The checking of everything, checking blood with others and drugs. There was a lot of cross checking and recording. ${ }^{268}$

Maureen recalls the daily routine.

Well we used to come on and you would do your assessment of the patient and observations and you would be looking to see when your drugs were due, so not dissimilar to now, this was on the day shift. You didn't always just have one patient it just depended on how it was, and then you often got your patient washed, so there was that and then you were working around the doctors' rounds and cares and weaning. ${ }^{269}$

ICU patients are vulnerable to infection and frequently immune-compromised. There were set guiding principles regarding patient care and surveillance for infection.

There were very strict routines. I do remember things like every morning we would do specimens from every orifice and every drain and we would take routine

\footnotetext{
${ }^{267}$ Oral history interview with Maureen.

${ }^{268}$ Oral history interview with Marie.

${ }^{269}$ Oral history interview with Maureen.
} 
everything. That changed over time but there were certain routine things we had to do. ${ }^{270}$

The checking of equipment and ensuring all of the essential items required to care for that patient, along with ensuring that the basic hygiene cares for each patient were completed prior to the doctors starting their rounds was considered good nursing.

You got handover, I always used to check everything, check that the bedside was set up as it should be and that you had everything. Then you would wash your patients, there were doctors' rounds, in between you would change all of your tubing, tapes, dressings, etc. If your patient was to be woken up you would then start to wean them. ${ }^{271}$

Night shifts were less busy and hence there was often more time for non-nursing activities such as catching up on the knitting.

Nights were a lot quieter, you still had the same routine, I can't remember turning them [the patients] strictly two hourly because you encouraged them to sleep but it could have been sort of three hourly or when they woke. I suppose because it wasn't so busy we actually got lots of knitting done. ${ }^{272}$

The night shift routine once the unit had moved to the CSB included the nurses sitting up in the central monitoring console, again doing their knitting.

On night duty that was where we all sat, we did not stay with the patients, only if they were really sick did they have full nursing protection at all times. ${ }^{273}$ We sat up there and we knitted, even some of the male nurses knitted. And we would monitor them all from up there; we could hear the ventilator going. Later on we got more alarms and we had to get up and go down to reset the alarm which was a

\footnotetext{
${ }^{270}$ Oral history interview with Maryanne.

${ }^{271}$ Oral history interview with Henny.

${ }^{272}$ Oral history interview with Henny.

${ }^{273}$ Full nursing protection refers to a nurse present at their bedside at all times.
} 
real nuisance. Someone in their wisdom decided that having an alarm that could be turned off up on the central console was a bad idea; you actually had to go and check your patient. $^{274}$

The practice of passing the time on night shifts with activities such as knitting was considered acceptable practice, provided the patients were not neglected.

\section{ICU Rituals}

Wiles and Daffurn describe how nursing care in the early days of ICU was governed by strict routines, familiar to most nurses of that era. Chest physiotherapy, oral and endotracheal suctioning, patient turns and oral hygiene were attended with religious monotony, usually every two hours. ${ }^{275}$ The recording of observations followed a similar pattern, mostly on the hour every hour. Burrell and Burrell suggested that the following routines be followed:

Temperature, pulse, respirations and blood pressure are to be taken routinely with the frequency depending on the patient's condition and the doctor's orders. A fluid intake and output record kept with the 24 hour total recorded by the night nurse at 7am with all irrigating solutions used being subtracted from the total amount of drainage in order to give the true drainage total. ${ }^{276}$

The experience in Wellington ICU was similar to these international recommendations with references made by interviewees referring to the routines and rituals of caring for the ICU patient.

We suctioned religiously every two hours. We didn't just suction the patient if they needed it, it was religious every two hours and at least once or twice they would get a good dose of full percussion physiotherapy to make sure that we moved that sputum. Two hourly turns, two hourly mouth cares, two hourly eye

\footnotetext{
${ }^{274}$ Oral history interview with Cheryl.

${ }^{275}$ Wiles and Daffurn, Bird and Bear, p. 249.

${ }^{276}$ Burrell and Burrell, Intensive Nursing, p. 258.
} 
cares, two hourly suctioning and if you had a neurosurgical patient you did half hourly neuro obs. ${ }^{277}$

Attending to unconscious patients' basic hygiene needs was a daily part of the ICU routine; making sure that this was done and the patients looked presentable for the doctors' ward round would appear to have been essential.

You were considered a failure if you hadn't washed your patient by nine o'clock. When you first came on you changed your ETT [endotracheal tube] tapes, you changed your nasogastric tube tapes. Your patient was absolutely beautiful by the time we had the ward round. All of your lines got changed, after lunch if they had to be changed that was when you did it. The lines all got changed every 24 hours because our patients were immunocompromised. ${ }^{278}$

Some rituals were not centred on patient care but more about the needs of the nurses and followed social convention of the time.

When I first started in ICU around three quarters of the staff smoked. You were allowed to smoke in the hospital grounds and everyone smoked in the tearoom. If you were really good you could get in three in a half hour lunch break. You'd have your first one preparing your lunch and cup of coffee, eat, have another smoke to relax with your cup of coffee and one to finish off. And on the window sill everyone kept their smokes with their lighters on top, wall to wall cigarettes and lighters. The room would be thick with smoke, it was gross. ${ }^{279}$

\section{Cleaning and Maintenance}

With no auxiliary staff, the nurses were expected to maintain the general tidiness of the unit, and ensure that all equipment was clean and in working order. The weekend routine was one of cleaning and completing checklists of tasks done.

\footnotetext{
${ }^{277}$ Oral history interview with Cheryl.

${ }^{278}$ Oral history interview with Cheryl.

${ }^{279}$ Oral history interview with Cheryl.
} 
We had cleaning routines ... all of the nurses from Friday to Monday morning would have to go through and clean the unit. You would have to up end all of the trolleys and clean all of the wheels and clean the trolleys with hot soapy water. All of the drugs were taken out of the shelves and repacked and checked for expiry dates and all of the shelves were wiped. The whole cleaning area was cleaned from top to toe... the cleaning routine started about Friday afternoon when you emptied out a bit and it was everybody's job. There was a list and you had to tick it off as it was completed. It was a very clean unit and everybody knew where everything was. $^{280}$

Ensuring that the unit, along with the patients, was presentable for each coming day was a priority for the nurses. “At six o'clock every morning we would replace everything and clean up the entire unit. Everyone knew they had to do it and everyone just got on with the job". ${ }^{281}$ In addition to this, ensuring all of the supplies and equipment necessary for the delivery of good patient care were readily available was the responsibility of each and every nurse rather than falling to one or two people. "At the end of every duty someone would restock all of the syringes, someone would empty the linen skips, all of that sort of stuff always got done, we had no nurse aide to do it". ${ }^{282}$

All of the equipment used in patient care required thorough cleaning; the majority of it by the nursing staff in the ICU or in the case of some select items, being packaged up and sent to the central sterile production centre within the hospital. The nursing staff became very skilled at doing this quickly.

We often didn't have enough equipment so we had to be very skilled in doing a quick turnaround so when one patient went we cleaned it up and had it ready for the next one. There was a cleaning regime, a process that wasn't quick. We did have a nurse aide that did it for us but she just worked during the daytime and had limited

\footnotetext{
${ }^{280}$ Oral history interview with Henny.

${ }^{281}$ Oral history interview with Cheryl.

${ }^{282}$ Excerpt from oral history interview with Cheryl.
} 
hours so the nurses became quite skilled and that was just part of their orientation and we just didn't give it very much thought, it was just very much a fact of life and we just had to get on with it. ${ }^{283}$

Prior to the introduction of single use and disposable items, recycling and reuse was commonplace. Reuse involved the nurses having to clean and sterilise the various reusable pieces of equipment.

One of my worst memories of equipment was the recycling, and it wasn't really until the late 1990s that the single use policy came in... All of the metal Yankers [suction catheters], rubber suction tubing, and rubber ET [endotracheal tubes] tubes, everything had to be cleaned and sterilised .... Hudson masks, they used to be soaked in HTH [cleaning solution]. We used to recycle all of that stuff ... All of the ventilator inners, all of that sort of stuff got soaked in either cydex or HTH, nothing ever got sent away to be autoclaved. The metal Yankers were just ghastly and they were very hard to clean. The plastic ones, we used to recycle them a lot initially, they were easier to clean, you just stuck the multi holed end up the tap... yes that was just purely hideous that part of the job. ${ }^{284}$

After the move to the new ICU in the CSB a nurse aide/cleaning person was employed. There was a cleaning room located between two of the single rooms which was where the equipment was cleaned either by her or the staff.

Between cubicles one and two was Mrs D's [the nurse aide] room. She always wore theatre scrubs, she was the only person who ever wore a theatre uniform and she probably had the worst job in the world. On the floor in that room was a big bicarb bucket. You used to use two scoops per 25 litre bucket and it was changed every second day. On the weekend, either Saturday or Sunday someone else got to do her job. All of the suction tubing, Yankers and three-way things got put in

\footnotetext{
${ }^{283}$ Oral history interview with Maryanne.

${ }^{284}$ Oral history interview with Cheryl.
} 
the bicarb bucket. Mrs D, her job was doing all of that good stuff, she loved her job and she was just great, she was one of the team. ${ }^{285}$

\section{Conclusion}

As technology and patient monitoring equipment became more sophisticated and user friendly over time the ICU nurses' role changed. Equipment became smaller and easier to use. However, there became more of it to understand and manage. The design and development of the new ICU was planned to accommodate this increased volume of equipment and with the increasingly complex needs of the ICU patient in mind.

Ventilation evolved from a simple air in - air out mode at a prescribed rate and volume, to a more patient friendly mode with the ventilator being able to synchronise its delivered breaths in accord with any respiratory effort generated by the patient. In turn this greater flexibility on the part of the technology led to a change in practice and delivery of patient care. No longer was the patient required to be paralysed in order to facilitate ventilation likely resulting in shorter ventilation times and more efficient weaning of the patient from the ventilator.

Much of the day's routine was task orientated and determined by routines and rituals that necessitated the patient looking 'spick and span' for the doctors' ward round, with the remainder of the day spent implementing the plan of care determined by him and carrying out tasks as per a strict two hourly prescription of care. Some of these are still recommended practice today. However, now there is more scope and flexibility for the nurse to determine the schedule and delivery of routine cares. Prior to the introduction of single use disposable items in healthcare all items utilised in patient care required cleaning. Generally this was a task undertaken by the nursing staff, with little knowledge or understanding of infection control, health and safety issues, and cross contamination between patients.

\footnotetext{
${ }^{285}$ Oral history interview with Cheryl.
} 
How nurses acquired and learnt the knowledge and skills needed to look after the ICU patient and utilise the technology discussed in this chapter will be considered in the following chapter on the development of formal education and the ICU course. 


\section{Chapter Seven - Formal and Informal Education}

\section{Introduction}

In the first few years following the development of intensive care internationally most units did not have formal teaching programmes for either doctors or nurses. For most staff the necessary skills and knowledge required to care for their patient were learned on the job by trial and error, and from their peers and the observation of their patients' responses to care and interventions. ${ }^{286}$ Most nurses were more than likely unaware of the impact that their lack of knowledge or skills could potentially have on the patient. This is succinctly described by an Australian nurse educator of his days as a student nurse in ICU.

I had learnt some basic facts about disease processes, yet at this point had little insight into the clinical imperatives of the many different diagnoses I encountered. I was sent to the intensive care unit, to an environment for which I was both illequipped and ill-prepared. For the next nine weeks I spent an average of four shifts a week delivering care to patients in a blur of emotions, oscillating between simple fear and abject terror. This reflection has ignited thoughts of no orientation, no support, no knowledge, no skills, of caring for patients connected to machines which I knew nothing about ... More importantly I was learning the rule 'never turn your back on the patient' ... I didn't really understand the inflexibility that underpinned this rule, probably because I didn't really have any insight into what I was doing. It is only with hindsight that I see that the absence of any alarms on the Bird ventilator was the major contributor. ${ }^{287}$

\footnotetext{
${ }^{286}$ Wiles and Daffurn, Bird and Bear, p.141.

287 Excerpt from an interview with Heron as cited in Wiles and Daffurn, Bird and Bear, p.201 on his recollections of his days as a student nurse in ICU in 1978.
} 
Wiles and Daffurn describe how early ICU nurses sought knowledge from protocol and procedure manuals if available, the unit library, manufacturers' guidelines and general nursing textbooks. Most importantly they emphasise that there were very few intensive care specific textbooks written for nurses in the 1960s and 1970s. After 1975 when nursing and medical conferences in intensive care were introduced in Australia, these were also seen as an important resource for both nursing and medical education and the sharing of knowledge and experiences. ${ }^{288}$ Trubuhovich and Judson also describe these conferences as a time for networking and contact amongst those with similar philosophies. ${ }^{289}$ The first Australasian meeting on intensive care was held in Adelaide, Australia in May 1976 and was held conjointly by ANZICS and the Critical Care Nurses Association. ${ }^{290}$ The first New Zealand symposium was held over two days in Auckland in 1978 and was a joint medical and nursing conference with the main nursing themes being shock, cross infection and intensive care organisation, education and work stress. ${ }^{291}$

This chapter will describe the formal education of nurses working in Wellington Hospital's ICU throughout the timeframe of this research. With the development of the Wellington Hospital ICU nursing course (the first to be developed in New Zealand) nurses were able to access a course of learning that focussed specifically on the care of those critically ill patients for whom they were responsible. The development of the course and its content is outlined. In addition, a proposed ongoing education programme for those nurses working in ICU is described.

\section{The ICU Course}

In 1967 the Intensive Care Subcommittee recognised the need for an intensive care nursing course at Wellington Hospital. This initiative was supported by the Medical Superintendent-in-Chief, the Matron-in-Chief and the Wellington Hospital Nursing

\footnotetext{
${ }^{288}$ Wiles and Daffurn, Bird and Bear, p.205.

${ }^{289}$ Trubuhovich and Judson, Intensive Care in New Zealand, p.7.

290 Trubuhovich and Judson, Intensive Care in New Zealand, p.7.

${ }^{291}$ Trubuhovich and Judson, Intensive Care in New Zealand, p.11
} 
School and approved by the Nurses and Midwives Board. ${ }^{292}$ The first course was tutored by Pauline, a nurse who had previously worked in the ICU.

I went over to the post graduate ICU course at St Vincent's in Melbourne. ${ }^{293}$ It was the only one in Australasia. I wanted something post grad and that was the only one offering really, so a couple of us went over and did that. I went over to do the course for 6 months and stayed 18 months and stayed on in the unit as a tutor over there. $^{294}$

When Pauline returned to Wellington in 1968, she was asked to set up and tutor the Wellington course.

I came back here and the medical people concerned who were using the unit at that stage, Cam Barrett was in charge, and Peter Leslie [cardiologist], Bruce Morrison [renal physician], all the guys were very keen for me to start up the course and so it was arranged with Betty Cook [Hospital Matron] that we would ... it was really through their enthusiasm that the course started because they gave me all of their time to do the lecturing, a day a week or something like that. It was quite good; we started up in with the physios as well. Leslie Askew [physiotherapist] and myself, we started up this course. Their course was three months and our course was six months. The first three months most of it was core, so the medical staff would lecture for both of us and of course there was a lot of respiratory and cardiac work in the core programme, and of course the physios were very involved in the ICU in those days so we were very good friends and so it worked out very well. At that stage we took people from all over NZ. ${ }^{295}$

\footnotetext{
${ }^{292}$ Wellington Hospital Archive, WOW00201, Wellington Hospital Post Basic Intensive Care Nursing Course, no date.

${ }^{293}$ This post-basic course in intensive care and recovery room nursing is believed to be the first of its kind in Australia and was established in 1962. Initially starting out as a six month course within a very short period of time this was extended to 12 months. Wiles and Daffurn, Bird and Bear, p.275.

${ }^{294}$ Oral history interview with Pauline.

${ }^{295}$ Oral history interview with Pauline.
} 
On 27 May 1968 the inaugural six month Intensive Care Post-Basic Nursing Course commenced. The Evening Post described the course as 'Ground Breaking' given that it was the first time that a course of this type had been offered in New Zealand. ${ }^{296}$ The article outlined how eight nurses from several parts of the country took part with the ultimate aim of the course being to provide an adequate number of nurses trained in the more technical and specialised procedures used in intensive care work, leading to better integration of patient care. According to the Wellington Hospital Matron-in-Chief, the course was to be a practical one and was intended to provide nursing experience in all fields of intensive nursing care: intensive care, neurosurgical, coronary care, cardiothoracic and renal nursing. ${ }^{297}$ It was recommended that applicants to the course should be staff nurses of at least six to twelve months standing and it was not necessary for the applicant to have had previous experience in any intensive care unit. Senior medical staff gave lectures in their own specialties and ward sisters instructed students in the principles and nursing technique involving their own unit. An examination was held at the end of each course in May and November of each year and a Diploma was issued to successful candidates. ${ }^{298}$

The practice of medical staff contributing to the lectures and content of the course was not unique to the Wellington Hospital experience. Indeed, Wiles and Daffurn ${ }^{299}$ describe how throughout Australia medical clinicians were significant not only in the teaching of nurses but were also instrumental in the introduction of post-registration intensive care nursing courses. Wiles and Daffurn acknowledge that this support and dedication had an immense impact on, and value to, the specialty and the profession of nursing. It is important to acknowledge this contribution. Not only were these clinicians often medical

\footnotetext{
${ }^{296}$ Nursing Course Breaks New Ground in New Zealand, Evening Post, page number unknown, 27 May 1968. Cutting contained in collection of papers held by the ICU medical director Wellington ICU.

${ }^{297}$ Wellington Hospital Archive, WOW00201, Wellington Hospital Advertisement for the first Intensive Care Post Certification Nursing Course, issued from the Matron-in-Chief on the 25 March 1968.

${ }^{298}$ Wellington Hospital Archive, WOW00201, Wellington Hospital Post Basic Intensive Care Nursing Course, no date.

${ }^{299}$ Wiles and Daffurn, Bird and Bear, p. 318.
} 
directors of the various units: they were also working around the clock providing patient care, and supervising less experienced medical staff. Yet despite this they were also able to dedicate time to the lecturing and assessment of nurses participating in these courses. $^{300}$

In a 1973 report on the Intensive Care Nursing course it was noted that smaller hospitals and those without ICU nursing courses continued to provide applicants for the Wellington Hospital course with their patients and other staff benefitting from the increased knowledge and skill acquisition upon the return of each nurse once they had completed their course. ${ }^{301}$ By the commencement of the $11^{\text {th }}$ course in the middle of 1973,83 nurses had completed the course with a further 10 enrolled in the $11^{\text {th }}$ intake. Of these, 27 nurses were from Wellington ICU, 50 came from hospitals within New Zealand and three came from Australia. Of the first 83 nurses to undertake the course, 42 remained at Wellington Hospital on completion of their course. ${ }^{302}$

Maureen shared her experiences whilst on the ICU course.

I actually did the course after about 6 months ... in those days my core area was ICU but we had to go to neonates, renal, coronary care and cardiothoracics, so we spent time in each of those areas and it was a real eye opener. It very much put in place the understanding behind what we were doing. It kind of helped you think and make sense of the process. It changed a huge amount my perception of how I nursed in ICU.... It was a combination of learning, there was definitely some revision, we did the physiology and possibly went more into lab results than I had before. We did a bit on physical examination which was quite new I think because we didn't really do that as student nurses. We learnt a lot about the

\footnotetext{
${ }^{300}$ Wiles and Daffurn, Bird and Bear, p. 318.

${ }^{301}$ Wellington Hospital Archive, WOW00210, Wellington Hospital Medical Staff Executive - Wellington Hospital Post-Basic Intensive Care Nursing Course: The case for continuing the course in its present form and Annex A: Wellington Hospital Post-Basic Intensive Care Nursing Course, 1973.

${ }^{302}$ Wellington Hospital Archive, WOW00201, Wellington Hospital Medical Staff Executive - Wellington Hospital Post-Basic Intensive Care Nursing Course: The case for continuing the course in its present form and Annex A: Wellington Hospital Post-Basic Intensive Care Nursing Course, 1973.
} 
equipment, but we learnt a lot going to the various units like the dialysis unit... and we had some of the physicians would come and would talk about the specialties. $^{303}$

Doing the ICU course enabled nurses to acquire a greater appreciation of the workload of other related areas in the rest of the hospital.

I did it was about a couple of years after I started, it must have been about 78 or 79. It was quite different, it was 6 months and we did four different areas, so you worked in cardiothoracic because it was separate and then you did CCU and worked in the unit there, you did renal so you worked in haemodialysis and NICU [neonatal ICU] we worked there. It was quite short times. The course would have been great if there was a longer period for you to get used to each area and not be so quick. I think it was great to go to all of those areas because you got to appreciate those areas' busy times, because we can say that we were busy and why can't dialysis come and dialyse our patient, but you could understand that because they run quite a tight ship there that they don't actually have the staff to just drop everything and come across. ${ }^{304}$

\section{Course Content}

The course was of six months' duration and consisted of 180 theoretical hours with two intakes per year in January and July. It comprised an initial week long orientation of five 8-hour days consisting of introductory lectures, followed by one 6-hour lecture day per week for the remainder of the course. The course was clinically focused giving the student experience in all fields of intensive care nursing and was designed to give the student basic principles of care and clinical practice with the care of the intensive care

\footnotetext{
303 Oral history interview with Maureen.

${ }^{304}$ Oral history interview with Henny.
} 
patient emphasised throughout. Requirements for entry into the course were at least 12 months' general staff nursing experience. ${ }^{305}$

Lectures were discipline based and were given by medical staff, allied health and nursing staff. Lecture topics were systems-based and covered the anatomy, physiology and nursing care of patients experiencing a variety of conditions. ${ }^{306}$ A full list of lecture topics is located in Appendix F. Clinical experience was to be completed in the four intensive nursing care areas: General ICU, CCU, Cardiothoracic Unit and the Renal Unit. Each clinical rotation was of six weeks' duration, consisting of four 8-hour shifts per week. In addition one week was spent in the outpatient clinics and one week allocated for revision prior to the final exam. ${ }^{307}$ This rotation and range of experience indicates that intensive care nursing at this time was seen as broader than just that provided in the ICU setting.

The aim of the course was to prepare nurses to undertake positions of responsibility in the various participating units: ICU, renal unit, CCU and the cardiothoracic unit. ${ }^{308}$ The course was designed to assist the nurse to develop a sense of responsibility for a safe environment for the patient by broadening their understanding of the emotional and physical factors associated with intensive care nursing. The course objectives were to assist the nurse to: $:^{309}$

- Build on his/her existing knowledge and to improve his/her skills in relation to intensive care nursing

\footnotetext{
${ }^{305}$ Wellington Hospital Archive, WOW00201, Wellington Hospital Post Basic Intensive Care Nursing Course, no date.

${ }^{306}$ Wellington Hospital Archive, WOW00201, ICU Course Lecture Topics: Medical lectures, Allied Health lectures, Lectures given by nursing staff, no date.

307 Wellington Hospital Archive, WOW00201, Wellington Hospital Post Basic Intensive Care Nursing Course, no date.

${ }^{308}$ Wellington Hospital Archive, WOW00201, Wellington Hospital Post Basic Intensive Care Nursing Course, no date.

${ }^{309}$ Wellington Hospital Archive, WOW00201, Wellington Hospital Post Basic Intensive Care Nursing Course, no date.
} 
- Increase his/her skills in relation to his/her responsibility in clinical teaching and unit administration

- Develop a greater understanding of the legal aspects of intensive care nursing

- Learn to operate and understand the technical equipment used in abnormal physiological conditions.

Also quoted in the course documentation, was the theoretical evaluation of each student throughout the course: ${ }^{310}$

- Test Papers: A one hour test paper monthly consisting of any aspect of theory presented to the students up until that date and marked out of a possible 100 marks. On the lecture day of the week following the test, one hour was spent going over the correct answers.

- Case Presentation: Each student was required to present two 30 minute patient case studies. This was intended as a valuable learning experience for the student to research in depth two patients, their past medical history and their present illness, its investigations and management and present it to the class in a formal way utilising x-rays, diagrams etc. Each presentation was assessed by the tutor and the mark given discussed with the student at a later date.

- Written Assignment: Each student was required to present a written assignment on a topic of their choice pertaining to intensive care nursing, to be completed five weeks before the end of the course. These assignments were evaluated by the tutor and circulated to nurses and doctors requesting comments and a grading. An overall grading was then given.

- Examination: One three hour written paper with questions submitted by medical and nursing lecturers. The questions were reviewed by the intensive care course committee four weeks prior to the date of the examination as to suitability, clarity, phrasing, and mark allocation.

- Clinical Evaluation: This was the on-going assessment of each student's performance in the clinical setting of each unit as to their ability to apply theory

\footnotetext{
310 Wellington Hospital Archive, WOW00201, Wellington Hospital Post Basic Intensive Care Nursing Course, no date.
} 
to practice whilst providing a high standard of nursing care on a one to one basis. In undertaking this evaluation the tutor sought the advice and assistance of the unit staff in assessing the students. Should a student fail to meet the required clinical standard they would be advised that they were not eligible to sit the examination. A formal written assessment was discussed with each student during the last week of their time in each unit. Each clinical evaluation was marked out of 100 and an average of this clinical assessment mark entered into their final record.

The results were circulated to students as soon as the final records were completed. Each student received a letter from the Director of Nursing Services informing them of the results of the examination together with a final record sheet stating the number of theoretical and clinical experience hours they had completed. The course work included learning in ways that were new and different to the students.

We had to do assignments, we had an exam obviously and we had tests in between ... We did one assignment that was interviewing or a research type thing. So that was a new introduction because we didn't do research in those days but this was a very simple form of research. And I think there was something else we had to do. We were given choices of things and one of them she suggested we do which I thought was a bit different was that we talk to student nurses about the effect on their social life which I thought was quite fun. I think it was just more about talking to people getting information ... and we had to present a case study. $^{311}$

The content of the lectures was delivered from both a nursing and a medical perspective with involvement from the medical staff in presenting information.

The lectures were primarily from the medical staff. About once a month we had a week in the classroom and we got lots and lots of lectures and the nurses did the nursing talks and the doctors did all of the subject matter, ventilation, all of the

${ }^{311}$ Oral history interview with Maureen. 
diseases. All of the surgeons, all of the physicians, all of the specialists came in to lecture. It was a damn good course you learnt everything, it was really good. ${ }^{312}$

The final exam at the end of the course consisted of a number of long answer questions with the content relating to the four clinical areas that the course students had worked in over the six months. The nurses were expected to have a comprehensive understanding of the management and assessment of a variety of patients and clinical situations. Examples of some of the questions set in the final exam in 1976 are referred to in Table 8. ${ }^{313}$ Cheryl referred to this exam.

At the end of it there was a three hour exam set by the doctors ... in mine the nursing management of drug overdose, a huge subject, the nursing management of trauma, a huge subject ... and the doctors marked it as well. But you knew it all. We had ECG [electrocardiograph] rhythms we had to interpret, blood gases we had to interpret, it was all good management stuff. The management of overdose or trauma is basic ICU stuff, all of the questions they wanted ABC [airway, breathing, circulation]. Yes the questions were set by doctors ... but the doctors knew that we could answer the questions, they knew what we had learnt on the course, and they knew what we knew ... it was a very very good course, and yes you studied like mad for that end of year exam because it was a biggie. You had to do so many skill assessments, you had to know how to do a 12 lead ECG, how to manage underwater seal drain, and take apart a ventilator and put it back together again. 314

\footnotetext{
${ }^{312}$ Oral history interview with Cheryl.

313 Wellington Hospital Archive, WOW00201, Memorandum to Post Graduate Intensive Care Course Committee Members for the review of examination questions for inclusion in the students final examination to be held in December 1976.

${ }^{314}$ Oral history interview with Cheryl.
} 


\section{Table 8: Examples of Final Exam Questions: ICU Course 1976}

1. What is the commonest organism responsible for wound infections in patients in an intensive care unit? [1 mark]

a) Give three important gram negative organisms which are among the more common causes of infection in an intensive care unit [3 marks]

b) In each of the following complications occurring in a patient after cardiopulmonary bypass state an important source of organisms:

i. $\quad$ septicaemia: [3 marks]

ii. broncho-pulmonary infection: [2 marks]

2. A patient who is being artificially ventilated starts to fight the respirator. What course of action would you take? [10 marks]

Discuss sputum retention associated with use of an artificial airway under the following headings: [10 marks]

i. prevention

ii. complications

3. How would you define a subarachnoid haemorrhage? [1 mark]

What is the chief symptom of a subarachnoid haemorrhage? [1 mark]

How is this diagnosis proven? [1 mark]

What methods can be used to differentiate a 'bloody tap' from a blood-stained C.S.F. due to a subarachnoid haemorrhage? [2 marks]

List a number of possible causes of subarachnoid haemorrhage [5 marks]

What method of investigation would be used in the first instance to try and differentiate the possible causes of subarachnoid haemorrhage? [1 mark]

What factors would be taken into account in considering whether a patient with a subarachnoid haemorrhage due to a berry aneurysm should have an operation? [6 marks] 
Over the years the course content developed to meet the changing learning needs of the nurses.

We moved away from it being a very much medical dominated sort of activity to it being much more nurse driven and that was great. The medical staff were very good at saying this is what I want them to know in order to look after our patients. It was very much them looking after their own patient workload and so on and so forth. What we actually did at that time is that we acknowledged that for nurses to work well in ICU where people were oftentimes hugely compromised from a physiological perspective. We recognised that they needed to have a really good understanding of sciences so we started getting into fluid balance and acid base balance and physiology; whereas previously the medical staff had been very much pathology driven and the management of their pathology. I think that there was quite a shift at that time, to really hone in on their understanding of what normal physiology was and therefore understanding when things were going off the boil and how they could actually do something about that so there was a lot of that going on. ${ }^{315}$

The content evolved to have more of a nursing focus and also began to examine the evidence behind common nursing interventions in ICU.

I think that the other thing that was really good was that we became much more nursing focused instead of just having that medical domination. We were starting to see nurses take a much bigger interest in things like the effects of ICU on the patient. We were starting to see things like the effects of sensory overload. We were starting to see them looking at things like interventions and nursing interventions and how they could improve those and so on and so forth. And although we didn't focus on evidence based practice because we didn't even know about that then and we didn't have any stuff on information literacy either, we even at that stage were really looking though in their assignments at starting to integrate literature so that we were really asking them to really look at what they

${ }^{315}$ Oral history interview with Maryanne. 
were doing and we were really wanting them to look out there and see what the literature was saying was the best thing to do. So in some respects I think that we were knocking on the door of evidence based practice but it wasn't you know, the big paradigm shift hadn't happened at that stage and it didn't have a name. ${ }^{316}$

Maryanne also mentions the requirements set down by ANZICS that a required number of nurses working in ICU had to have undertaken some form of intensive care training course. $^{317}$

We had a huge commitment to getting as many people through the course as possible because we had ANZICS in the background and they had criteria as to how many people should have done some ICU courses and we met that criteria very generously all of the time ... we had people from outside as well who would come in and stay at the Nurses' Home for that six months and that was great because we did have cross fertilisation as well with other areas which was really positive I think. While I was doing the course and once I finished tutoring the course we still had girls going into the four different units rather than just the one unit, and I can't but help think that that was a fantastic thing to do. You know, it gave you a breadth of understanding and it just gave you a real good exposure to different specialties. ${ }^{318}$

\footnotetext{
${ }^{316}$ Oral history interview with Maryanne.

${ }^{317}$ I have been unable to find any requirements set down prior to 1994 regarding numbers of qualified or course certified ICU nurses. The College of Intensive Care Medicine of Australia and New Zealand: Minimum Standards for Intensive Care Units first published guidelines in regards to nursing staff in 1994, stating that "all nurses involved in direct patient care should be registered nurses and the nurse in charge and the majority of nursing staff in each unit should have a post registration qualification in intensive care." The Australian College of Critical Care Nurses (ACCCN) ICU Staffing Position Statement (2003) cites the Australian Council on Healthcare Standards (1997) as stating that "ICUs must have a minimum of 50\% qualified Critical Care Nurses." ACCCN supports this as a minimum standard with the optimum qualified Critical Care Nurse ratio being $75 \%$.

${ }^{318}$ Oral history interview with Maryanne.
} 
On completion of each course an evaluation questionnaire was sent out to students asking them their thoughts and opinions on such matters as: ${ }^{319}$ what they expected to get out of the course, were their expectations met, did they find the theory difficult, did the present course programme and theoretical instruction meet the needs of the course, did they find the allocation of time to the four unit areas suitably divided, did they find the physical workload too demanding, and were there any unexpected stress factors associated with intensive care nursing. Students were also asked for suggestions or comments on the course as a whole and on the individual units. The information gathered from this questionnaire was collated and a summary of the answers and comments was circulated to the intensive care course committee. ${ }^{320}$ In addition there was an evaluation of the course by the course tutors summarising the results of the final examination and the number of successful candidates, the tutors' opinions of the theoretical standard of the students and the standards of patient care demonstrated by the student group. The employment status of each student on completion of the course was also included with the number of students retained on staff in each of the clinical areas as well as those students who left the hospital. An appraisal of the course's success and deficiencies as well as the support and cooperation of the various clinical areas were also included. ${ }^{321}$

\section{On-going Education}

By the early 1970s the need for clinical teaching and formal orientation programmes was beginning to be recognised and clinical teaching in the intensive care unit was deemed to be both important and necessary. During those early years of intensive care nursing in Wellington there was no nurse educator (only the course tutor) so the knowledge and experience gained by novice ICU nurses from working alongside an experienced ICU nurse was pivotal to their learning and development. Even with the introduction of the

\footnotetext{
319 Wellington Hospital Archive, WOW00201, Post basic nursing course evaluation sheet, July 1974, February 1975, December 1977.

${ }^{320}$ Circulation was referred to as the senior medical staff of the ICU, renal unit, coronary care unit and cardiothoracic unit, also the director of nursing services and the charge nurses of the four unit areas.

321 Wellington Hospital Archive, WOW00201, Post basic nursing course evaluation sheet, July 1974, February 1975, December 1977.
} 
ICU course the course tutor's time was spent on the planning and running of each course and the clinical support of the students.

This need for ongoing education was recognised by the then ICU course tutor and was mentioned in an article on clinical teaching written by her and published in Kai Tiaki. ${ }^{322}$

As nurses we are assuming tasks which our basic training has not prepared us for and we must therefore be continually re-evaluating our educational needs... nurses in charge of units have very definite responsibilities in meeting the ongoing needs of their staff. If you are not meeting these needs then you do your staff a grave injustice and put your patients at grave risk. Every nurse has an obligation to share her knowledge, and you must develop this attitude to expand the potential of your staff... Planning is the key to the success of this ... The constraints I am often confronted with are people's fears that they may not have all of the answers. No one can know everything. If you have enough knowledge about enough things you will find the necessity to say 'I don't know' neither damages you ego nor your image in the eyes of those you are teaching.

In 1973 there was a proposal put forward by the Health Department that courses such as the post-basic intensive care nursing course be discontinued and replaced by a less formal type of in-service education catering for different grades of nursing. ${ }^{323}$ In a meeting between the Intensive Care Committee and the hospital matron it was agreed that alternative systems of in-service training be tried as suggested by the Department of Health, but that the six-month Intensive Care Nursing course be continued until the relative value of the new system could be properly assessed. ${ }^{324}$ The subsequent outline of

\footnotetext{
${ }^{322}$ Collins, 'Methods of clinical teaching', p.17.

${ }^{323}$ Referred to in Hospital correspondence as 'circular letter number Hospital 1973/136 Department of Health dated July 1973' however no copy of this document was able to be obtained or held in the Hospital archive records accessed.

${ }^{324}$ Wellington Hospital Archive, WOW00201, Letter from the Members of the Intensive Care Committee to the Chairman of Medical Staff at Wellington Hospital , Wellington Hospital Postgraduate Nursing Courses, 9 October 1973.
} 
Intensive Care education is described below. However I was unable to find any evidence as to whether this teaching programme was implemented.

A proposed programme of intensive care education was put together by the intensive care nursing course tutor consisting of four levels of education aimed at initially preparing nurses to nurse in units, moving on to on-going education and familiarisation to the area and finally preparing nurses to work in senior or charge positions. A broad outline of the proposed programme content was: ${ }^{325}$

Programme 1: A basic orientation programme of short duration and principally theoretical

Programme 2: Extension of programme 1. Theory and clinical instruction with some participation in clinical work

Programme 3: Mainly theoretical with current trends in patient management presented and other clinical aspects covered with an emphasis on total patient care.

Programme 4: Management of staffing and staff development and nursing care, interpersonal relations and the role of ICU in the hospital and the community. Again an emphasis on total patient care would be provided. Possibly also a lecture from the doctors of each area related to the function of the unit as they see it and aspects of patient care.

However, it was the belief of the course tutor that such a programme of education would not fit alongside the 6 month intensive care nursing course as each of the above programmes would have to extend over several weeks. A case for continuing the intensive care course in its present form was put forward by the Intensive Care Subcommittee to the Wellington Hospital medical staff executive for retaining the post-basic course. This was in turn forwarded (by the medical staff executive) to the Director General of Health, Department of Health, seeking his support to retain the course to meet

\footnotetext{
${ }^{325}$ Wellington Hospital Archive, WOW00201, PA/AB, Wellington Hospital Department of Nursing Education: Intensive Care Education, 28 August 1973.
} 
specific needs in post-basic nursing education. ${ }^{326}$ Whilst it was acknowledged by the committee that nursing education was undergoing considerable change (polytechnic training of nurses had just commenced) it was their belief that the proposed four level programme of education could not replace the more formal 6-month course presently run. In support of this argument it was considered that the current course provided nurses not yet committed to a specific sphere in intensive care an introduction to the broad field available in Wellington Hospital. ${ }^{327}$

Several concerns were raised in opposition to this change in education structure. Firstly, smaller hospitals continued to provide applicants for the course in the expectation of fulfilling their own needs by the return of trained staff once they had completed the course. There was concern that the proposed change to shortened intensive programmes would not fulfil the needs of these smaller hospitals. Additionally the longer course played a role in retention of nurses from within Wellington Hospital. As the course was certificated it was also deemed to have some worth particularly when nurses were applying for overseas posts, something that an informal non-certificated in-service education programme would not offer. Finally the six-month post-basic course was considered to put no undue strain on the relatively limited numbers of nursing, technical and medical staff involved in tutoring and lecturing. However, repeated short programmes throughout the year would put a considerable load onto these limited resources. $^{328}$

At a 1976 meeting of the Intensive Care Sub-Committee the serious lack of in-service training for unit nursing staff was once again discussed and it was recommended that urgent measures should be taken to rectify this problem. Providing in-service education

\footnotetext{
${ }^{326}$ Wellington Hospital Archive, WOW00201, letter from the Chairman of the Medical Staff Executive to the Director General of Health, Department of Health, 23 October 1973.

${ }^{327}$ As mentioned earlier it was not necessary for nurses applying for the ICU course to be specifically employed in any of the intensive nursing areas of the hospital.

${ }^{328}$ Wellington Hospital Archive, WOW00201, Memorandum by Wellington Hospital Medical Staff Executive on the case for Continuing the Post Basic Intensive Care Nursing Course in its present form, no date.
} 
was considered to be an effective way of breaking the current vicious cycle of staff shortages and resignations and could only improve patient care. ${ }^{329}$ It was agreed that continuing education be considered a fundamental requirement for providing suitable levels of patient care, staff recruitment and retention and a basis upon which to build the post-basic intensive care nursing course. As the course tutors were judged to be the only adequately experienced teaching staff immediately able to commence work on an organised in-service training programme, it was proposed that the post-basic intensive care nursing course scheduled to commence in January 1977 be omitted in order to initiate a comprehensive training programme for staff in the intensive care units. ${ }^{330}$ In cancelling this it was on the understanding that steps be taken to appoint two further clinical tutors to enable continuation of the in-service education programme once the ICU course recommenced in July 1977; that once the 1976 course was completed the course tutors would be able to devote their time entirely to teaching nursing staff and not be involved in other service commitments; that the July 1977 course be advertised earlier than usual with the condition that priority be given to applicants with greater ICU experience; and finally that a minimum of two month's nursing experience in one or more of the intensive care units within the hospital be a prerequisite for acceptance. ${ }^{331}$

A questionnaire was sent to all unit nursing staff to assist in the planning of this staff training programme. In it staff were asked if they felt that they would benefit from increased clinical teaching; in which aspects of nursing practice they felt least confident; whether they would like to see any changes in the orientation of new staff; whether they felt confident in providing clinical teaching to new staff; whether they would be prepared to lead a teaching session; how often they would like formal teaching sessions and what they would like to see included; if formal teaching sessions were scheduled during off duty time whether they would be prepared to attend these; if they saw any value in

\footnotetext{
${ }^{329}$ Wellington Hospital Archive, WOW00201, quote from a letter from Dr Cam Barrett, Convener, Intensive Care Committee to Miss G.A.Grattan, Director of Nursing Services, Wellington Hospital, 20 August 1976.

${ }^{330}$ The units referred to are ICU, coronary care, renal cardiothoracic units.

${ }^{331}$ Wellington Hospital Archive, WOW00201, letter from Dr Cam Barrett, Convener, Intensive Care Committee to Miss G.A. Grattan, Director of Nursing Services, Wellington Hospital, 20 August 1976.
} 
regularly scheduled case presentations which included all team members; and finally if they would be prepared to work in other units to gain wider clinical experience. They were also invited to give any other suggestions or comments in regards to education and training. A summary of the results of the questionnaire revealed that there was a definite need for some form of education other than the ICU nursing course. ${ }^{332}$

Overwhelmingly, the nurses' believed that they would benefit from increased clinical teaching and that should this occur it would stimulate interest, maintain standards of practice, help them to acquire new knowledge and refresh current knowledge. Additionally, as ideas in patient care, technology and equipment were frequently changing, this would facilitate these being introduced into the unit. Many also felt that they lacked confidence in all aspects of intensive care nursing, with the areas of practice in which most felt least confident being respirators and other equipment; ECGs; arrhythmia diagnosis; acid base balance and arterial blood gas analysis; artificial airways; cardiac arrests and defibrillation; care of the neonate; drug and intravenous fluid therapy; insertion of intravenous cannulas; central venous pressure monitoring; and finally dialysis related procedures. ${ }^{333}$

When it came to providing clinical teaching to new staff and leading teaching sessions, the responses varied depending on the length of time the nurse had been working in the unit. Those who had been there for six months or longer felt more confident and were more prepared to share their knowledge. Although almost half of the nurses who responded to the questionnaire were prepared to lead a teaching session, they also stated that they were reluctant to do so, with the rest emphatically responding that they were not prepared to lead a teaching session. This left the tutors in no doubt that it would indeed be themselves or the medical staff who would be providing the instruction on any inservice education. When it came to regularly scheduled case presentations all respondents were enthusiastically in favour of this.

\footnotetext{
${ }^{332}$ Wellington Hospital Archive, WOW00201, Summary of the responses of a questionnaire sent to all unit nursing staff to assist in the planning of staff training programmes for 1977, no date.

${ }^{333}$ Wellington Hospital Archive, WOW00201, Summary of the responses of a questionnaire sent to all unit nursing staff to assist in the planning of staff training programmes for 1977, no date.
} 
As a result of the survey it became apparent to the ICU course tutors that a curriculum focussing on respiratory and cardiac patient management was required. A programme of eight half-day lecture sessions was developed to be delivered one half-day per week for the first eight weeks of 1977, with follow up sessions in the clinical area by the course tutors and experienced nursing staff to ensure that theory was related to practice. The expectation was that the more experienced staff would share their knowledge by instructing and supervising those less experienced. Following the completion of this eight-week programme an assessment would be made as to the need to repeat this and/or develop programmes on other features of ICU nursing. In addition to the development of a basic core programme, a programme of on-going lectures would be developed to meet specific educational needs.

It was proposed that this core programme of in-service education not include detailed aspects of care as it was assumed that those attending would have a fundamental basic knowledge; however, anatomy and physiology related to the altered regulatory mechanisms seen in the critically ill would be included. If individual nurses required a review of basic anatomy and physiology then it was anticipated that this would be pursued via independent study.

None of the nurses interviewed recalled receiving any education or participating in any study or education sessions other than the ICU course. Their recollections were more of on the job training or learning from each other. At times there was the opportunity to observe the surgery of patients commonly admitted to the ICU.

We must have done but I can't recall. A lot of it was learning on the job. We would go to theatre, neuro theatre because that was only down the corridor when they were in the 2-10 block so we would go to theatre and learn what they were doing to our patients, a lot of time you were in neuro theatre or vascular theatre ... so we would often go in and see something like a AAA [abdominal aortic 
aneurysm] done, that was big surgery in those days, it was just huge so you would learn then. ${ }^{334}$

Despite this, many nurses had particular areas that they were especially interested in and they were encouraged to pursue these interests.

There were still people that went forward and did academic studies and things like that, although the bulk of them just stayed at the bedside and did their clinical courses. We had quite a few nurses that were really interested in researching what they were doing to see if we could do it better. They didn't understand the research process like we know it now but you know they were really looking at lots of things especially like suctioning and things like nasogastric feeding and urinary catheters, all of those sorts of things, we had people that were really enthusiastic about that. ${ }^{335}$

This could be considered to be the start of what is known as evidence based practice in the ICU.

Although we didn't focus on evidence based practice because we didn't even know about that then and we didn't have any stuff on information literacy either, we even at that stage were really looking at starting to integrate literature in their assignments. So that we were really asking them to really look at what they were doing and we were really want them to look out there and see what the literature was saying was the best thing to do, so in some respects I think that we were knocking on the door of evidence based practice but it wasn't you know, the big paradigm shift hadn't happened at that stage and it didn't have a name. ${ }^{336}$

\footnotetext{
${ }^{334}$ Oral history interview with Henny.

${ }^{335}$ Oral history interview with Maryanne.

${ }^{336}$ Oral history interview with Maryanne.
} 
By the 1980s nurses were starting to have access to external study days and conferences. However, some of the nurses interviewed perceived that these were available to only a handful of senior or fortunate nurses.

That was actually the only education there was [the ICU course]. There was no mention of university. There would be the odd study day you could go to, you didn't have to go to any if you didn't want to. I remember I got sent off to a study day somewhere, I think it was a pain management one, it was one of the first ones and I was bored stupid. I remember thinking what a stupid study day this was, the information was too basic. ICU nurses dealt with epidurals and PCAs [patient controlled analgesia pumps] whereas everyone else was only just starting to do them. ${ }^{337}$

From the beginnings of ANZICS as a foundation for the sharing of information and knowledge amongst ICU medical staff, interest groups and professional nursing bodies started to evolve the Wellington ICU was part of this from the beginning.

We actually had a very strong presence, the medical staff had a strong presence with ANZICS, and I was the first national president of the intensive care special interest group, and that was phenomenal. We actually had meetings and as part of that we would set up weekend seminars and people would come from all over to have seminars and we would have a neuro focused one or a respiratory focused one or whatever, and they would fly into Wellington for the weekend and that was great, and that was hugely beneficial. ${ }^{338}$

In addition, some nurses within the ICU were encouraged to extend themselves professionally and take on greater roles, particularly in regard to any strong interests that they had.

I was really keen on professional development from very early on ... I remember people having different portfolios to just extend them beyond patient care just to

\footnotetext{
${ }^{337}$ Oral history interview with Cheryl.

${ }^{338}$ Oral history interview with Maryanne.
} 
support their on-going professional development, and I used to do that a lot with teaching ... we always had people in the unit who had a bigger passion for ventilated patients and we had some that had a bigger passion for neuro patients and a bigger passion for renal and so they used to become our experts, if you like, and they used to become involved with teaching, not just on the ICU course but the cardiothoracic course and perhaps the renal course, so I think we tried to do that. $^{339}$

Experienced nurses who had done the ICU course several years previously had few study options available to them, but eventually this changed.

It took us a while to look at that group I have to say ... what we did was between courses we would actually pull those senior groups out and have study days and they loved it. You know, they were the ones who had been doing all the nurturing and they just needed some sort of recharge. So we would pull them out and we would tend to ask them what they wanted, and just updating them on some of the current things really because some of them had done the ICU course years before. So we also were very good at getting them off to conferences, but we did do a lot of in-house things and there were also those seminars, remember I said the weekend things, so they would come to them. We were conscious of getting them off to things and just trying to maintain their interest and their development and all of that sort of thing. ${ }^{340}$

\section{Conclusion}

This chapter has outlined the process of educating those nurses working in the intensive care environment describing the development of a nursing course specifically developed to impart the knowledge necessary to care for and operate the technology required in the care of this patient group. The education and professional development nurses working

\footnotetext{
${ }^{339}$ Oral history interview with Maryanne.

${ }^{340}$ Oral history interview with Maryanne.
} 
in this specialty was recognised and a programme of on-going educational opportunities was developed over time.

One key group of nurses requiring support and teaching were those nurses new to the ICU environment and the orientation of these nurses evolved from a process of instruction from the charge nurse on starting, to a six-week period of buddying with experienced nurses. The evolution of this process was described in this chapter and it was found that this evolutionary process was similar to the experiences of orientating and educating nurses in the specialty of ICU internationally. 


\section{Chapter Eight - Final Thoughts}

Intensive care nursing developed internationally as the result of the recognition from both medical and nursing staff that there was benefit in grouping certain patients together in one area in order to provide them with close monitoring and intensive nursing care. Along with advances in medical knowledge and technology, ICUs emerged. As a result of this desire to deliver the best care to the sickest patients in the right environment, nurses (and doctors) developed the skills in which to treat, monitor and care for these critically unwell patients. As with many other ICUs internationally, Wellington Hospital's ICU developed from the dedication of some medical staff who had seen such units develop and succeed overseas. Training of nurses to work in this environment evolved from no formal orientation in the early years, other than some instruction from the Ward Sister, to a six week orientation period in the 1980 s, where new nurses were nurtured and buddied by more experienced ICU nurses. Whilst this trend was noted in the international literature, it was also driven by the nurses of Wellington ICU who in 1976, responded to a questionnaire regarding their educational needs. In this they indicated a desire for a 'buddy system' orientation to ICU including supervised clinical teaching of at least two to three weeks. Wellington also played a major role in leading education for ICU nurses nationally, and with the formalisation of the education programme, the need to travel overseas by New Zealand nurses to train in ICU was no longer necessary.

In analysing the demographics of the patients admitted to the ICU it is clear that with each passing year greater numbers of patients were admitted in each of the sample years. Whilst it is clear that the ICU enlarged from a 7-bedded unit to 14 beds in 1980 with the move to its new location, without knowing the nursing resource numbers for each year of the ICUs operation it is difficult to definitively say whether the unit became busier or if the nurse to patient ratios remained similar. However, on paper, with a few exceptions, although the clinical profile of the patients admitted has remained similar, the length of stay however, has shortened. According to the nurses interviewed, the patient acuity 
became higher, but this was difficult to clearly ascertain from the demographic and clinical profile data collected.

Caring for these patients who came from all ages involved a collaborative approach from both the nursing and medical staff. From the beginning it was a process of each discipline learning from each other and developing knowledge and skills together. As a result of this the relationships between doctors and nurses evolved more quickly, becoming less hierarchical than in other areas of the hospital. The ICU medical staff, both internationally and in Wellington Hospital, were involved in the instruction of ICU nurses in formal educational courses, as well as less formally at the bedside. Nurses interviewed for this research recalled the medical staff being very involved in teaching them what it was that they needed to know to look after the patients. The advent of the ICU nursing course four years after the ICU opened ensured that nursing staff were taught the essential knowledge and skills to care for these critically ill patients. Over time this course became less medically based and developed more of a nursing focus. Nurses began to examine their practice and look at rationales and evidence regarding the nursing care of the ICU patient.

The technology available to care for this increasingly complex patient group become more advanced throughout the timeframe, requiring greater skill and knowledge on the part of both the medical and nursing staff. Much of the nursing care was based on routines that involved not only the patients looking pristine for the doctors' ward rounds by also attending to the basic needs of the patient regularly. Due to the simplicity of the early ventilator technology patients were frequently paralysed to facilitate adequate ventilation. Rituals also existed in regards to the cleaning and sterilisation of much of the equipment. With no auxiliary staff, ensuring that the unit was clean and tidy was a nursing duty. Additionally, with most items not yet disposable much of the nurse's time was spent ensuring that equipment utilised in patient care was cleaned and ready to reuse on the next patient. 


\section{Scope for Further Research}

Given the limited amount of literature available on Wellington ICU and ICU nursing in New Zealand there are many opportunities for further historical analysis related to all of the topics contained within this research. In regards to the patient admission records, there is scope to undertake a comparative study of ICU patient demographics looking at the clinical profile of patients then and now, utilising current patient databases. With knowledge of the patient profile, there is also an opportunity to interview nurses about the particular nursing care that they provided for specific population groups. Continuation of the development of training and education of ICU nurses would further add not only to the body of literature of ICU nursing but also to the general array of literature concerning nursing education in New Zealand. Further analysis on the nature of the hierarchical doctor-nurse working relationships and how these changed over time would further add to the work already done by Stein and others on this topic. In addition, exploration of the changes to nursing hierarchy within New Zealand hospitals has been identified during this research as a field in which there is limited if any current research available. Finally, research exploring the changing patient experience and role of the family in ICU is required. These areas could be investigated on their own or in conjunction with other aspects of ICU nursing care. Such ongoing research would contribute further to the body of literature available internationally strengthening the appreciation of ICU and nursing history.

In conclusion, this history of the first 25 years of the Wellington Hospital ICU provides a background for both experienced and new ICU nurses to understand the underlying principles behind some of the rituals of ICU nursing and the care that they provide today. In addition, it illustrates the changing role of the ICU nurse in regard to the patient demographic profile, assimilation of technology and nursing care, professional relationships between the nursing and medical staff and the education of ICU nursing staff. Much of the history of this unit has not been documented prior to this thesis. There is only a small volume of written information of the initial history of the unit, and much of this is mixed up amongst other historical hospital documents. In addition, there is little in the way of photographic records of the ICU work environment, the equipment and the 
technology. As a result of the generosity of the six nurses interviewed in sharing their stories of ICU nursing it has made me aware of two things. Firstly, how important it is to capture the memories and recollections of these early nurses and secondly the importance of capturing them sooner rather than later as the passage of time means that much is forgotten. 


\title{
Appendices
}

\section{Appendix A - Ethics Approval}

Health
and
Disability
Ethics
Committees

2010

[Amendment to letter dated 22 December 2009]

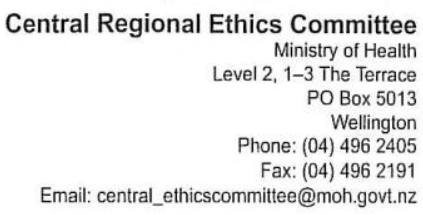

Email: central_ethicscommittee@moh.govt.nz

\author{
Elinore Harper \\ Intensive Care Nursing at Wellington Hospital \\ 53a Mana Esplanade \\ Mana \\ Porirua 5026 \\ Wellington
}

Dear Ms Elinore Harper

Ethics ref: CEN/09/60/EXP

Study title: Intensive Care Nursing at Wellington Hospital

The above study has been given ethical approval by the Central Regional Ethics Committee.

\section{Approved Documents}

- Research Proposal for Admission to NURS 592

- Participant information form

- Consent Form - Oral History Interviews

- Oral History Project Interview Questions

\section{Accreditation}

The Committee involved in the approval of this study is accredited by the Health Research Council and is constituted and operates in accordance with the Operational Standard for Ethics Committees, April 2006.

\section{Progress Reports}

The study is approved until 31 July 2011. The Committee will review the approved application annually and notify the Principal Investigator if it withdraws approval. It is the Principal Investigator's responsibility to forward a progress report covering all sites prior to ethical review of the project in 16 March 2011. The report form is available on http://www.ethicscommittees.health.govt.nz. Please note that failure to provide a progress report may result in the withdrawal of ethical approval. A final report is also required at the conclusion of the study.

\section{Amendments}

It is also a condition of approval that the Committee is advised if the study does not commence, or is altered, including all documentation eg advertisements, letters to participants. 
Please quote the above ethics committee reference number in all correspondence.

The Principal Investigator is responsible for advising any other study sites of approvals and all other correspondence with the Ethics Committee.

It should be noted that Ethics Committee approval does not imply any resource commitment or administrative facilitation by any healthcare provider within whose facility the research is to be carried out. Where applicable, authority for this must be obtained separately from the appropriate manager within the organisation.

We wish you well with your study.

Yours sincerely

Sonia Scott

Administrator

Central Regional Ethics Committee

Email: sonia_scott@moh.govt.nz 


\title{
Appendix B - Oral history Interviewee Letter
}

\author{
Elinore Harper \\ Associate Charge Nurse Manager \\ Intensive Care Services \\ Wellington Hospital \\ Private Bag 7902 \\ Wellington South \\ [date] \\ [Interviewee name and address] \\ Dear
}

I work in the Intensive Care Unit at Wellington Hospital and am currently undertaking a Master of Nursing thesis at the Graduate School of Nursing, Midwifery \& Health, Victoria University of Wellington. The purpose of my research is to explore the development of intensive care nursing as a specialty and the training and education of intensive care nurses at Wellington Hospital from 1964 to 1989.

As you were a former staff nurse, [and any other relevant positions held] of the Wellington Hospital Intensive Care Unit, I would be interested in interviewing you as part of the oral history component of my research.

Should you be willing to involve yourself in this research project, I will send you the participant information sheet and arrange a mutually suitable time and place in which to carry out the interview.

I can be contacted at the above address or via email eah@xtra.co.nz. My supervisor is Dr Pamela Wood, Associate Professor, Graduate School of Nursing, Midwifery \& Health. She can be contacted at: Victoria University of Wellington

P.O. Box 600

Wellington

Pamela.wood@vuw.ac.nz

I look forward to hearing from you.

Yours sincerely

Elinore Harper 


\section{Appendix C - Oral History Interviewee Information Form WELLINGTON HOSPITAL INTENSIVE CARE UNIT HISTORY PARTICIPANT INFORMATION FORM}

My name is Elinore Harper. I am an Associate Charge Nurse Manager in the Intensive Care Unit at Wellington Hospital. I am currently undertaking a Master of Nursing thesis at Victoria University of Wellington Graduate School of Nursing, Midwifery \& Health. I would like to interview past and present Intensive Care Nurses for an oral history project which relates to the history of Wellington Hospital Intensive Care Unit.

The purpose of this research is to explore the development of intensive care nursing as a specialty and the training and education of intensive care nurses at Wellington Hospital from 1964 to 1989 . This research will offer a descriptive history of the Wellington Hospital Intensive Care Unit, documenting how the nursing aspect of its work evolved during its first 25 years.

Ethical approval for this project has been granted by the National Ethics Advisory Committee.

\section{What would participating involve?}

Participating in this project would mean being interviewed by me about your memories of working in the ICU during this time period. The interview would be conducted at a time and place to be negotiated between the two of us. The interview would be tape-recorded and would last between one to two hours. You could ask for the tape recorder to be switched off at any time, and you would not be obliged to answer any question if you did not wish to respond to it.

On completion each participant will be contacted with information on how they can access a copy of the thesis should they wish to read it.

\section{What will happen to the tapes?}

At this point it is intended that the tapes will be erased at the completion of the thesis. However if it is felt that the interviews are suitable to be submitted to an oral history 
sound archive then I would seek separate ethical approval for this and you would be contacted to obtain further consent for this to happen. Other material such as my notes will be destroyed at the end of the project. A copy of your interview tape will be given to you if you would like this.

\section{Will interviewees be identified?}

Comments in the thesis will be attributed to people by name. However, if a participant does not wish to be named they can still participate and I would do my best to ensure that no identifying information was included about them in the thesis. Interviewees can decide at the end of the interview process whether they wish to be named in the project. It is also possible for a participant to choose a pseudonym.

\section{Is it possible to withdraw from the project?}

It will be possible to withdraw from the project at any time prior to submission of the thesis. If you have already been interviewed your tape will then be wiped.

\section{What is the next step in participating?}

If you would like to participate in this research project you can contact me by email, eah@xtra.co.nz, or by writing to me:

Elinore Harper

Associate Charge Nurse Manager

Intensive Care Services

Wellington Hospital

Private Bag 7902

Wellington South

My supervisor for this thesis is:

Dr Pamela Wood

Associate Professor

Graduate School of Nursing, Midwifery \& Health

Victoria University of Wellington

P.O. Box 600

Wellington

Pamela.wood@vuw.ac.nz

I look forward to hearing from you. 


\section{Appendix D - Oral History Interview Schedule WELLINGTON HOSPITAL INTENSIVE CARE UNIT HISTORY \\ Oral History Project Interview Questions}

These are the kind of questions I might be asking you during our oral history interview. I will not necessarily be using these exact words or following this order of questions, but our conversation will cover these kinds of issues and points.

- What year did you first start working in the ICU at Wellington Hospital? Was this the first ICU you had worked in?

- What kind of orientation (if any) were you given? For example did you have a period of working alongside another more experienced member of the nursing staff when you first started working in the ICU?

- How long did you, or have you, worked in ICU?

- What interested you or attracted you to working in ICU?

- How was the day structured? What did your shift by shift patient care involve?

- What are your recollections of the way the nurses worked together?

- What were the working relationships between the nursing staff and the doctors like? Did you, or have you, seen these relationships alter over time? If so how have they changed?

- What equipment did you have and what training did you receive in its use? Who instructed you or taught you how to use it?

- Did you do the ICU course? If so what are your memories of what you learnt, how it was taught, and who did their lectures - medical or nursing staff?

- Do you recall any other nursing education or training given in the ICU? If so conducted it? What did it involve? 


\section{Appendix E - Oral History Interview Consent Form WELLINGTON HOSPITAL INTENSIVE CARE UNIT HISTORY CONSENT FORM - ORAL HISTORY INTERVIEWS}

I have read the information sheet about this project and any questions I have had about it have been answered to my satisfaction. I understand that my participation in this interview is voluntary, and that I may withdraw my involvement, or any information I have provided, before the project is completed.

I understand that the information I provide and the audiotape of the interview will be kept confidential to the interviewer and her course supervisor. I understand that this Consent Form will be kept confidential to the researcher.

On completion of the project I understand that I will be contacted by Elinore Harper and given information on where I can access a copy of the completed thesis should I wish to read it.

1. I agree to be interviewed for this oral history project. My agreement is based on the information given in the Information Sheet and discussed with me.

Name of Participant:

Signature of Participant:

Date:

2. EITHER: I agree to be named in this project and to have comments attributed to me by name.

Signature:

OR: I do not agree to be named in this project or to have any comments attributed to me by name.

Signature: 
Appendix F - ICU Course Lecture Topics

\begin{tabular}{|c|c|c|}
\hline Medical & Allied Health & Nursing \\
\hline \multicolumn{3}{|c|}{ Cardiac } \\
\hline $\begin{array}{l}\text { Congenital heart defects } \\
\text { Valvular heart disease } \\
\text { Problems of coronary artery disease } \\
\text { Myocardial infarction } \\
\text { Cardio-electrophysiology and the ECG } \\
\text { Arrhythmias/heart block } \\
\text { Cardiogenic shock } \\
\text { Heart failure } \\
\text { Pacemakers } \\
\text { Defibrillation } \\
\text { Myocardial revascularisation } \\
\text { Coronary angiography }\end{array}$ & $\begin{array}{l}\text { ECG theory (electronics) } \\
\text { ECG practical (electronics) } \\
\text { Monitoring (electronics) } \\
\text { Pressures (electronics) } \\
\text { Social problems of coronary care } \\
\text { (social workers) }\end{array}$ & $\begin{array}{l}\text { A \& P of the heart } \\
\text { Cardiac conducting system } \\
\text { Outline \& treatment of cardiac disorders } \\
\text { Pre \& post operative management of the } \\
\text { cardiac patient } \\
\text { Myocardial revascularisation } \\
\text { Nursing management of myocardial infarction } \\
\text { Arrhythmias } \\
\text { Electronics and monitoring } \\
\text { Electrocariography } \\
\text { Practical experience with machines } \\
\text { Cardio-pulmonary resuscitation theory \& } \\
\text { practice }\end{array}$ \\
\hline \multicolumn{3}{|c|}{ Respiratory } \\
\hline $\begin{array}{l}\text { Oxygenation \& humidification } \\
\text { Intubation \& extubation } \\
\text { Physiological changes associated with artificial } \\
\text { ventilation } \\
\text { Assessment of lung function } \\
\text { Respiratory failure } \\
\text { Severe pulmonary disease } \\
\text { Functional anatomy of the respiratory system } \\
\text { Chest x-ray interpretation }\end{array}$ & $\begin{array}{l}\text { Breathing (physio) } \\
\text { Postural drainage (physio) } \\
\text { Chronic chest conditions (physio) }\end{array}$ & $\begin{array}{l}\text { Intercostal chest drains } \\
\text { A \& P of the respiratory system } \\
\text { Artificial ventilation - function of the } \\
\text { respirator } \\
\text { Artificial airways including tracheostomy } \\
\text { Nursing management of respiratory failure } \\
\text { Aspiration of artificial airways } \\
\text { Oxygen therapy } \\
\text { Blood gases } \\
\text { Transport of gases }\end{array}$ \\
\hline \multicolumn{3}{|c|}{ Renal } \\
\hline
\end{tabular}




\begin{tabular}{|c|c|c|}
\hline $\begin{array}{l}\text { Acute renal failure } \\
\text { Fluid balance } \\
\text { Renal function } \\
\text { Principles of dialysis } \\
\text { Chronic renal failure } \\
\text { Transplantation } \\
\text { Acid-base balance (renal aspects) }\end{array}$ & $\begin{array}{l}\text { Patient safety in renal units } \\
\text { (electronics) } \\
\text { Renal diets (diet therapy) } \\
\text { Social problems of renal patients } \\
\text { (social worker) }\end{array}$ & $\begin{array}{l}\text { A \& P of the kidney } \\
\text { Acute and chronic renal failure } \\
\text { Principles of dialysis - haemodialysis and } \\
\text { peritoneal dialysis } \\
\text { Management of renal patients } \\
\text { Management of peritoneal dialysis } \\
\text { Diet therapy } \\
\text { Care and use of dialysis equipment } \\
\text { Renal transplantation and post operative } \\
\text { management } \\
\text { Access to blood stream - fistula and shunt } \\
\text { Renal investigations }\end{array}$ \\
\hline \multicolumn{3}{|c|}{ Surgical } \\
\hline $\begin{array}{l}\text { Major abdominal surgery } \\
\text { Vascular surgery }\end{array}$ & & $\begin{array}{l}\text { Major abdominal surgery } \\
\text { Vascular surgery }\end{array}$ \\
\hline \multicolumn{3}{|c|}{ Neuro } \\
\hline $\begin{array}{l}\text { Applied neuro-anatomy } \\
\text { Neurological investigations } \\
\text { Severe neurological disorders } \\
\text { Neurological investigations - practical } \\
\text { Head injuries } \\
\text { Tumours } \\
\text { Investigations and abnormalities } \\
\text { Subarachnoid haemorrhage } \\
\text { Cerebral aneurysms }\end{array}$ & & $\begin{array}{l}\text { Cerebrospinal fluid } \\
\text { Structure of the ventricles } \\
\text { Nursing management of neurosurgical patients } \\
\text { Nursing management of severe neurological } \\
\text { disorders } \\
\text { Neurological observations } \\
\text { Myasthenia gravis and polyneuritis }\end{array}$ \\
\hline \multicolumn{3}{|c|}{ Medical } \\
\hline $\begin{array}{l}\text { Severe liver disease } \\
\text { Shock } \\
\text { Sepsis } \\
\text { Disseminated intravascular coagulation }\end{array}$ & & $\begin{array}{l}\text { A \& P of the nervous system } \\
\text { Nursing management of poisonings }\end{array}$ \\
\hline
\end{tabular}




\begin{tabular}{|c|c|c|}
\hline $\begin{array}{l}\text { syndrome } \\
\text { Fat embolism }\end{array}$ & & \\
\hline \multicolumn{3}{|c|}{ Paediatrics } \\
\hline $\begin{array}{l}\text { Major surgery } \\
\text { Neonatal resuscitation } \\
\text { Paediatric ventilation }\end{array}$ & & \\
\hline \multicolumn{3}{|c|}{ Pharmacology } \\
\hline $\begin{array}{l}\text { Respiratory drugs } \\
\text { Cardiac drugs } \\
\text { Intravenous therapy }\end{array}$ & & $\begin{array}{l}\text { Intravenous therapy - sites, fluids and } \\
\text { venepuncture } \\
\text { Intravenous nutrition }\end{array}$ \\
\hline \multicolumn{3}{|c|}{ General } \\
\hline $\begin{array}{l}\text { Bacterial problems in ICU } \\
\text { Chest injuries } \\
\text { Basic body chemistry } \\
\text { Poisonings } \\
\text { Tissue typing } \\
\text { Acid-base balance } \\
\text { Blood gases } \\
\text { Multiple trauma } \\
\text { Auscultation of heart and chest sounds } \\
\text { Mental hygiene } \\
\text { Radiology } \\
\text { Burns }\end{array}$ & $\begin{array}{l}\text { Role of the chaplains in ICU } \\
\text { (ministers) } \\
\text { Lifting (physios) } \\
\text { Unconscious patient (physios) } \\
\text { Practical (physios) } \\
\text { Methods of radiology (radiology) } \\
\text { Introduction to safety (electronics) } \\
\text { Social problems of ICU patients } \\
\text { (social workers) }\end{array}$ & $\begin{array}{l}\text { Diet therapy } \\
\text { A\& P of the nervous system } \\
\text { Nursing management of multi trauma } \\
\text { Nursing management of burns } \\
\text { Central venous pressure monitoring } \\
\text { Electrolyte balance and imbalance }\end{array}$ \\
\hline \multicolumn{3}{|c|}{ Administration and Human Resources } \\
\hline & & $\begin{array}{l}\text { Role of the unit } \\
\text { Staffing } \\
\text { - Recruitment } \\
\text { - Selection } \\
\text { - Evaluation } \\
\text { - Allocation }\end{array}$ \\
\hline
\end{tabular}




\begin{tabular}{|l|l|l|}
\hline & $\begin{array}{l}\bullet \text { Utilisation of staff } \\
\text { Management for nursing care } \\
\bullet \text { Staff development }\end{array}$ \\
& $\begin{array}{l}\text { - Planning nursing service in the unit } \\
\text { - Planning and teaching for staff } \\
\text { development }\end{array}$ \\
& Communication and interpersonal relations \\
\hline
\end{tabular}




\section{Reference List}

\section{Primary Sources}

\section{Administrative Archives}

\section{Archives New Zealand}

Archives New Zealand, Wellington Archives, ABRR, 7563, W4990, 2, Intensive Care Unit, Envelope of photographs of Wellington Hospital ICU, Ward 10, no date.

Archives New Zealand, Wellington Archives, ABRR, 7563, W4990, 10, Nursing Staff Wellington Hospital, Envelope of Photographs, 1960-1970.

\section{Wellington Hospital Archives}

Wellington Hospital Archive, WOW00200, Intensive Care Unit Patient Admission Books, 1964-1989.

Wellington Hospital Archive, WOW00201, advertisement for the first Intensive Care Post Certification Nursing Course, issued from the Matron-in-Chief Wellington Hospital, $25^{\text {th }}$ March 1968.

Wellington Hospital Archive, WOW00201, ICU Course Lecture Topics: Lectures given by medical, allied health and nursing staff, no date.

Wellington Hospital Archive, WOW00201, letter from Dr J.C. Barrett, Convener, Intensive Care Committee to Miss G.A. Grattan, Director of Nursing Services, Wellington Hospital, August 1976.

Wellington Hospital Archive, WOW00201, letter from the Chairman of the Medical Staff Executive to the Director-General of Health, Department of Health, $23^{\text {rd }}$ October 1973. 
Wellington Hospital Archive, WOW00201, letter from the Members of the Intensive Care Committee to the Chairman of Medical Staff at Wellington Hospital, 'Wellington Hospital Postgraduate Nursing Courses', 9 October 1973.

Wellington Hospital Archive, WOW00201, letter from the Wellington Hospital Intensive Care Committee to Mr. C. L. Tucker, Chairman Detailed Planning Committee Wellington Hospital, 7 June 1972.

Wellington Hospital Archive, WOW00201, Memorandum by Wellington Hospital Medical Staff Executive on the Case for Continuing the Post Basic Intensive Care Nursing Course in its Present Form, no date.

Wellington Hospital Archive, WOW00201, Memorandum re: Management of Drug Overdose Patients, 8 March 1976.

Wellington Hospital Archive, WOW00201, PA/AB, Wellington Hospital Department of Nursing Education: Intensive Care Education, 28 ${ }^{\text {th }}$ August, 1973.

Wellington Hospital Archive, WOW00201, Post Basic Nursing Course Evaluation Sheets, July 1974, February 1975, December 1977.

Wellington Hospital Archive, WOW00201, Summary of Questionnaire sent to ICU Nursing Staff by the Intensive Care Course Tutors to assist in the planning of staff training in 1977 , no date.

Wellington Hospital Archive, WOW00201, Wellington Hospital Intensive Care Unit Committee, First Report: Intensive Care Planning, 19 June 1972.

Wellington Hospital Archive, WOW00201, Wellington Hospital Medical Staff Executive, Wellington Hospital Post-Basic Intensive Care Nursing Course: The case for 
continuing the course in its present form and Annex A: Wellington Hospital Post-Basic Intensive Care Nursing Course, 1973.

Wellington Hospital Archive, WOW00201, Wellington Hospital Memorandum to Post Graduate Intensive Care Course Committee Members: Review of Examination Questions for Inclusion in the Students' Final Examination to be held in December 1976, no date.

Wellington Hospital Archive, WOW00201, Wellington Hospital Post Basic Intensive Care Nursing Course, no date.

\section{Official Records}

The Department of Health New Zealand Occasional Paper Number 7: Intensive Nursing Care Units in Public Hospitals, 1978, Management Services and Research Unit, Department of Health, Wellington.

\section{Newspapers}

Nursing Course Breaks New Ground in New Zealand, Evening Post, 27 May 1968.

\section{Books}

Burrell, Zeb. L. Jr. and Burrell, Lenette Owens, Intensive Nursing Care, C.V. Mosby Company, Saint Louis, 1969.

Storlie, Francis, Rambousek, Elizabeth, and Shannon, Eutha, Principles of Intensive Nursing Care, Appleton-Century-Crofts Educational Division, Meredith Corporation, New York, 1969.

\section{Articles and Papers}


Collins, B. E., 'Methods of clinical teaching in intensive care units', The New Zealand Nursing Journal, (June 1977), pp.17-18.

Ford, M .J., 'Intensive therapy overseas', The New Zealand Nursing Journal, (February 1968), pp.7-8.

Hilberman, M., 'The evolution of intensive care units', Critical Care Medicine, 3, 4 (1975), pp.159-165.

Mercer, B., 'Intensive care units at Wellington', The New Zealand Nursing Journal, (August 1971), pp.21-22.

\section{Secondary Sources}

\section{Books}

Fairman, Julie and Lynaugh, Joan, Critical Care Nursing: A History, University of Pennsylvania Press, Philadelphia, 1998.

Hess, Dean and Kacmarek, Robert M., Essentials of Mechanical Ventilation, $2^{\text {nd }}$ ed., The McGraw-Hill Companies Inc, United States of America, 1996.

Hutching, M., Talking History: A Short Guide to Oral History, Bridget Williams Books Ltd, Wellington, 1993.

Lewenson, Sandra B. and Herrmann, Eleanor Krohn. Capturing Nursing History: A Guide to Historical Methods in Research, Springer Publishing Company, New York, 2008.

Tosh, J., The Pursuit of History: Aims, Methods and New Directions, Longman, London and New York, 1991. 
Trubuhovich, R.V. and Judson, J.A., Intensive Care in New Zealand: A History of the New Zealand Region of ANZICS, Cox and Dawes, Auckland, 2001.

Wiles, Valda and Daffurn, Kathy, There's a Bird in my Hand and a Bear by the Bed - I Must be in ICU, Southwood Press Pty Ltd, Marrickville, NSW, 2002.

Zalumas, J., Caring in Crisis: An Oral History of Critical Care Nursing, University of Pennsylvania Press, Philadelphia, 1995.

\section{Articles}

Atkinson, B.L. 'Training nurses for intensive care', Intensive Care Nursing, 6 (1990), pp.172-178.

Barnard, Kathryn, 'Research designs: The historical method', American Journal of Maternal and Child Nursing, 6 (1981), p.319.

Biedermann, N. 'The voices of days gone by: Advocating the use of oral history in nursing', Nursing Inquiry, 8 (2001), pp.61-62.

Crocker, C. 'The development of critical care in England', Intensive and Critical Care Nursing, 23 (2007), pp.323-330.

D’Antonio, P. 'Nursing and history', Nursing Inquiry, 12, 4 (2005), pp.241-242.

Fairman, Julie, 'Watchful vigilance: Nursing care, technology and the development of intensive care units', Nursing Research, 41,1 (1992), pp.56-60.

Footner, A. 'Nursing specialism or nursing specialization?', Journal of Orthopaedic Nursing, 2 (1998), pp.219-223. 
Judson, J. A., and Fisher, M. 'Intensive care in Australia and New Zealand', Critical Care Clinics, 22 (2006), pp.407-423.

Lusk, B., 'Historical methodology for nursing research', Image: Journal of Nursing Scholarship, 29, 4 (1997), pp.355-364.

Lynaugh, J., 'Moments in nursing history: 1970', Nursing Research, 39, 4 (1990), pp. 254-255.

Peplau, H., 'Specialization in professional nursing', Clinical Nurse Specialist, 17, 1 (2003), pp.3-9.

Robnet, M. K., 'Critical care nursing: Workforce issues and potential solutions', Critical Care Medicine, 34, 4 (supplement), (2006), pp.S25-S30.

Rosengart, Matthew R., 'Critical care medicine: Landmarks and legends', Surgical Clinics of North America, 86 (2006), pp.1305-1321.

Sarnecky, M. T., 'Historiography: A legitimate research method for nursing', Advances in Nursing Science, 12, 4 (1990), pp.1-10.

Smoyak, Shirley, A. 'Specialisation in nursing: From then to now', Nursing Outlook, 24, 11 (1976), pp.676-681.

Stein, L.I. 'The doctor nurse game', Archives of General Psychiatry, 16, (1967), pp.699703.

Stein, L.I., Watts, D.T., and Howell, T. 'The doctor nurse game revisited', Nursing Outlook, 38, 6 (1990), pp.264-268. 
Sweeney, J.F. 'Historical research: Examining documentary resources', Nurse Researcher, 12, 3 (2005), pp.61-73.

Tellis-Nayak, M. and Tellis-Nayak, V. 'Games that professionals play: The social psychology of physician-nurse interaction', Social Science Medicine, 18, 12 (1984), pp.1063-1069.

Wall, B.M., Edwards, N.E., and Porter, M.L. 'Textual analysis of retired nurses' oral histories', Nursing Inquiry, 14, 4 (2007), pp. 279-288.

Wiklund, Per Erik, 'Intensive care units: design, location, staffing ancillary areas, equipment', Anesthesiology, 31 (1969), pp122-139.

\section{Websites}

www.ccdhb.org.nz/hhist/staff/roytowers.htm

www.paperspast.natlib.govt.nz

www.pcc.govt.nz

www.safekids.org.nz

www.samemory.sa.gov.au

www.thewahine.co.nz

www.wnmeds.ac.nz/about/historical_note.html 


\section{Official records}

Health Research Council, Guidelines on Ethics in Health Research, Ministry of Health, Wellington, New Zealand, 2002.

National Ethics Advisory Committee, Ethical Guidelines for Observational Studies: observational Research, Audits and Related Activities, Ministry of Health, Wellington, New Zealand, 2006. 